EBERHARD WILLE

ANGELIKA MEHNERT

JAN PHILIPP ROHWEDER

\title{
ZUM \\ GESELLSCHAFTLICHEN \\ NUTZEN \\ PHARMAZEUTISCHER \\ INNOVATIONEN
}


EBERHARD WILLE

ANGELIKA MEHNERT

JAN PHILIPP ROHWEDER

\section{ZUM GESELLSCHAFTLICHEN NUTZEN PHARMAZEUTISCHER INNOVATIONEN}

Um den gesellschaftlichen Nutzen pharmazeutischer Innovationen abzuschätzen, bedarf es adäquater Beurteilungskriterien. Nach einem empirischen Abriß über die Entwicklung der Arzneimittelausgaben erörtern die Autoren die beurteilungsrelevanten gesamtwirtschaftlichen Ziele. Auf mikroökonomischer Basis bietet sich zur Ermittlung der Nützlichkeit von Arzneimitteln die KostenNutzen-Analyse an. Im Prozeß gesundheitlicher Leistungserstellung nimmt das Arzneimittel den Rang eines Produktionsfaktors ein, der zumeist in Verbindung mit anderen Behandlungsarten eine Verbesserung des Gesundheitszustandes erzeugt. Dabei besitzen unter Effektivitäts- und Effizienzaspekten Innovationsund Imitationsprodukte unterschiedliche allokative Funktionen. Die beinahe weltweiten gesundheitspolitischen Regulierungen begünstigen die Imitationen und drohen damit die Forschungsanreize zu reduzieren.

Eberhard Wille wurde 1942 in Berlin geboren. Nach dem Dipl.-Examen 1966 an der Universität Bonn, der Promotion 1969 und der Habilitation 1973 an der Universität Mainz, ist er seit 1975 Professor an der Universität Mannheim. Er ist Mitglied des Finanzwissenschaftlichen und des Gesundheitsökonomischen Ausschusses des Vereins für Socialpolitik, der Euopean Economic Association, der American Economic Association, des Wissenschaftlichen Beirats beim Bundesministerium für Wirtschaft und des Sachverständigenrates für die Konzertierte Aktion im Gesundheitswesen.

Angelika Mehnert wurde 1962 in Kiel geboren. Sie legte ihr Dipl.-Examen in Volkswirtschaft 1990 in Mannheim ab.

Jan Philipp Rohweder wurde 1965 in Hamburg geboren. Er legte den M.A. in Philadelphia 1989 und das Dipl.-Examen als Volkswirt 1992 in Mannheim ab. 
Zum gesellschaftlichen Nutzen pharmazeutischer Innovationen 


\section{ALLOKATION IM MARKTWIRTSCHAFTLICHEN SYSTEM \\ Herausgegeben von \\ Heinz König, Hans-Heinrich Nachtkamp, Ulrich Schlieper, Eberhard Wille}

\section{Band 35}

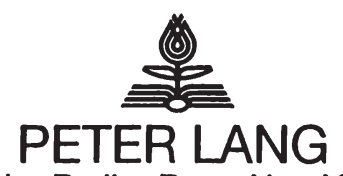

Frankfurt am Main · Berlin · Bern · New York · Paris · Wien 


\section{EBERHARD WILLE \\ ANGELIKA MEHNERT \\ JAN PHILIPP ROHWEDER}

\section{ZUM \\ GESELLSCHAFTLICHEN NUTZEN \\ PHARMAZEUTISCHER INNOVATIONEN}

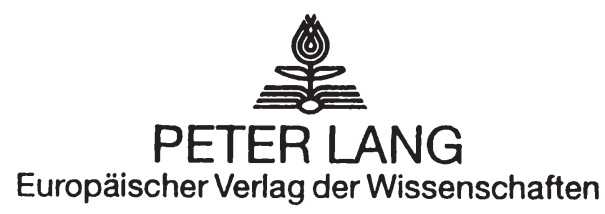


Die Deutsche Bibliothek - CIP-Einheitsaufnahme

Wille, Eberhard:

Zum gesellschaftlichen Nutzen pharmazeutischer Innovationen / Eberhard Wille ; Angelika Mehnert ; Jan Philipp Rohweder. Frankfurt am Main ; Berlin ; Bern ; New York ; Paris ; Wien : Lang, 1994

(Allokation im marktwirtschaftlichen System ; Bd. 35) ISBN 3-631-47575-6

NE: Mehnert, Angelika:; Rohweder, Jan-Philipp:; GT

Open Access: The online version of this publication is published on www.peterlang.com and www.econstor.eu under the international Creative Commons License CC-BY 4.0. Learn more on how you can use and share this work: http://creativecommons.org/licenses/ by/4.0.

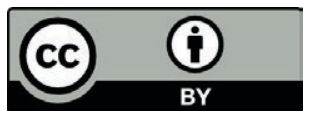

This book is available Open Access thanks to the kind support of ZBW - Leibniz-Informationszentrum Wirtschaft.

\author{
ISSN 0939-7728 \\ ISBN 3-631-47575-6 \\ ISBN 978-3-631-75615-7 (eBook) \\ (C) Peter Lang $\mathrm{GmbH}$ \\ Europäischer Verlag der Wissenschaften \\ Frankfurt am Main 1994 \\ Alle Rechte vorbehalten.
}

Das Werk einschließlich aller seiner Teile ist urheberrechtlich geschützt. Jede Verwertung außerhalb der engen Grenzen des Urheberrechtsgesetzes ist ohne Zustimmung des Verlages unzulässig und strafbar. Das gilt insbesondere für Vervielfältigungen, Übersetzungen, Mikroverfilmungen und die Einspeicherung und Verarbeitung in elektronischen Systemen.

$$
\text { Printed in Germany } 124567
$$




\section{Inhaltsübersicht}

Tabellen- und Abbildungsverzeichnis

1. Einleitung: Arzneimittelmarkt im Umbruch

2. Zur Empirie der Arzneimittelausgaben in Deutschland

2.1 Aktuelle Daten und Relationen

2.1.1 Apothekenumsatz und Gesamtproduktion

2.1.2 Der bundesdeutsche Pharma-Außenhandel

2.2 Die Entwicklung der Arzneimittelausgaben innerhalb der GKV

3. Beurteilungskriterien für den Nutzen von Arzneimitteln

3.1 Gesamtwirtschaftliche Ziele

3.2. Die Ermittlung der Nützlichkeit einzelner Innovationen

3.2.1 Das Anliegen der Kosten-Nutzen Analyse

3.2.2 Das Nutzenspektrum pharmazeutischer Innovation

\section{Das Arzneimittel im System gesundheitlicher Leistungserstellung}

4.1 In- und Outputebenen der Gesundheitsproduktion

4.2 Dimensionen gesundheitlicher Outcome-Indikatoren

4.3 Das Medikament als Teil medizinischer Behandlung

4.3.1 Beziehungen zwischen den Behandlungsarten

4.3.2 Die Preis- und Mengenentwicklung von Behandlungsarten 
5. Innovation und Imitation im Arzneimittelbereich

5.1 Zum Wettbewerb in der pharmazeutischen Industrie

5.2 Zur Bedeutung von Innovation und Imitation

5.3 Bestimmungsfaktoren für die Standortwahl

5.4 Alternative Finanzierungsformen von Forschung und Entwicklung

6. Forschungsanreize vor dem Hintergrund gesundheitspolitischer Regulierungen

6.1 Das Gesundheits-Reformgesetz

77

6.1.1 Die gesetzlichen Regelungen $\quad 77$

6.1.2 Auswirkungen auf GKV und Arzneimittelmarkt $\quad 80$

6.2 Das Gesundheitsstrukturgesetz $\quad 85$

6.2.1 Maßnahmen im Arzneimittelbereich $\quad 85$

6.2.2 Absehbare Auswirkungen $\quad 89$

7. Ergebnisse und Schlußfolgerungen in Thesen 95

Literaturverzeichnis 


\section{Tabellen- und Abbildungsverzeichnis}

Tabelle 1: Anteil der Zweitanmelder am generikafähigen und am $\begin{array}{ll}\text { Gesamtmarkt } & 10\end{array}$

Tabelle 2: Gesundheitsquoten im internationalen Vergleich 12

Tabelle 3: Außenhandel mit pharmazeutischen Produkten (in Mio. DM) 19

Tabelle 4: Die GKV-Ausgaben nach globalen Leistungsarten 21

Tabelle 5: Die GKV-Ausgaben nach einzelnen Behandlungsarten 22

Tabelle 6: Die PKV-Ausgaben nach einzelnen Behandlungsarten 24

Tabelle 7: Anteile der GKV-Ausgaben für Mitglieder und Rentner an den jeweiligen Behandlungsarten 26

Tabelle 8: Anteile an den GKV-Ausgaben für Mitglieder und Rentner nach Behandlungsarten $\quad 27$

Tabelle 9: GKV-Ausgaben in DM pro Kopf für Mitglieder und Rentner 29

Abbildung 1: Jährliche Veränderungsraten der Ausgaben für Arzneimittel sowie der beitragspflichtigen Einnahmen

Abbildung 2: Das Nutzenspektrum pharmazeutischer Innovationen 44

Abbildung 3: Ziel- und Mittelebenen von Gesundheitsindikatoren 47

Tabelle 10: Dimensionen der Lebensqualität 51

Tabelle 11: Der Preisstruktureffekt im Bereich medizinischer Behandlung 57

Tabelle 12: Preis- und Mengenkomponente von Behandlungsleistungen 58

Abbildung 4: Einfluß der Verwertungssperre nach Paragraph 24a AMG und des EU-Zertifikates auf die Schutzfrist am Markt

Tabelle 13: Durchschnittliche Wachstumsraten der GKV-Ausgaben nach Behandlungsarten (1970 - 1992)

Tabelle 14: Komponenten der Ausgabenentwicklung 83

Tabelle 15: Das Arzneimittelpreisniveau in der EU (Durchschnitt = 100) 91 
Eberhard Wille, Angelika Mehnert and Jan Philipp Rohweder - 978-3-631-75615-7 Heruntergeladen von PubFactory am05/04/2021 12:53:36PM via Victoria University of Wellington 


\section{Einleitung: Arzneimittelmarkt im Umbruch}

Das bundesdeutsche Gesundheitswesen sieht sich seit Mitte der siebziger Jahre nahezu permanent mit staatlichen Reformmaßnahmen konfrontiert, die primär auf eine Eingrenzung des Ausgabenanstiegs im Bereich der Gesetzlichen Krankenversicherung (GKV) abzielen. Im Rahmen dieser sog. Kostendämpfungspolitik (vgl. Hauser/Sommer, 1984, Berg, 1986 und Molinaro, 1986) lag das Schwergewicht der staatlichen Einsparbemühungen innerhalb der medizinischen Behandlungsarten insgesamt gesehen beim Zahnersatz und den Arzneimitteln. Von den vorausgegangenen Regulierungen ${ }^{1)}$ unterscheiden sich das Gesundheits-Reformgesetz $\left.(\mathrm{GRG})^{2}\right)$ und das Gesundheitsstrukturgesetz (GSG)3) vor allem durch ihren breiteren Ansatz, der einmal mehrere Behandlungsarten umfaßt und auch innerhalb einer Behandlungsart mehrere Eingriffe vorsieht, sowie durch ihre ehrgeizigere fiskalische Zielsetzung (siehe auch unten unter 6.). Sodann spricht neben theoretischen Überlegungen auch die bisherige empirische Entwicklung dafür, daß das GSG im Gegensatz zu seinen Vorgängern das anvisierte Einsparungsziel im Arzneimittelbereich realisiert, im Jahre 1993 sehr wahrscheinlich sogar deutlich übertrifft (vgl. Erbsland/Wille, 1993)4).

Obgleich es den Reformbestrebungen vor dem GSG nicht gelang, das Wachstum der GKV-Arzneimittelausgaben im Niveau wie gewünscht abzubremsen, gingen sie jedoch mit relevanten strukturellen Verschiebungen am Arzneimittelmarkt einher. So stieg der Anteil, der im Marktsegment für wirkstoffgleiche Medikamente auf die Generika-Hersteller entfiel, schon ab Anfang der siebziger Jahre an

1) Das Krankenversicherungs-Kostendämpfungsgesetz vom 27.06.1977 und das Kostendämpfungs-Ergänzungsgesetz vom 22.12.1981 können unter diesem fiskalischen Aspekt als Vorläufer von GRG und GSG gelten. Vgl. Institut "Finanzen und Steuern", 1993, S. 39).

2) Vgl. Gesundheits-Reformgesetz (GRG) vom 20.12.1988, in: Bundesgesetzblatt I, S. 2477.

3) Vgl. Gesetz zur Sicherung und Strukturverbesserung der gesetzlichen Krankenversicherung (Gesundheitsstrukturgesetz) vom 21.12.1992, in: Bundesgesetzblatt, Jg. 1992, Teil I, S. 2266-2334.

4) In diesem Zusammenhang danken wir Herrn Manfred Erbsland, Zentrum für Europäische Wirtschaftsforschung (ZEW), für die Bereitstellung aktueller Forschungsergebnisse zu den Themengebieten Demographie und Ausgabenentwicklung im Gesundheitwesen. 
(vgl. Huber, 1988, S. 97ff.) und erhielt im Zuge der sog. Kostendämpfungspolitik weiteren Anschub. Bezogen auf den Gesamtmarkt nahm der Anteil der Zweitanmelderpräparate zwischen 1981 und 1992 an den Verordnungen von 11,2 vH auf $29,4 \mathrm{vH}$ und beim Umsatz von $11,5 \mathrm{vH}$ auf $22,1 \mathrm{vH}$ zu (vgl. Schwabe/Paffrath, 1993, S. 10f.). Wie Tabelle 1 ausweist, verstärkten das GRG und das GSG diesen Trend, und es zeichnet sich derzeit kein Ende dieser Strukturverschiebung ab. Sofern das GSG das künftige Wachstum der GKV-Arzneimittelausgaben spürbar eingrenzt, können die forschenden Unternehmen am GKV-Markt ihre strukturellen Einbußen nicht mehr - zumindest nicht mehr im bisherigen Ausmaß über Niveaueffekte kompensieren.

Tabelle 1: Anteil der Zweitanmelder am generikafähigen und am Gesamtmarkt

\begin{tabular}{|c|c|c|c|c|c|}
\hline \multicolumn{2}{|c|}{} & \multicolumn{2}{c|}{ generikafähiger Markt } & \multicolumn{2}{c|}{ Gesamtmarkt } \\
\hline Jahr & $\begin{array}{c}\text { Anzahl der } \\
\text { Wirkstoffe }\end{array}$ & $\begin{array}{c}\text { Anteil nach } \\
\text { Verordnungen } \\
\text { in vH }\end{array}$ & $\begin{array}{c}\text { Anteil nach } \\
\text { Umsatz } \\
\text { in vH }\end{array}$ & $\begin{array}{c}\text { Anteil nach } \\
\text { Verordnungen } \\
\text { in vH }\end{array}$ & $\begin{array}{c}\text { Anteil nach } \\
\text { Umsatz } \\
\text { in vH }\end{array}$ \\
\hline 1987 & 256 & 45,7 & 31,4 & 17,2 & 13,2 \\
\hline 1988 & 281 & 50,4 & 39,7 & 20,4 & 15,3 \\
\hline 1989 & 290 & 53,2 & 42,4 & 21,9 & 16,3 \\
\hline 1990 & 306 & 55,5 & 44,9 & 23,8 & 17,0 \\
\hline 1991 & 307 & 57,5 & 48,1 & 26,6 & 18,9 \\
\hline 1992 & 299 & 58,3 & 48,5 & 29,4 & 22,1 \\
\hline 1993 & 299 & $63,01)$ & $53,31)$ & $\left.33,1^{2}\right)$ & $24,02)$ \\
\hline
\end{tabular}

1) Nach dem 1. Quartal 1993

2) Nach dem 1. Halbjahr 1993

Quelle: Zusammengestellt aus Schwabe/Paffrath ,1987-1993, und Wissenschaftiches Institut der Ortskrankenkassen, 1993. 
Der im Vergleich zum entsprechenden Bruttosozialprodukt überproportionale Anstieg der Gesundheitsausgaben fand in den sechziger und siebziger Jahren fast weltweit statt. Wie Tabelle 2 belegt, liegen Niveau und Entwicklung der bundesdeutschen Gesundheitsquote im wesentlichen im OECD-Trend. Ab 1980 schwächte sich das relative Wachstum der Gesundheitsausgaben in vielen Ländern spürbar ab, wobei die Gesundheitsquote von 1980 bis 1991 in Deutschland und Japan stagnierte und in Dänemark, Irland und Schweden sogar zurückging. Für diese Abschwächung des Wachstums der Gesundheitsausgaben zeichnen in den meisten Ländern, ähnlich wie in Deutschland, staatliche Kostendämpfungsmaßnahmen verantwortlich (vgl. Abel-Smith, 1984, OECD, 1985, 1987, 1990 und 1993 sowie Burstall, 1990). Vor dem Hintergrund eingeengter Finanzierungsspielräume in den öffentlichen bzw. den Sozialhaushalten und der sich abzeichnenden demographischen Entwicklung sehen die meisten Staaten derzeit keinen Anlaß, von ihren Kostendämpfungsbemühungen und damit auch von ihrer Regulierung des heimischen Arzneimittelmarktes abzurücken. Dies bedeutet, daß es den forschenden Unternehmen, die im Unterschied zu den Generika-Herstellern ihre Präparate überwiegend weltweit anbieten5), zunehmend schwerer fällt, Umsatzverluste im heimischen Markt über ihr Auslandsgeschäft auszugleichen.

Schließlich stellt die politisch anvisierte Vollendung eines einheitlichen Europäischen Binnenmarktes die Arzneimittelindustrie und hier insbesondere die forschenden, international tätigen Unternehmen vor erhebliche Anpassungsprobleme (vgl. Boroch/Cassel, 1993). Die Europäische Gemeinschaft6) erließ bereits in der Vergangenheit eine Vielzahl von Arzneimittel-Direktiven, die vor allem auf eine Harmonisierung von Produktions- und Marktzulassungsstandards abzielten (vgl. Commission of the European Communities, 1989). Sie beinhalten u.a. einheitliche Kriterien zur Definition nicht verschreibungspflichtiger Präparate, Regelungen bezüglich Packungsbeschriftung, Beipackzettel, Werbung und Dauer des Patentschutzes sowie Vorschriften über die Transparenz der nationalen Vergütungssysteme (vgl. NERA, 1993b).

5) Insoweit forschende Unternehmen nur den inländischen Markt beliefern, verfügen sie dies trifft vor allem für zahlreiche mittelständische Betriebe zu - über keine Kompensationsmöglichkeiten im Exportgeschäft.

6) Der Einfachheit halber bezeichnen wir im folgenden die Staatengemeinschaft der Europäischen Gemeinschaft grundsätzlich mit dem seit Inkrafttreten des Vertrags von Maastricht üblichen Namen Europäische Union (EU). 
Tabelle 2: Gesundheitsquoten im internationalen Vergleich 1 )

\begin{tabular}{|l|c|c|c|c|c|}
\hline Land & 1960 & 1970 & 1980 & 1990 & 1991 \\
\hline Australien & 4,9 & 5,7 & 7,3 & 8,2 & 8,6 \\
\hline Belgien & 3,4 & 4,1 & 6,6 & 7,6 & 7,9 \\
\hline Dänemark & 3,6 & 6,1 & 6,8 & 6,3 & 6,5 \\
\hline Deutschland & 4,8 & 5,9 & 8,4 & 8,3 & 8,5 \\
\hline Finnland & 3,9 & 5,7 & 6,5 & 7,8 & 8,9 \\
\hline Frankreich & 4,2 & 5,8 & 7,6 & 8,8 & 9,1 \\
\hline Griechenland & 2,9 & 4,0 & 4,3 & 5,4 & 5,2 \\
\hline Großbritannien & 3,9 & 4,5 & 5,8 & 6,2 & 6,6 \\
\hline Irland & 4,0 & 5,6 & 9,2 & 7,0 & 7,3 \\
\hline Island & 3,5 & 5,2 & 6,4 & 8,3 & 8,4 \\
\hline Italien & 3,6 & 5,2 & 6,9 & 8,1 & 8,3 \\
\hline Japan & 3,0 & 4,6 & 6,6 & 6,6 & 6,6 \\
\hline Kanada & 5,5 & 7,1 & 7,4 & 9,5 & 10,0 \\
\hline Luxemburg & -- & 4,1 & 6,8 & 7,2 & 7,2 \\
\hline Neuseeland & 4,3 & 5,2 & 7,2 & 7,2 & 7,6 \\
\hline Niederlande & 3,9 & 6,0 & 8,0 & 8,2 & 8,3 \\
\hline Norwegen & 3,3 & 5,0 & 6,6 & 7,4 & 7,6 \\
\hline Österreich & 4,4 & 5,4 & 7,9 & 8,3 & 8,4 \\
\hline Portugal & -- & 3,1 & 5,9 & 6,7 & 6,8 \\
\hline Schweden & 4,7 & 7,2 & 9,4 & 8,6 & 8,6 \\
\hline Schweiz & 3,3 & 5,2 & 7,3 & 7,8 & 7,9 \\
\hline Spanien & 1,5 & 3,7 & 5,6 & 6,6 & 6,7 \\
\hline Türkei & -- & -- & 4,0 & 4,0 & 4,0 \\
\hline USA & 5,3 & 7,4 & 9,2 & 12,4 & 13,4 \\
\hline & & & & & \\
\hline Durchschnitt2) & 3,9 & 5,3 & 7,0 & 7,6 & 7,9 \\
\hline
\end{tabular}

1) Die gesamten Gesundheitsausgaben des jeweiligen Landes in $\mathrm{vH}$ des entsprechenden Bruttoinlandsprodukts.

2) Für 1960 ohne Luxemburg, Portugal und Türkei; für 1970 ohne Türkei.

Quelle: Zusammengestellt und berechnet nach OECD, 1993.

Eberhard Wille, Angelika Mehnert and Jan Philipp Rohweder - 978-3-631-75615-7 
Im Unterschied zu Produktion und Marktzulassung weichen die Marktordnungen und die Vergütungssysteme, die in den einzelnen Ländern vorherrschen, noch sehr stark voneinander ab (vgl. Burstall, 1991). Diese Abweichungen resultieren nicht zuletzt aus den unterschiedlichen Sozialversicherungssystemen, die für ihre heimischen Arzneimittelmärkte jeweils spezielle Regulierungsformen vorsehen. Letztere erklären auch die erheblichen Preisunterschiede, die trotz einer spürbaren Abschwächung in den letzten Jahren innerhalb der Europäischen Union (EU) von Land zu Land immer noch bestehen. Die international tätigen Unternehmen reagierten auf die national unterschiedlichen Preisregulierungen mit einer Preisdifferenzierung bzw. einer internationalen Marktaufspaltung. Sofern der herannahende Binnenmarkt die nationalen Regulierungssysteme nicht zu vereinheitlichen und keine Deregulierungstendenzen auszulösen vermag, gleichzeitig aber über die Förderung von Re- und Parallelimporten die räumliche Preisdifferenzierung weiter einengt oder gar unmöglich macht, entfällt für die forschende europäische Arzneimittelindustrie ein relevantes Finanzierungsinstrument (vgl. Hilken, 1989, S. 180ff.).

Die angeführten Veränderungen, d.h. Abschwächung des Wachstums der GKVArzneimittelausgaben, fortgesetzte Marktausdehnung der Zweitanmelderpräparate, beinahe weltweite Intensivierung der Ausgabenbegrenzung im Gesundheitswesen und schwindende Möglichkeiten zur internationalen Preisdifferenzierung, stellen in ihrer Kombination für die forschende pharmazeutische Industrie in Deutschland zweifellos die größte Herausforderung nach dem Kriege dar. Unbeschadet sicherlich noch vorhandener bzw. unausgeschöpfter Effizienzpotentiale stellt sich unter diesen Bedingungen die Frage, ob sich die pharmazeutische Forschung auf mittlere Frist7) weltweit oder nur in Europa abschwächt, und welche Rolle Deutschland künftig als Standort für forschende Arzneimittelfirmen spielt. Bei der Beurteilung dieser Entwicklungstendenzen konzentrieren sich unsere Überlegungen im folgenden über den Stellenwert, den der Standort Deutschland für forschende Arzneimittelfirmen besitzt, hinaus auf die Bedeutung, die pharmazeutischen Innovationen unter gesamtwirtschaftlichen Aspekten zukommt. Dabei stehen nach einem empirischen Abriß über die Entwicklung der Arzneimittelausgaben das Nutzenspektrum von pharmazeutischen Innovationen,

7) Längerfristig dürfte die demographische Entwicklung in den meisten industrialisierten Ländern zumindest zu einem stärkeren Anwachsen des Verordnungsvolumens pro Kopf führen. 
das Arzneimittel als Produktionsfaktor im Prozeß gesundheitlicher Leistungserstellung und das Verhältnis von Innovation und Imitation im Mittelpunkt des Interesses. Vor diesem Hintergrund, d.h. unter Effizienz-, Effektivitäts- und Wettbewerbsaspekten, erfolgt dann auch eine Analyse von GRG und GSG sowie ein Blick auf den ordnungspolitischen Rahmen der Pharmaforschung in Deutschland. 


\section{Zur Empirie der Arzneimittelausgaben in Deutschland}

\subsection{Aktuelle Daten und Relationen}

\subsubsection{Apothekenumsatz und Gesamtproduktion}

Der Umsatz der öffentlichen Apotheken in Deutschland belief sich im Jahre 1992 auf 46,7 Mrd. DM. Nach Abzug der Mehrwertsteuer betrug der Umsatz in den alten Bundesländern 35,5 Mrd. DM, von denen 33,2 Mrd. DM oder 93,5 vH auf Arzneimittel und die restlichen 6,5 vH auf medizintechnische Produkte und das Ergänzungssortiment entfielen (vgl. ABDA, 1993a, S. 39). An dem Umsatz mit Arzneimitteln nahmen verschreibungspflichtige Medikamente einen Anteil von 65,5 vH ein, die nicht rezeptpflichtigen Medikamente trugen 32,3 vH bei, und der Rest bestand aus nicht apothekenpflichtigen Arzneimitteln.

In den etwa 2200 Apotheken der neuen Bundesländer erreichte der Umsatz abzüglich der Mehrwertsteuer und der Krankenkassenrabatte 5,7 Mrd. DM (vgl. ABDA, 1993a, S. 43). Der GKV-Umsatz, d.h. die Einnahmen aus der Abgabe aller zu Lasten der gesetzlichen Krankenkassen verschriebenen Medikamente, machte hier 4,9 Mrd. DM aus, was einem Anteil von $86 \mathrm{vH}$ entspricht. In den alten Bundesländern betrug der Anteil des GKV-Marktes am Gesamtumsatz der Apotheken dagegen nur $70 \mathrm{vH}$. Allerdings entspricht dies einem Anteil von über drei Vierteln des Umsatzes mit apothekenpflichtigen Arzneimitteln. Diese fragmentarischen Daten und Relationen verdeutlichen bereits, daß der gesetzlichen Krankenversicherung für Volumen und Struktur des inländischen Absatzes an Arzneimitteln sowohl in den neuen wie in den alten Bundesländern eine dominante Rolle zukommt.

Der Gesamtproduktionswert der pharmazeutischen Industrie in Deutschland belief sich im Jahre 1992 auf 32,6 Mrd. DM. Ein Anteil von etwas über $4 \mathrm{vH}$ hiervon stammte aus den neuen Bundesländern. 1991 betrug dieser Anteil noch 5,5 vH, wobei der Rückgang sowohl auf die schwindenden Absatzmöglichkeiten in Osteuropa als auch auf den 22prozentigen Sonderabschlag auf den GKVUmsatz zurückging (vgl. BPI, 1993a, S. 10). Der Apothekenmarkt, d.h. der Absatz an pharmazeutischen Produkten an öffentliche Apotheken zum individuelEberhard Wille, Angelika Mehnert and Jan Philipp Rohweder - 978-3-631-75615-7 
len Verkauf, umfaßte ein Volumen von 22,8 Mrd. DM zu Herstellerabgabepreisen, wovon $83 \mathrm{vH}$ auf die alten Bundesländer entfielen. 14,4 Mrd. DM oder 63 vH des Apothekenmarktes wurden auf dem GKV-Markt erlöst, was einem Volumen von 28,1 Mrd. DM zu Apothekenabgabepreisen entspricht. Hiervon finanzierten die gesetzlichen Krankenkassen $27 \mathrm{Mrd}$. DM, die restlichen 1,1 Mrd. DM leisteten Patienten in Form von Zuzahlungen. Die Unterschiede zwischen Apotheken- und Fabrikabgabepreisen gehen auf die Handelsspannen von Großhandel und Apotheken sowie auf die 14prozentige Mehrwertsteuer zurück. Am Apothekenabgabepreis partizipiert der entsprechende Fabrikabgabepreis also im Durchschnitt mit etwa $51 \mathrm{vH}$.

1991 befanden sich etwa 60.000 Fertigarzneimittel im Umlauf, darunter Humanarzneimittel, Homöopathika und Veterinärarzneimittel, jeweils aus industrieller Fertigung, Herstellung durch Krankenhausapotheken, öffentlichen Apotheken, Drogerien oder Reformhäusern (vgl. BPI, 1993a, S. 48). Einen besseren Überblick über die Medikamente zur humanmedizinischen Verwendung gibt die Rote Liste, die etwa 8000 Präparate umfaßt, wobei unterschiedliche Stärken und Darreichungsformen nur dann einzeln aufgeführt sind, wenn die anteilige Zusammensetzung der Wirkstoffe variiert. Das Verschreibungsverhalten der Ärzte konzentriert sich auf 2000 Arzneimittel, die $90 \mathrm{vH}$ des Apothekenumsatzes tragen. Von diesen 2000 Medikamenten besaßen die 500 meistverkauften einen Umsatzanteil von $62 \mathrm{vH}$ des Gesamtumsatzes (vgl. BPI, 1993a, S. 17). In den alten Bundesländern waren die umsatzstärksten Arzneimittelgruppen systemische Antiinfektiva $(5,6 \mathrm{vH})$, Antirheumatika $(4,1 \mathrm{vH})$, Vasotherapeutika $(3,9 \mathrm{vH})$ und Kalzium-Antagonisten (3,5 vH) (vgl. BPI, 1993a, S. 57). Überdurchschnittlich zur Verdoppelung des Arzneimittelumsatzes seit 1980 trugen Cytostatika, KalziumAntagonisten, Beta-Blocker und Antiinfektiva bei.

Die pharmazeutische Gesamtproduktion verteilt sich auf gut 1000 Arzneimittelhersteller, die 1992 nach einer Erhebung des Statistischen Bundesamtes in den alten Bundesländern 118.000 und in den neuen Bundesländern 7000 Mitarbeiter fachlicher Betriebsteile beschäftigten. Da die Apotheken in ganz Deutschland etwa 123.000 Beschäftigte zählen, kommt man mit den Mitarbeitern des pharmazeutischen Großhandels auf über 350.000 Personen, die unmittelbar an der Arzneimittelversorgung in Deutschland mitwirken.

Die Umsatzanteile am westdeutschen Arzneimittelmarkt, welche auf die 5 bis 100 umsatzstärksten Unternehmen entfallen, nahmen von 1970 bis 1992 kontinu- 
ierlich ab. Besaßen die 5 führenden Firmen 1970 noch einen Marktanteil von knapp $20 \mathrm{vH}$, so schrumpfte dieser Anteil bis 1992 auf $13 \mathrm{vH}$. Der Anteil der umsatzstärksten 20 Firmen ging in der gleichen Zeit von etwa $50 \mathrm{vH}$ auf $36 \mathrm{vH}$ zurück (vgl. BPI, 1993a, S. 15). Berücksichtigt man jedoch die Konzernverflechtung, so zeigt sich trotz ebenfalls rückläufiger Tendenz doch eine stärkere Konzentration: Die 5 umsatzstärksten Konzerne erreichten 1970 einen Umsatzanteil von $27 \mathrm{vH}$, der bis 1992 auf knapp $20 \mathrm{vH}$ abnahm. Wegen der Konzentration der Firmen auf bestimmte Teilmärkte bzw. Indikationsgebiete sagt eine solche Auflistung zwar noch wenig über die Wettbewerbssituation aus, gleichwohl deutet sie auf eine gestiegene räumliche Dezentralisierung der pharmazeutischen Produktion in Deutschland hin. Innerhalb der Bundesländer nahm 1992 Nordrhein-Westfalen mit 19,7 vH der Gesamtproduktion die erste Stelle ein, knapp dahinter folgten Baden-Württemberg mit 18,3 vH und Hessen mit 17,3 vH sowie, nun mit deutlichem Abstand, Bayern mit $11 \mathrm{vH}$ und Berlin mit 10,2 vH.

Neben zunehmender internationaler Konkurrenz könnte auch das Wachstum des Generikamarktes mit dem Auftreten neuer Produzenten für die abnehmende Konzentration auf dem Pharmamarkt verantwortlich zeichnen. Ausländische Konzerne mit ihren deutschen Tochterunternehmen hielten 1992 einen Umsatzanteil von knapp $50 \mathrm{vH}$ am westdeutschen Apothekenmarkt (vgl. BPI, 1993a, S. 17), und im generikafähigen Teilmarkt konnten die Zweitanmelder ihren Marktanteil nach Verordnungen zwischenzeitlich auf über $60 \mathrm{vH}$ ausweiten (siehe oben Tabelle 1).

\subsubsection{Der bundesdeutsche Pharma-Außenhandel}

Die pharmazeutische Industrie in Deutschland weist eine enge Verflechtung mit dem Weltmarkt auf, der nach Schätzungen des Instituts für Medizinische Statistik 1992 ein Volumen von 226 Mrd. DM umfaßte (vgl. BPI, 1993a, S. 23). Jeweils ein Drittel der Weltumsätze mit pharmazeutischen Produkten wurde in Europa und Nordamerika getätigt; Afrika, Asien und Australien vereinigten knapp ein Viertel des Umsatzes auf sich. Die Verbindung der pharmazeutischen Industrie in Deutschland mit dem Ausland erstreckt sich auf drei Gebiete: a) Tochterunternehmen deutscher Konzerne im Ausland und ausländischer Unternehmen in Deutschland, b) Export und Import von pharmazeutischen Produkten und c) Ausgaben für den Erwerb und Einnahmen aus der Erteilung von Lizenzen zur Produktion oder zum Vertrieb patentgeschützter Arzneimittel. 
Tochterunternehmen und Vertriebsorganisationen ausländischer Konzerne besaBen 1992 einen Anteil von $49 \mathrm{vH}$ am westdeutschen Arzneimittelmarkt, wovon Firmen mit US-amerikanischen Mutterkonzernen knapp zwei Fünftel erlösten (vgl. BPI, 1993a, S. 17). Eine Mitgliederbefragung des Bundesverbandes der Pharmazeutischen Industrie für 1990 ergab, daß Tochterunternehmen der Mitgliedsfirmen über $10 \mathrm{Mrd}$. DM zusätzlich zum direkten Export deutscher Produkte im Ausland erwirtschafteten (vgl. BPI 1993a, S. 23). Mit der Ansiedlung von Tochterunternehmen auf Auslandsmärkten versuchen die Pharmaunternehmen, sich besser an das regulative Umfeld in dem jeweiligen Land anzupassen.

Die pharmazeutische Industrie in Deutschland exportierte 1992 Waren im Wert von 12,8 Mrd. DM. Gleichzeitig wurden pharmazeutische Produkte für $8 \mathrm{Mrd}$. DM eingeführt. Mit einem kontinuierlich wachsenden Ausfuhrüberschuß von über einem Drittel des Exportvolumens trug die pharmazeutische Industrie seit jeher überdurchschnittlich zur aktiven Handelsbilanz Deutschlands bei. Hauptabnehmer deutscher pharmazeutischer Produkte waren, wie Tabelle 3 ausweist, Japan (10 vH), die Schweiz $(9,4 \mathrm{vH})$, Italien $(7,7 \mathrm{vH})$, Großbritannien $(7,1 \mathrm{vH})$ und die USA (6,7 vH). Die EU vereinte einen Anteil von $38 \mathrm{vH}$ der deutschen Pharmaexporte auf sich, was die Bedeutung dieses Marktes für die bundesdeutsche pharmazeutische Industrie verdeutlicht. Die Arzneimittelimporte kamen vornehmlich aus der Schweiz (16 vH), Frankreich und Großbritannien (beide knapp $13 \mathrm{vH}$ ) sowie den USA (etwa $11 \mathrm{vH}$ ). Auch bei den Importen spielte die EU mit einem Anteil von etwa der Hälfte eine dominierende Rolle (vgl. Marx, 1993).

Die Basis für den Handel mit Lizenzen bildet die Innovationstätigkeit von Industrieunternehmen. $\mathrm{Zu}$ den Handelsströmen immaterieller Wirtschaftsgüter im Pharmasektor existieren nur sehr unspezifische Daten. Das Bundesministerium für Forschung und Technologie (1993, S. 595) weist in seinem Bundesbericht Forschung 1993 für die chemische Industrie ohne Mineralölverarbeitung Einnahmen von 1,2 Mrd. DM und Ausgaben von 991 Mill. DM für Patente und Lizenzen auf Erfindungen und Verfahren für das Jahr 1991 aus. Der positive Saldo spiegelt die starke internationale Stellung der deutschen Chemieindustrie in Bezug auf Forschung und Entwicklung innovativer Produkte und Produktionstechniken wider. Allerdings geht die Zahl der angemeldeten Patente auf pharmazeutische Produkte von deutschen Firmen in den letzten Jahren stark zurück (siehe unten Punkt 5.1). Auch im internationalen Vergleich hat die deutsche pharmazeutische Industrie an Boden verloren, wenn man die Anteile der angemeldeten $\mathrm{Pa}$ tente an allen weltweit neu zugelassenen Präparaten (NCE's) betrachtet.

Eberhard Wille, Angelika Mehnert and Jan Philipp Rohweder - 978-3-631-75615-7 
Tabelle 3: Außenhandel mit pharmazeutischen Produkten (in Mio. DM)

\begin{tabular}{|c|c|c|c|c|c|}
\hline Jahr & 1980 & 1985 & 1990 & 1991 1) & $19921)$ \\
\hline Ausfuhren & 5.581 & 9.726 & 10.559 & 12.067 & 12.820 \\
\hline Japan & 376,2 & 615,7 & $1.100,6$ & $1.289,5$ & $1.281,7$ \\
\hline Schweiz & 309,7 & 498,6 & 863,0 & $1.115,6$ & $1.200,5$ \\
\hline Italien & 493,7 & 982,9 & $1.022,8$ & 935,5 & 989,6 \\
\hline UK & 245,9 & 595,2 & 689,3 & 778,8 & 913,4 \\
\hline USA & 287,1 & 636,6 & 650,1 & 776,6 & 858,5 \\
\hline Einfuhren & 3.276 & 6.078 & 6.081 & 7.682 & $\mathbf{8 . 0 0 3}$ \\
\hline Schweiz & 632,3 & 917,4 & $1.191,4$ & $1.528,6$ & $1.271,2$ \\
\hline Frankreich & 448,2 & 664,1 & 811,1 & $1.043,6$ & $1.022,1$ \\
\hline UK & 545,9 & $1.219,1$ & 643,7 & 935,3 & $1.020,2$ \\
\hline USA & 272,0 & 596,3 & 602,2 & 716,9 & 857,0 \\
\hline $\begin{array}{l}\text { Ausfuhrüber- } \\
\text { schuB }\end{array}$ & 2.305 & $\mathbf{3 . 6 4 8}$ & $\mathbf{4 . 4 7 8}$ & 4.385 & $\mathbf{4 . 8 1 7}$ \\
\hline
\end{tabular}

1) Ab 1991 gesamtdeutsche Werte

Quelle: Bundesverband der Pharmazeutischen Industrie e.V., 1993b, 1987.

Während die Anzahl der eingeführten neuen Präparate weltweit von 289 im Fünfjahresabschnitt 1981-85 um 7 vH auf 269 in den Jahren 1986-90 zurückging, verzeichnete die deutsche pharmazeutische Industrie einen Rückgang von über 50 vH, von 45 auf 22, für dieselben Vergleichsjahre (vgl. Reis-Arndt, 1993). Hierbei ist jedoch zu bedenken, daß diese Zahlen eine Bewertung der Patente nach Markterfolg oder Innovationsgehalt der Produkte nicht ohne weiteres zuläßt.

\subsection{Die Entwicklung der Arzneimittelausgaben innerhalb der GKV}

Die Arzneimittelausgaben bilden zunächst lediglich die monetären Inputs, die in das Gesundheitssystem fließen, während im Sinne der Aufgabenerfüllung eigentlich die entsprechenden Outputs bzw. Outcomes im Mittelpunkt stehen sollten (vgl. Wille/Ulrich, 1991, S. 38ff.). Die Feststellung, daß eine Darstellung der Ausgabenentwicklung der zentralen Leistungs- bzw. Behandlungsarten keine 
Hinweise auf die damit einhergehende Zielrealisierung enthält, bedeutet aber nicht, daß ihr im Rahmen einer gesamtwirtschaftlichen Analyse der Gesundheitsversorgung nur eine geringe oder gar keine Bedeutung zukommt.

Zunächst informiert die Ausgabenebene über die Opportunitätskosten der Gesundheitsversorgung, welche dadurch anfallen, daß die im Gesundheitswesen gebundenen Ressourcen nun in keine andere Verwendung mehr fließen und dort Nutzen stiften können. Die Problematik steigender Beitragssätze läßt sich u.a. unter dem Opportunitätskosten-Aspekt subsumieren. Sodann bilden die Gesundheitsausgaben zwar nicht die einzige, aber eine sehr wichtige Mittelkategorie für die Verwirklichung von Gesundheitszielen. Ferner lassen sich von dieser untersten Stufe der Zielhierarchie zwar nicht unmittelbare Folgerungen über die Gesundheitsziele ableiten, häufig aber schrittweise Erkenntnisse über die jeweils höher postierten Ziel-Mittel-Ebenen gewinnen. Schließlich bilden die Gesundheitsausgaben die konkreten Ansatzpunkte des budgetären Willensbildungsprozesses und insofern die primären Schalthebel der diversen Steuerungs- bzw. Anreizmechanismen.

Die GKV-Ausgaben für "Arzneien, Heil- und Hilfsmittel aus Apotheken" (im folgenden einfach: Arzneimittelausgaben) erscheinen in der amtlichen Statistik7) als eine Untergruppe der Ausgaben für medizinische Behandlung, deren Anteil an den Gesamtausgaben der GKV im Zeitraum von 1970 bis 19918) von 78,4 vH auf $82,3 \mathrm{vH}$ anstieg (Tabelle 4). Die Behandlungsausgaben dominieren innerhalb der globalen Leistungsarten aber nicht nur in quantitativer Hinsicht, sie stehen auch unter dem Aspekt gesundheitlicher Leistungserstellung im Mittelpunkt des Inter-

7) Während unsere Ausführungen ansonsten auf den Statistiken des Bundesministeriums für Arbeit (BMA) aufbauen, beziehen sich die Tabellen 4 bis 6 auf die Daten des Statistischen Bundesamtes. Letztere klassifizieren die Gesundheitsausgaben nach einem einheitlichen Schema für alle Ausgabenträger und erlauben deshalb auch einen Vergleich der Ausgabenentwicklung von GKV und Privater Krankenversicherung (PKV).

8) Bei diesem Beobachtungszeitraum mag die Festlegung des Basisjahres eine gewisse Zufälligkeit bzw. Willkür beinhalten, was aber hier für jeden anderen Ausgangspunkt mindestens gleichermaßen gelten würde. Die Jahre vor 1970 werfen u.a. das methodisch kaum lösbare Problem auf, die Entwicklung der Ausgabenstruktur um die Effekte des Gesetzes über die Fortzahlung des Arbeitsentgelts im Krankheitsfalle vom 27.7.1969 zu bereinigen. Die Wahl eines späteren Basisjahres besitzt den Nachteil, daß die Anzahl der Beobachtungseinheiten dann kaum mehr Aussagen über mittelfristige Entwicklungstendenzen erlaubt. Da die gesetzlichen Eingriffe im Gesundheitswesen auch nach 1970 praktisch nie abrissen, treten nahezu ständig andere diskretionäre Maßnahmen als Störgrößen auf. 
esses. Bei den "Krankheitsfolgeleistungen" handelt es sich schwergewichtig um Transferzahlungen und bei den "nicht aufteilbaren Ausgaben" vor allem um Verwaltungsausgaben und Investitionsausgaben für Verwaltungseinrichtungen (vgl. Statistisches Bundesamt, 1980, S. 5). Als direkte monetäre Inputs der "Gesundheitsproduktion" verdienen von den übrigen Kategorien die "vorbeugenden und betreuenden Maßnahmen" am meisten Beachtung, obgleich sie bisher quantitativ keine so große Rolle spielten. Die betreffenden Ausgaben dienen vornehmlich der Krankheitsfrüherkennung bzw. Maßnahmen der sekundären Prävention und fließen kaum in die sog. primäre Prävention, welche darauf abzielt, über Vorsorgemaßnahmen, z.B. im Bereich des Umweltschutzes oder des persönlichen Lebensstils, das Auftreten von Krankheiten zu vermeiden. Grundsätzlich existiert noch eine fünfte globale Leistungsart, aber die GKV tätigt, ähnlich wie die PKV, keine Ausgaben für "Ausbildung und Forschung".

Tabelle 4: Die GKV-Ausgaben nach globalen Leistungsarten1)

\begin{tabular}{|c|c|c|c|c|c|c|}
\hline Leistungssart & 1970 & 1975 & 1980 & 1985 & 1990 & 1991 \\
\hline $\begin{array}{c}\text { (1) vorbeugende } \\
\text { Maßnahmen }\end{array}$ & 3,4 & 3,7 & 2,9 & 2,9 & 3,3 & 4,3 \\
\hline (2) Behandlung & 78,7 & 82,3 & 83,0 & 84,7 & 83,4 & 82,3 \\
\hline $\begin{array}{l}\text { (3) Krankheits- } \\
\text { folgeleistungen }\end{array}$ & 12,6 & 9,2 & 9,6 & 7,2 & 7,9 & 8,1 \\
\hline $\begin{array}{l}\text { (4) nicht aufteil- } \\
\text { bare Ausgaben }\end{array}$ & 5,4 & 4,8 & 4,5 & 5,2 & 5,5 & 5,4 \\
\hline
\end{tabular}

1) Jeweilige Ausgaben in vH der GKV-Ausgaben insgesamt.

Quelle: Statistisches Bundesamt, 1991, S. 63-66, Müller, 1992 sowie für das Jahr 1991 Informationen des Statistischen Bundesamtes.

Die Ausgaben für medizinische Behandlung erstrecken sich weitgehend auf die in Tabelle 5 aufgefuihrten Behandlungsarten, die im Jahr 1991 insgesamt einen Anteil von $79,1 \mathrm{vH}$ an den gesamten Gesundheitsausgaben der GKV besaßen. Unsere Zusammenstellung vernachlässigt innerhalb der medizinischen Behandlung lediglich die beiden Positionen "Behandlung durch sonstige Heilpersonen" 
sowie "stationäre Kurbehandlung", welche aber nur einen sehr geringen Ausgabenanteil aufweisen und zudem im Rahmen der PKV-Ausgaben nicht gesondert erscheinen. Wie Tabelle 5 belegt, verursachten die stationäre Behandlung9), die Heil- und Hilfsmittel sowie der Zahnersatz den starken Anstieg der GKV-

Tabelle 5: Die GKV-Ausgaben nach einzelnen Behandlungsarten

\begin{tabular}{|l|c|c|c|c|c|c|}
\hline \multirow{2}{*}{ Behandlungsart Jahr } & \multicolumn{5}{|c|}{ Anteile1) } & $\begin{array}{c}\text { Wara } 2) \\
1970- \\
1991\end{array}$ \\
\cline { 2 - 6 } & 1970 & 1975 & 1980 & 1985 & 1991 & 199 \\
\hline $\begin{array}{c}\text { (1) Behandlung } \\
\text { durch Ärzte }\end{array}$ & 22,8 & 18,8 & 17,6 & 17,1 & 17,1 & 359,1 \\
\hline $\begin{array}{c}\text { (2) Behandlung } \\
\text { durch Zahnärzte }\end{array}$ & 7,1 & 6,9 & 6,3 & 6,0 & 5,8 & 440,3 \\
\hline $\begin{array}{c}\text { (3) stationäre } \\
\text { Behandlung }\end{array}$ & 25,3 & 30,2 & 30,0 & 32,1 & 32,9 & 737,0 \\
\hline \begin{tabular}{c} 
(4) Arzneimittel 3$)$ \\
\hline $\begin{array}{c}\text { (5) Heil- und Hilfs- } \\
\text { mittel4) }\end{array}$
\end{tabular} & 17,1 & 14,9 & 14,3 & 14,9 & 15,6 & 482,6 \\
\hline (6) Zahnersatz & 3,4 & 7,0 & 8,3 & 6,9 & 3,6 & 577,9 \\
\hline
\end{tabular}

1) Jeweilige Ausgaben in vH der GKV-Ausgaben für Gesundheit insgesamt.

2) Veränderung im angegebenen Zeitraum in $\mathrm{vH}$.

3) Sog. Arzneien, Heil- und Hilfsmittel aus Apotheken.

4) Sog. Arzneien, Heil- und Hilfsmittel von anderen Stellen.

Quelle: Statistisches Bundesamt, 1991, S. 63-68 sowie für die Jahre 1990 und 1991 Informationen des Statistischen Bundesamtes.

9) Die Ausgaben für stationäre Behandlung schließen auch die Aufwendungen für im Krankenhaus verabreichte Arzneimittel ein. Da letztere anderen Rahmenbedingungen, insbesondere Abgabemodalitäten und Preisbildungsprozessen, unterliegen, konzentriert sich unsere Analyse im folgenden auf die Arzneimittel aus öffentlichen Apotheken. 
Gesundheitsausgaben, während die Arzneimittelausgaben ebenso wie die Ausgaben für die Behandlung durch Ärzte und durch Zahnärzte im Beobachtungszeitraum anteilsmäßig zurückgingen. $\mathrm{Ab}$ dem Jahre 1980 verzeichnet der Arzneimittelanteil innerhalb der GKV-Ausgaben allerdings eine steigende Tendenz.

Die Einteilung der Ausgabenentwicklung in Fünfjahresabschnitte zeigt, daß die strukturellen Verschiebungen zwischen den einzelnen Behandlungsarten vornehmlich zwischen 1970 und 1975 stattfanden, als die Anteile für die Behandlung durch Ärzte und für Arzneimittel deutlich abnahmen und die Ausgaben für stationäre Behandlung eine kräftige relative Expansion verzeichneten. Die anschließenden Maßnahmen zur sog. Kostendämpfung im Gesundheitswesen gingen eher mit einer Verfestigung der Budgetstruktur einher, die sich insbesondere von 1975 bis 1980 nur geringfügig veränderte. Die finanziellen Auswirkungen der Kostendämpfungsmaßnahmen trafen vor allem den Zahnersatz, der im Beobachtungszeitraum den stärksten diskretionären Eingriffen unterlag, und die Arzneimittel. Bereinigt um die fiskalischen Effekte der Kostendämpfungsmaßnahmen (vgl. Berg, 1986, S. 35) läge schon im Jahre 1985 der Arzneimittelanteil um knapp einen Prozentpunkt und die Ausgabenquote des Zahnersatzes um gut 1,5 Prozentpunkte höher.

Für eine weitere Interpretation der Position, welche die Arzneimittel im Rahmen der medizinischen Behandlungsarten einnehmen, bietet sich ein kursorischer Vergleich mit der korrespondierenden Ausgabenentwicklung im Bereich der PKV an. Dabei besitzen Divergenzen im Niveau des Wachstums wegen der offensichtlichen Unterschiede im Hinblick auf Versichertenkreis und Risikostruktur nur eine geringe Aussagekraft. Dagegen lassen Abweichungen im Niveau der Anteile einzelner Behandlungsarten und insbesondere Unterschiede in der Entwicklung der Ausgabenstruktur durchaus gewisse gesundheitsökonomische Aussagen zu.

Wie Tabelle 6 ausweist, nahmen auch im Bereich der PKV die Ausgabenanteile für ärztliche Behandlung und für Arzneimittel ab, wohingegen die Behandlungsarten stationäre Behandlung, Heil- und Hilfsmittel sowie Zahnersatz, ebenfalls ähnlich wie bei der GKV, relativ expandierten. In deutlichem Unterschied zur GKV stiegen die PKV-Ausgaben für Zahnbehandlung weit überproportional an, wobei ihr Wachstum sogar noch die Ausgabensteigerung beim Zahnersatz weit übertrifft. Bei einem Vergleich mit der GKV-Ausgabenentwicklung fällt ferner das starke Absinken des Arzneimittelanteils auf, der sich im Bereich der PKV nahezu halbierte. Dieser Befund nährt u.E. Zweifel an der weitverbreiteten These, daß 
Tabelle 6: Die PKV-Ausgaben nach einzelnen Behandlungsarten

\begin{tabular}{|c|c|c|c|c|c|c|}
\hline \multirow{2}{*}{ Behandlungsart } & \multicolumn{5}{|c|}{ Anteile1) } & $\begin{array}{c}\text { Wara2) } \\
1970- \\
1991\end{array}$ \\
\cline { 2 - 6 } & 1970 & 1975 & 1980 & 1985 & 1991 & 1991 \\
\hline $\begin{array}{c}\text { (1) ärztliche } \\
\text { Behandlung }\end{array}$ & 15,8 & 14,8 & 15,8 & 13,8 & 16,0 & 427,8 \\
\hline (2) Zahnbehandlung & 1,4 & 2,3 & 3,9 & 4,6 & 7,0 & $2.444,2$ \\
\hline $\begin{array}{c}\text { (3) stationäre } \\
\text { Behandlung }\end{array}$ & 24,9 & 29,2 & 29,9 & 30,1 & 30,9 & 547,7 \\
\hline $\begin{array}{c}\text { (4) Arzneien und } \\
\text { Verbandsmittel }\end{array}$ & 12,1 & 8,2 & 6,6 & 6,5 & 6,3 & 174,3 \\
\hline $\begin{array}{c}\text { (5) Heil- und } \\
\text { Hilfsmittel }\end{array}$ & 2,1 & 3,1 & 3,7 & 3,2 & 4,2 & 903,2 \\
\hline (6) Zahnersatz & 2,2 & 3,4 & 5,8 & 4,6 & 4,3 & 926,6 \\
\hline
\end{tabular}

1) Jeweilige Ausgaben in vH der PKV-Ausgaben für Gesundheit insgesamt.

2) Veränderung im angegebenen Zeitraum in $\mathrm{vH}$.

Quelle: Statistisches Bundesamt, 1991, S. 78-80, Müller, 1992 sowie für das Jahr 1991 Informationen des statistischen Bundesamtes.

bei der Arzneimittelversorgung angebotsseitige Determinanten eindeutig dominieren. Eine solche Argumentationsweise vermag die starken Abweichungen in der Entwicklung der Ausgabenstruktur von GKV und PKV nicht hinreichend zu erklären. Schließlich konsumieren sowohl GKV- als auch PKV-Patienten pharmazeutische Produkte derselben Unernehmen, die hier wie dort identische Absatzstrategien anwenden, und es verordnen im wesentlichen dieselben Ärztc mit den gleichen Motivationsstrukturen.

\subsection{Der Einfluß der Rentnerquote auf die GKV-Arzneimittelausgaben}

Innerhalb der GKV entfiel im Jahre 1970 auf eine sog. Rentnerquote, d.h. auf einen Anteil der Rentner an der Gesamtzahl von Mitgliedern in der Allgemeinen 
Krankenversicherung (im folgenden "Mitglieder" genannt) und Rentnern, von 26,1 vH ein nur geringfügig höherer Anteil von 27,6 vH an den GKV-Gesamtausgaben. Da die Ausgaben für Rentner zwischen 1970 und 1992 mit 962,0 vH $(1970=100)$ wesentlich stärker anstiegen als jene für Mitglieder mit 462,2 vH, beanspruchte im Jahre 1992 eine Rentnerquote von 28,7 vH einen entsprechenden Ausgabenanteil von 41,7 vH. Wie bereits ein flüchtiger Blick auf Tabelle 7 andeutet, divergieren die Anteile, welche die Ausgaben für Rentner jeweils einnehmen, zwischen den verschiedenen Behandlungsarten erheblich, so daß von der relativen Ausdehnung der GKV-Ausgaben für Rentner auch relevante Einflüsse auf die Ausgabenstruktur ausgehen können 10). Dabei verzeichneten die Arzneimittelausgaben schon 1970 mit 43,7 vH den höchsten Rentneranteil aller Behandlungsarten, und dieser wuchs bis 1992 noch auf 54,3 vH an. Dies bedeutet, daß zuletzt eine Rentnerquote von $28,7 \mathrm{vH}$ einen Anteil von 54,3 vH an den Arzneimittelausgaben einnahm. Dieser Anteil ging allerdings nach 1985 (55,9 $\mathrm{vH})$ wieder leicht zurück.

Eine nach Mitgliedern und Rentnern getrennte Analyse der GKV-Ausgaben zeigt, daß der Arzneimittelanteil bei den Mitgliedern zwischen 1970 und 1992 von 13,8 $\mathrm{vH}$ auf 12,7 vH abnahm (Tabelle 8). Nach 1980 weist er allerdings eine leicht steigende Tendenz auf. Die Arzneimittelausgaben für Mitglieder rangieren in ihrem Wachstum ähnlich wie die gesamten Arzneimittelausgaben innerhalb der sechs Behandlungsarten an drittletzter Stelle, nur noch gefolgt von den Ausgaben für Behandlung durch Zahnärzte und den Aufwendungen für die Behandlung durch Ärzte. Innerhalb der GKV-Ausgaben für Renter sank der Arzneimittelanteil im Beobachtungszeitraum von 28,1 vH auf 21,0 vH ab, bildet aber immer noch nach der stationären Behandlung die ausgabenintensivste Behandlungsart. Gleichwohl steigt der Arzneimittelanteil bei den Rentnern im Unterschied zu den Mitgliedern nach 1980 nicht an ${ }^{11)}$.

10) Im Gegensatz zu den Daten des Statistischen Bundesamtes, auf denen die Tabellen 4 bis 6 aufbauen, vernachlässigen die BMA-Statistiken die nicht-aufteilbaren Ausgaben, was die Anteile der verbleibenden Kategorien tendenziell leicht erhöht. Zudem grenzen sie die Ausgaben für stationäre Behandlung etwas anders $a b$, so daß Anteile und Wachstum der verschiedenen Behandlungsarten in den Tabellen 5 und 8 geringfügig voneinander abweichen.

11) Diese unterschiedliche Entwicklung des Ausgabenanteils für Arzneimittel bei Mitgliedern und Rentnern könnte eine Erklärung dafür bilden, daß eine Bereinigung des gesamten Arzneimittelanteils um die Effekte, die ab 1970 von der Rentnerquote ausgingen, nur zu einer Reduktion um gut einen Prozentpunkt füht (siehe dazu ausführlich Wille/Erbsland 1993, S. 188ff.).

Eberhard Wille, Angelika Mehnert and Jan Philipp Rohweder - 978-3-631-75615-7 
Tabelle 7: Anteile der GKV-Ausgaben für Mitglieder und Rentner an den jeweiligen Behandlungsarten

\begin{tabular}{|c|c|c|c|c|c|c|c|}
\hline \multicolumn{2}{|c|}{$\begin{array}{ll}\text { Behandlungsart } & \text { Jahr } \\
\end{array}$} & 1970 & 1975 & 1980 & 1985 & 1990 & $1992^{a)}$ \\
\hline \multirow{2}{*}{$\begin{array}{l}\text { (1) Behandlung } \\
\text { durch Ärzte }\end{array}$} & Mitglieder $b$ ) & 73,2 & 69,6 & 66,1 & 64,0 & 64,6 & 64,4 \\
\hline & Rentnerc) & 26,8 & 30,4 & 33,9 & 36,0 & 35,4 & 35,6 \\
\hline \multirow{2}{*}{$\begin{array}{l}\text { (2) Behandlung } \\
\text { durch Zahnärzte }\end{array}$} & Mitglieder & 91,6 & 92,0 & 91,2 & 89,7 & 88,7 & 87,9 \\
\hline & Rentner & 8,4 & 8,0 & 8,8 & 10,3 & 11,3 & 12,1 \\
\hline \multirow{2}{*}{$\begin{array}{l}\text { (3) Stationäre } \\
\text { Behandlung }\end{array}$} & Mitglieder & 64,4 & 60,0 & 54,1 & 49,5 & 47,9 & 47,8 \\
\hline & Rentner & 35,6 & 40,0 & 45,9 & 50,5 & 52,1 & 52,2 \\
\hline \multirow[t]{2}{*}{ (4) Arzneimittel } & Mitglieder & 56,3 & 51,8 & 49,8 & 44,1 & 45,2 & 45,7 \\
\hline & Rentner & 43,7 & 48,2 & 50,2 & 55,9 & 54,8 & 54,3 \\
\hline \multirow{2}{*}{$\begin{array}{l}\text { (5) Heil- und } \\
\text { Hilfsmittel }\end{array}$} & Mitglieder & 69,9 & 65,9 & 62,8 & 56,0 & 54,1 & 51,2 \\
\hline & Rentner & 30,1 & 34,1 & 37,2 & 44,0 & 45,9 & 48,8 \\
\hline \multirow[t]{2}{*}{ (6) Zahnersatz } & Mitglieder & 69,7 & 74,8 & 79,8 & 76,0 & 71,3 & 70,9 \\
\hline & Rentner & 30,3 & 25,2 & 20,2 & 24,0 & 28,7 & 29,1 \\
\hline
\end{tabular}

a) Vorläufige Ergebnisse.

b) Mitglieder und Familienangehörige in der Allgemeinen Krankenversicherung.

c) Rentner und Familienangehörige in der Krankenversicherung der Rentner.

Quelle: Zusammengestellt und errechnet aus: Der Bundesminister für Arbeit und Sozialordnung, 1970 bis 1989 sowie 1992 und 1993. 
Tabelle 8: Anteile an den GKV-Ausgaben für Mitglieder und Rentner nach Behandlungsarten

\begin{tabular}{|c|c|c|c|c|c|c|c|}
\hline Behandlungsart & Jahr & 1970 & 1980 & 1985 & 1990 & 1992a) & Warab) \\
\hline \multirow{2}{*}{$\begin{array}{l}\text { (1) Behandlung } \\
\text { durch }\end{array}$} & Insgesamt $c$ ) & 22,9 & 17,9 & 18,1 & 18,2 & 17,4 & 432,4 \\
\hline & Mitgliederd) & 23,1 & 18,0 & 19,2 & 19,9 & 19,2 & 368,6 \\
\hline Ärzte & Rentnere) & 22,2 & 17,7 & 16,3 & 15,6 & 14,8 & 606,6 \\
\hline \multirow{2}{*}{$\begin{array}{l}\text { (2) Behandlung } \\
\text { durch Zahn- }\end{array}$} & Insgesamt & 7,2 & 6,4 & 6,1 & 6,1 & 6,0 & 490,3 \\
\hline & Mitglieder & 9,1 & 8,9 & 9,1 & 9,2 & 9,1 & 466,9 \\
\hline ärzte & Rentner & 2,2 & 1,7 & 1,6 & 1,7 & 1,7 & 745,1 \\
\hline \multirow{3}{*}{$\begin{array}{l}\text { (3) Stationäre } \\
\text { Behandlung }\end{array}$} & Insgesamt & 25,2 & 29,6 & 32,2 & 33,2 & 32,3 & 798,9 \\
\hline & Mitglieder & 22,4 & 24,4 & 26,5 & 27,0 & 26,5 & 567,2 \\
\hline & Rentner & 32,5 & 39,7 & 40,9 & 42,1 & 40,4 & 1217,9 \\
\hline \multirow{3}{*}{$\begin{array}{l}\text { (4) Arznei- } \\
\text { mittel }\end{array}$} & Insgesamt & 17,7 & 14,3 & 15,3 & 16,3 & 16,2 & 539,8 \\
\hline & Mitglieder & 13,8 & 11,1 & 11,2 & 12,5 & 12,7 & 419,7 \\
\hline & Rentner & 28,1 & 21,4 & 21,4 & 21,7 & 21,0 & 694,4 \\
\hline \multirow{3}{*}{$\begin{array}{l}\text { (5) Heil- und } \\
\text { Hilfsmittel }\end{array}$} & Insgesamt & 2,8 & 5,7 & 6,0 & 6,3 & 6,4 & 1497,0 \\
\hline & Mitglieder & 2,7 & 5,4 & 5,6 & 5,7 & 5,7 & 1083,5 \\
\hline & Rentner & 3,1 & 6,2 & 6,6 & 7,1 & 7,4 & 2455,7 \\
\hline \multirow{3}{*}{$\begin{array}{l}\text { (6) Zahn- } \\
\text { ersatz }\end{array}$} & Insgesamt & 3,5 & 8,6 & 7,1 & 3,6 & 4,0 & 712,4 \\
\hline & Mitglieder & 3,3 & 10,4 & 8,9 & 4,4 & 4,9 & 726,5 \\
\hline & Rentner & 3,8 & 5,1 & 4,2 & 2,5 & 2,8 & 680,1 \\
\hline
\end{tabular}
a) Vorläufige Ergebnisse.
b) Veränderung im angegebenen Zeitraum in $\mathrm{vH}$.
c) Jeweilige Ausgaben in vH der Ausgaben der GKV für Gesundheit (letztere hier ohne die nicht aufteilbaren, sonstigen Aufwendungen).
d) Jeweilige Ausgaben für Mitglieder in $\mathrm{vH}$ der gesamten GKV-Gesundheitsausgaben für Mitglieder.
e) Jeweilige Ausgaben für Rentner in vH der gesamten GKV-Gesundheitsausgaben für Rentner.

Quelle: siehe Tabelle 7. 
Die absoluten GKV-Ausgaben pro Rentner lagen im Jahre 1970 mit 821 DM nur geringfügig über den entsprechenden Aufwendungenen für Mitglieder von 763 DM (Tabelle 9). Beliefen sich damit die Ausgaben pro Rentner im Jahre 1970 noch auf das 1,1 fache der Aufwendungen für Mitglieder, so betrugen sie im Jahre 1992 mit 6.209,- DM gegenüber 3.481,- DM aber schon fast das 1,8fache12). Während die Differenz zwischen den Ausgaben pro Rentner und denen pro Mitglied bei der Behandlung durch Ärzte vergleichsweise gering ausfiel, betrugen die Aufwendungen pro Rentner bei den Heil- und Hilfsmitteln das 2,3fache derjenigen pro Mitglied, bei der stationären Behandlung das 2,7fache und bei den Arzneimitteln gar fast das 3fache. Die Rentner verursachten 1992 mit durchschnittlich 1304,- DM deutlich mehr Arzneimittelausgaben als Aufwendungen für die Behandlung durch Ärzte (919,- DM), während es sich bei den Mitgliedern tendenziell umgekehrt verhielt. Aus dieser Perspektive, d.h. auf der Grundlage eines Vergleichs der GKV-Ausgaben pro Rentner und pro Mitglied, besitzen die Arzneimittelausgaben von allen Behandlungsarten die stärkste Rentner- und damit wohl auch Altersabhängigkeit.

12) Die GKV-Ausgaben in Tabelle 9 schließen auch die Aufwendungen für beitragsfrei mitversicherte Familienangehörige ein, d.h. es handelt sich hier im strengen Sinne nicht um pro Kopf-Ausgaben, die insofern niedriger liegen. Da aber auf ein Mitglied im Durchschnitt mehr mitversicherte Familienangehörige als auf einen Rentner entfallen, würde eine entsprechende pro Kopf-Betrachtung die Unterschiede noch stärker hervortreten lassen. Für eine solche pro Kopf-Analyse fehlt bisher leider die notwendige Datenbasis. 
Tabelle 9: GKV-Ausgaben in DM pro Kopf für Mitglieder und Rentner

\begin{tabular}{|c|c|c|c|c|c|c|c|}
\hline \multicolumn{2}{|l|}{ Behandlungsart } & 1970 & 1975 & 1980 & 1985 & 1990 & $1992^{a)}$ \\
\hline \multirow{2}{*}{$\begin{array}{l}\text { (1) GKV-Ausgaben } \\
\text { insgesamt }\end{array}$} & Mitglieder & 763,2 & 1663,0 & 2232,8 & 2559,3 & 2945,3 & 3480,9 \\
\hline & Rentner & 821,1 & 1919,5 & 2858,5 & 4047,2 & 5010,7 & 6208,7 \\
\hline \multirow{2}{*}{$\begin{array}{l}\text { (2) Behandlung } \\
\text { durch Ärzte }\end{array}$} & Mitglieder & 176,7 & 28,4 & 404,4 & 491,0 & 586,6 & 668,7 \\
\hline & Rentner & 182,9 & 355,4 & 508,6 & 666,0 & 783,1 & 919,2 \\
\hline \multirow{2}{*}{$\begin{array}{l}\text { (3) Behandlung } \\
\text { durch Zahnärzte }\end{array}$} & Mitglieder & 69,2 & 159,1 & 200,5 & 233,6 & 270,0 & 316,7 \\
\hline & Rentner & 18,0 & 34,6 & 47,6 & 64,4 & 83,9 & 108,2 \\
\hline \multirow{2}{*}{$\begin{array}{l}\text { (4) Stationäre } \\
\text { Behandlung }\end{array}$} & Mitglieder & 170,9 & 441,0 & 548,7 & 678,1 & 796,5 & 922,0 \\
\hline & Rentner & 267,2 & 728,0 & 1135,3 & 1667,7 & 2108,4 & 2507,5 \\
\hline \multirow[t]{2}{*}{ (5) Arzneimittel } & Mitglieder & 150,0 & 193,1 & 249,4 & 286,7 & 367,5 & 441,4 \\
\hline & Rentner & 230,5 & 445,8 & 612,7 & 873,0 & 1087,7 & 1303,9 \\
\hline \multirow{2}{*}{$\begin{array}{l}\text { (6) Heil- und } \\
\text { Hilfsmittel } \\
\end{array}$} & Mitglieder & 20,6 & 71,3 & 122,1 & 142,7 & 174,4 & 197,0 \\
\hline & Rentner & 25,1 & 91,3 & 176,5 & 296,6 & 360,7 & 456,7 \\
\hline \multirow[t]{2}{*}{ (7) Zahnersatz } & Mitglieder & 25,5 & 131,0 & 233,7 & 228,0 & 128,5 & 170,3 \\
\hline & Rentner & 31,3 & 109,4 & 144,4 & 172,9 & 126,3 & 174,1 \\
\hline
\end{tabular}

a) Vorläufige Ergebnisse.

Quelle: siehe Tabelle 7. 
Eberhard Wille, Angelika Mehnert and Jan Philipp Rohweder - 978-3-631-75615-7 Heruntergeladen von PubFactory am05/04/2021 12:53:36PM via Victoria University of Wellington 


\section{Beurteilungskriterien für den Nutzen von Arzneimitteln}

\subsection{Gesamtwirtschaftliche Ziele}

Im Zentrum der politischen Diskussionen über das bundesdeutsche Gesundheitswesen und allfällige GKV-Strukturreformen stand in den letzten Jahren eindeutig das fiskalische Ziel der Beitragssatzstabilität (ähnlich Jung, 1989, S. 15). Der Grundsatz der Beitragssatzstabilität erhielt dann auch in $\S 71$ GRG bzw. $\S 71$ SGB V eine eigenständige gesetzliche Verankerung. Steigende Beitragssätze, so erläutert der Gesetzentwurf zum GRG, hemmen die Leistungsbereitschaft der Arbeitnehmer, fördern den Anreiz zur Schattenwirtschaft und gefährden den Abbau der Arbeitslosigkeit (vgl. Fraktionen der CDU/CSU und FDP, 1988, S. 134). Da die Arbeitgeberbeiträge zur GKV gewichtige Bestandteile der Personalzusatzkosten bildeten, minderten sie die internationale Wettbewerbsfähigkeit bundesdeutscher Unternehmen und engten die Investitionsspielräume für die Schaffung zusätzlicher Arbeitsplätze ein. Bei dieser Argumentation fällt auf, daß die Beitragssatzstabilität ihren Zielcharakter hier nicht per se, sondern erst instrumental über das Beschäftigungsziel gewinnt.

Im Zuge der absoluten und relativen Expansion des Gesundheitssektors kletterte der durchschnittliche Beitragssatz in der GKV von gut $8 \mathrm{vH}$ im Jahre 1970 auf zwischenzeitlich 13,4 vH. Zu dieser Entwicklung trugen auch die Arzneimittelausgaben bei, denn ihre Wachstumsrate lag zwar unter derjenigen der gesamten Gesundheitsausgaben, überschritt aber, wie alle Behandlungsarten, die Steigerungsrate des Sozialprodukts (siehe Abbildung 1). Im Hinblick auf das Niveau der Sozialabgabenquote sowie des Anteils der Sozialversicherungsbeiträge an den Lohnkosten nimmt die Bundesrepublik zwar innerhalb der Europäischen Union einen Mittelplatz ein, aber die Vereinigten Staaten und Japan, als die vielfach relevanten Konkurrenten auf den Weltmärkten, belasten hier ihre Unternehmen wesentlich geringer (vgl. Deutsche Bundesbank 1986, S. 23f.). Gleichwohl besitzen die beschäftigungspolitischen Hoffnungen, die sich derzeit vielerorts an die Beitragssatzstabilität oder eine Reduktion der Lohnnebenkosten um 0,5 Prozentpunkte knüpfen, kaum eine ökonomische Fundierung. Es besteht u.E. kein Grund zu der Annahme, daß die im Gesundheitswesen eingesparten Mittel, 
Abbildung 1: Jährliche Veränderungsraten der Ausgaben für Arzneimittel sowie der beitragspflichtigen Einnahmen1)

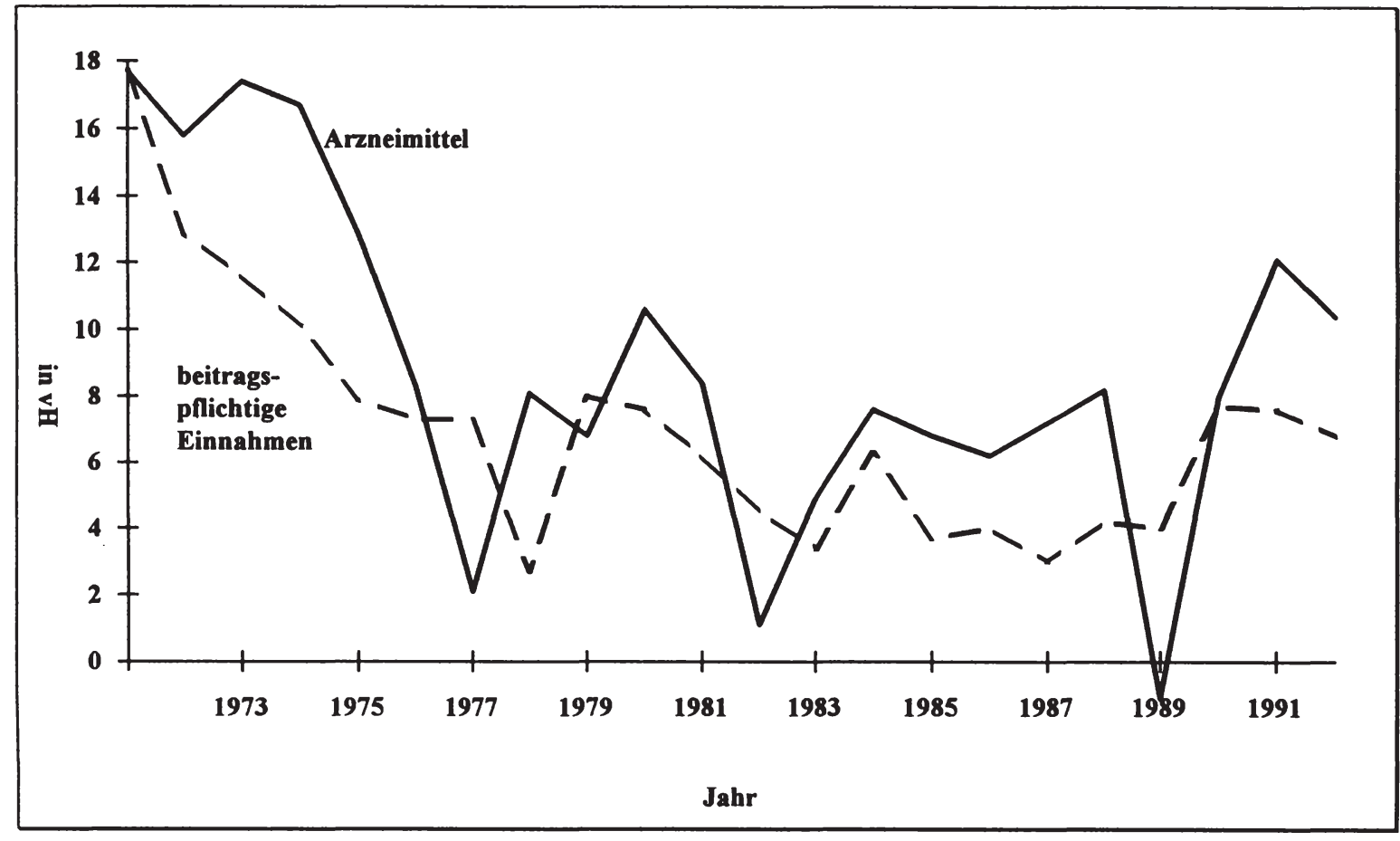

1) Ab 1978 geänderte Berechnungsmethode, schränkt Vergleichbarkeit mit vorangehenden Jahren ein. Quelle: siehe Tabelle 7. 
die nun in andere Bereiche fließen, dort mehr Arbeitsplätze schaffen als durch diese Ressourcenverlagerung entfallen (vgl. Ulrich/Wille, 1989, S. 386).

Wie bereits angedeutet, bildet der fiskalische Aspekt nicht für sich betrachtet, sondern nur abgeleitet ein gesamtwirtschaftliches Ziel. Gesamtwirtschaftliche Relevanz erhalten fiskalische Aspekte in diesem Kontext vor allem insoweit, als sie die Opportunitätskosten von Gesundheitsleistungen betonen. Unabhängig von dem hohen Stellenwert, den der Lebensbereich Gesundheit laut Umfragen nach wie vor besitzt, besteht aus allokativer Sicht der Verdacht, daß bei zahlreichen Gesundheitsausgaben die erzielten gesellschaftlichen Nutzen die entsprechenden Opportunitätskosten nicht mehr rechtfertigen. Bei finaler Betrachtung münden fiskalische Aspekte letztlich in allokative Fragestellungen, d.h. sie erhalten erst durch das Allokationsziel normative Elemente.

Das Allokationsproblem wurzelt in der Knappheit der verfügbaren Ressourcen und besteht in der Aufteilung knapper Ressourcen auf verschiedene Produktionsprozesse bzw. unter Entscheidungsaspekten betrachtet in ihrer Zuordnung auf divergierende und konkurrierende Wirtschaftspläne. Die Ressourcenknappheit begründet damit auch die Notwendigkeit eines Allokationsmechanismus, der die Vielzahl der Wünsche und Ansprüche mit dem jeweils vorhandenen Ressourcenfundus koordiniert. Normatives Bezugssystem bildet in theoretischer Hinsicht die optimale Allokation, die bei effizienter Ressourcenverwendung im Sinne der individuellen Präferenzen die höchstmögliche gesellschaftliche Wohlfahrt repräsentiert. Die Effizienznorm fordert, daß die von einer Maßnahme oder einem Projekt erzeugten gesamtwirtschaftichen Nutzen mindestens ihren Opportunitätskosten entsprechen.

In allokativer Hinsicht besteht die gesundheitsökonomische Aufgabe somit darin, die Ressourcen bzw. Inputs, die als Ausgaben in das Gesundheitswesen fließen, effizient mit der gesellschaftlichen Wohlfahrt, d.h. positiven Effekten auf den Gesundheitszustand, zu verbinden. Da alle Effizienz- und Effektivitätskonzepte (siehe ausführlicher unten unter 4.1) irgendein Output-Input-Verhältnis beinhalten, bieten Ausgabensteigerungen, welche die Wachstumsrate der Grundlohnsumme übersteigen, noch kein hinreichendes Indiz für eine ineffiziente Allokation und belegen insofern auch noch nicht eine Fehlleitung knapper volkswirtschaftlicher Ressourcen. Ohne ausreichende Kenntnis (1) der konkreten Allokationsziele, d.h. der gewünschten Gesundheitsoutputs, (2) der zu ihrer Erstellung möglichen Produktionsverfahren bzw. Mittelkombinationen und (3) der relativen Preise jener 
Produktionsfaktoren, welche die angestrebten medizinischen Endprodukte jeweils erzeugen, lassen sich kaum fundierte Aussagen über eine effiziente und effektive Gesundheits- und Arzneimittelversorgung ableiten.

Das Allokationsziel impliziert darüber hinaus in ordnungspolitischer Hinsicht, für alle an der Gesundheitsversorgung Beteiligten die Anreize so zu setzen, daß sie die knappen volkswirtschaftlichen Ressourcen effizient nutzen. In diesem Kontext sollte das gesundheitsökonomische Anreizsystem die Leistungsfähigkeit und Innovationsbereitschaft der Leistungsanbieter stimulieren, was letztlich der Wohlfahrt der Patienten dient. Hierzu gehören vor allem verläßliche Rahmendaten, da sie u.a. die Grundlage für stärker fremdkapitalfinanzierte Neugründungen von Arztpraxen oder für risikoreiche Investitionen im technischen sowie im pharmazeutischen Bereich bilden. Die seit Mitte der siebziger Jahre beinahe permanenten staatlichen Interventionen, die vornehmlich fiskalischen Zielen dienten, schufen über sich ständig verändernde Rahmenbedingungen eine schlechte Voraussetzung für ein innovatives Gesundheitswesen ${ }^{13}$ ).

Neben die allokativen Gesundheitsziele tritt als zentrales Kriterium das Verteilungspostulat, an dem sich vor allem die Beitragsgestaltung innerhalb der GKV orientiert. Die Mittelaufbringung innerhalb der GKV zielt auf eine Verwirklichung des Solidarausgleichs ab. Letzterer beinhaltet im wesentlichen die folgenden Umverteilungswirkungen:

- von gesunden zu kranken Versicherten (Risikoausgleich),

- von Beziehern höherer Einkommen zu solchen mit niedrigerem Einkommen (Einkommensumverteilung),

- von Alleinstehenden über kleine zu großen Familien (Familienlastenausgleich) sowie

- von jungen zu alten Versicherten (Generationsausgleich).

Während ex-post Umverteilungen zwischen schadensfreien und geschädigten Versicherten in jedem Versicherungssystem stattfinden, handelt es sich bei obi-

13) Dieser Aspekt spricht nicht generell gegen Reformen, sofern Mißstände oder überholte Strukturen diese nahelegen, sondern lediglich gegen eine Interventionskette im Drei- bis Vierjahresrhythmus. 
gem Risikoausgleich um eine ex ante-Umverteilung, denn die Beitragszahlung erfolgt unabhängig vom individuellen Krankheitsrisiko.

Dieser Sozialbezug der GKV, der dem Gedanken der Solidargemeinschaft folgt, wird häufig als Bestandteil des Sozialstaatsprinzips interpretiert (vgl. Genzel, 1987, S. 138; Henke, 1986, S. 616f.). Innerhalb der verfassungsmäßigen Schranken obliegt die jeweils anzuvisierende Mixtur zwischen Allokations- und Sozialzielen letztlich den politischen Entscheidungsträgern. Bei der normativen Festlegung der erwünschten bzw. noch tolerablen Distribution sollten allerdings die allokativen Kosten, die als Rückwirkungen von verteilungspolitischen Maßnahmen ausgehen, nicht außer Ansatz bleiben.

Üblicherweise steht die Stabilisierungsfunktion mit im Zentrum ökonomischer Zielsysteme. Da aber die Patienten die Gesundheitsleistungen medizinisch gesehen weitestgehend unabhängig vom Konjunkturverlauf benötigen, eignen sich Gesundheitsausgaben und -einnahmen kaum als Mittel zur konjunkturpolitischen Steuerung. Insofern reduziert sich hier die Stabilisierungsaufgabe darauf, daß von der Einnahmen- und Ausgabengestaltung der GKV nach Möglichkeit keine prozyklischen bzw. konjunkturverstärkenden Effekte ausgehen sollten.

\subsection{Die Ermittlung der Nützlichkeit einzelner Innovationen}

\subsubsection{Das Anliegen der Kosten-Nutzen Analyse}

Unter allokativen Effizienzaspekten reicht es zur Begründung der gesamtwirtschaftlichen Vorteilhaftigkeit einer Innovation noch nicht aus, wenn diese gegenüber dem bisherigen Produkt bzw. Verfahren unter rein medizinischen Gesichtspunkten gewisse, möglicherweise geringfügige Vorzüge besitzt. Eine ökonomische Wohlfahrtsanalyse stellt den zusätzlichen Nutzen, die aus diesen differenziellen Vorteilen erwachsen, die entsprechenden Kostenunterschiede gegenüber und gelangt auf diese Weise zu einer gesamtwirtschaftlichen Würdigung. Indem sie die projektbezogenen Nutzen mit den entsprechenden Opportunitätskosten vergleicht, bildet die Kosten-Nutzen Analyse (KNA) ${ }^{14}$ ) ein analytisches Hilfsmit-

14) Zur KNA siehe grundlegend Andel, 1977; Pearce, 1983; Hanusch, 1987 und Mishan, 1988. 
tel zur Lösung derartiger Allokationsprobleme. Wie bereits angedeutet, strebt die KNA primär nach einer Verwirklichung der Allokationseffizienz, sie kann daneben aber auch distributive und konjunkturpolitische Aspekte berücksichtigen.

Im Sinne einer gesamtwirtschaftlichen Betrachtung versucht die KNA bei der Beurteilung eines Projektes oder einer Maßnahme15) alle Kosten und Nutzen zu berücksichtigen, die dadurch in der Gesellschaft anfallen. Im Gegensatz dazu schenkt das einzelwirtschaftliche Vorteilhaftigkeitskalkül nur jenen projektbezogenen Effekten Beachtung, die sich bei einer spezifischen Entscheidungseinheit niederschlagen. Die betriebswirtschaftliche Investitionsplanung, die ähnliche formale Kriterien wie die KNA anwendet, erfaßt zumeist in Form von Ausgaben und Einnahmen nur internalisierte Vor- und Nachteile, die z.B. einem pharmazeutischen Unternehmen, einer Arztpraxis oder einem bestimmten Krankenhaus aus einem Vorhaben erwachsen. Auch eine gruppenbezogene Analyse trägt nur jenen Projektwirkungen Rechnung, die sich auf diese abgegrenzte Einheit, z.B. die Ärzteschaft oder die pharmazeutische Industrie, beschränken. Die KNA differenziert dagegen per se nicht nach bestimmten Personen oder Gruppen, sondern strebt auf der Grundlage eines gesamtwirtschaftlichen Zielsystems die Einbeziehung sämtlicher Nutzen und Kosten an, die das zur Diskussion stehende Projekt verursacht (vgl. Prest/Turvey, 1965, S. 684). Als Norm steht dabei zumeist das Allokationspostulat im Mittelpunkt, die KNA kann aber auch je nach Untersuchungsgegenstand und Erkenntnisinteresse Verteilungs- und Stabilisierungsaspekte mit in ihr Zielsystem aufnehmen. Insgesamt gesehen unterscheidet sie sich vor allem durch ihre gesamtwirtschaftliche Betrachtungsweise von einzelwirtschaftlichen und gruppenbezogenen Vorteilhaftigkeitskalkülen.

Die einzelwirtschaftliche oder gruppenbezogene Analyse erstreckt sich nur auf marktbewertete, internalisierte In- und Outputs (zumeist in Form von Einnahmen und Ausgaben) und vernachlässigt jene Wirkungen, die zwar ebenfalls aus dem Projekt erwachsen, aber bei Dritten anfallen. Demgegenüber berücksichtigt die KNA entsprechend ihrer gesamtwirtschaftlichen Ausrichtung, zumindest von ihrer Intention her, auch externe Effekte. Diese schlagen sich nicht als Vor- und Nachteile bei dem Betreiber des Projektes bzw. dem Verursacher, sondern als nichtkompensierte Nutzen und Kosten bei anderen Wirtschaftssubjekten nieder. Wäh-

15) Bei der KNA handelt es sich primär um ein Planungsinstrument, so daß sie infolgedessen ex ante-Charakter besitzt. Gleichwohl lassen sich ihre Kriterien auch im Rahmen einer ex post erfolgenden Evaluierung auf bereits getroffene Maßnahmen anwenden. 
rend bei der einzelwirtschaftlichen Investitionsplanung die Verwirklichung der finanziellen bzw. marktwirtschaftlichen Effizienz (vgl. Wille, 1985, S. 18ff.) im Mittelpunkt der Bemühungen steht, orientiert sich die KNA im Sinne der ökonomischen Wohlfahrtstheorie an der allokativen bzw. Pareto-Effizienz (vgl. Drummond, 1981, S. 125ff.; Birch/Donaldson, 1987, S. $211 \mathrm{ff}$.).

Die KNA und einzelwirtschaftliche Kalküle führen somit zu unterschiedlichen Ergebnissen, wenn die marktbewerteten, internalisierten Vor- und Nachteile eines Projektes nicht mit den gesamtwirtschaftlichen Nutzen und Kosten übereinstimmen. Externe Effekte beinhalten Fehlallokationen, die mit gesellschaftlichen Wohlfahrtsverlusten einhergehen. Die gesamtwirtschaftlichen Kosten übersteigen die einzelwirtschaftlichen, wenn das Projekt, z.B. in Form von Umweltverschmutzung, externe Kosten (negative externe Effekte) verursacht, die zwar die gesellschaftliche Wohlfahrt mindern, aber nicht das Budget des Verursachers belasten. Analog liegen die gesamtwirtschaftlichen Nutzen über den einzelwirtschaftlichen, wenn bei einem Projekt externe Nutzen (positive externe Effekte) auftreten. Letztere beinhalten gesellschaftliche Nutzen, die bei ökonomischer Bilanzierung nicht ihrem Verursacher zugute kommen. Impfungen gegen anstekkende Krankheiten sowie bedeutsame Innovationen, insoweit der Patentschutz die durch sie ausgelösten Nutzenströme unvollkommen internalisiert, können solche Wirkungen erzeugen, von denen zwar die Gesellschaft profitiert, nicht aber in ökonomisch adäquater Weise ihre Verursacher.

Die KNA zielt bei der Beurteilung eines Projektes somit darauf ab, alle seine relevanten Wohlfahrtseffekte verursachungsgerecht zu erfassen und, soweit möglich, quantitativ oder qualitativ zu bewerten. Einer solchen gesamtwirtschaftlichen Betrachtungsweise kommt gerade im Gesundheitswesen ${ }^{16)}$ besondere Bedeutung zu, denn im Rahmen medizinischer Leistungen fallen die Nutzen und Kosten einer bestimmten Maßnahme häufig in zeitlicher, behandlungsmäßiger und institutioneller Hinsicht stark auseinander. Mögliche Auswirkungen einer Behandlung auf die Resistenz und Rekonvaleszenzfähigkeit der Patienten sowie negative Nebenwirkungen treten üblicherweise mit erheblicher zeitlicher Verzögerung auf. Eine Intensivierung oder Qualitätssteigerung bei diagnostischen Maßnahmen führt zwar in diesem Bereich zumeist zu Kostensteigerungen, kann aber im Rahmen

16) Zur KNA im Gesundheitswesen siehe u.a. Horisberger/van Eimeren, 1986; Birch/Donaldson, 1987; Drummond/Stoddart/Torrance, 1987; Drummond/Smith/Wells, 1988. 
der anschließenden Therapie - möglicherweise überproportionale - Einsparungen und darüber hinaus positive Effekte auf den Gesundheitszustand bewirken. Sodann können bei einer medizinischen Leistung die entsprechenden Ausgaben und Einnahmen sowie die projektbezogenen gesellschaftichen Kosten und Nutzen bei den unterschiedlichsten Entscheidungseinheiten anfallen. Dieser breit gestreute Kreis umfaßt u.a. die Gebietskörperschaften, soziale und private Krankenversicherungen, Krankenhäuser, ambulant behandelnde Ärzte, Patienten und deren Angehörige, Versicherte sowie Arbeitgeber. Da sich diese zeitlichen, behandlungsmäßigen und institutionellen Verflechtungen zuweilen noch überlagern, vermag eine isolierte Vorteilhaftigkeitsbetrachtung, die zeitpunktbezogen bei einer bestimmten Leistungsart und einer einzelnen Entscheidungseinheit die Kosten und Nutzen eines Projektes ermittelt, dem komplexen Beziehungsgeflecht medizinischer Produktions- und Finanzierungsprozesse nicht gerecht zu werden.

Bei der Bewertung der projektbezogenen Effekte knüpft die KNA im Sinne eines methodisch streng individualistischen Ansatzes unmittelbar an den Präferenzen der Betroffenen an. Als Bewertungsinstanz fungieren grundsätzlich jene Wirtschaftssubjekte, bei denen sich die Nutzen und Kosten jeweils niederschlagen, und nicht irgendwelche - noch so wohlmeinende - parternalistische Gremien. Als Bewertungsmaßstab für die ermittelten Nutzen und Kosten zieht die KNA die maximale Zahlungsbereitschaft bzw. Zahlungswilligkeit ("willingness to pay") heran. Im Mittelpunkt der Bewertung steht die Frage, welche Zahlungsbereitschaft die betroffenen Wirtschaftssubjekte besitzen, um sich die projektbezogenen Wirkungen zu sichern bzw. um diese Effekte zu vermeiden (vgl. Sugden/ Williams, 1978, S. 89ff.; Cornwall, 1984, S. 575ff.). "An observable alternative for measuring the intensities of preferences of an individual for one situation versus another is the amount of money the individual is willing to pay or accept to move from one situation to another" (Just/Hueth/Schmitz, 1982, S. 10). Die Nutzenmessung orientiert sich z.B. bei der Kompensationsvariation 17) an dem Wert, den die Empfänger maximal zu opfern bereit wären, um in den Genuß dieser positiven Effekte zu gelangen. Analog bewertet die kompensierende Variation die Kosten dann mit jenem Betrag, den die Betroffenen mindestens einfordern, um die Projektwirkungen zu akzeptieren. Im letzteren Fall entspricht die

17) Die Äquivalenzvariation legt dagegen jene Beträge zugrunde, welche die Betroffenen maximal zahlen würden bzw. mindestens verlangen, sofern die Projektwirkungen nicht eintreten. Die äquivalente Variation wählt somit als Bezugspunkt das Nutzenniveau, das sich bei der Durchführung des Projektes eingestellt hätte. 
Kompensationsvariation einem Transfer, der dazu dient, die individuelle Wohlfahrt der "Nettoverlierer" wieder auf das Ausgangs- bzw. ursprüngliche Nutzenniveau zu bringen (vgl. Mishan, 1988, S. 181).

Das Konzept der maximalen Zahlungsbereitschaft impliziert als Bewertungsmaßstab für die KNA einen Informationsbedarf, der sich in der Praxis nur selten befriedigen läßt. Um aber die individuelle Wertschätzung, welche die betroffenen Individuen den Projektwirkungen entgegenbringen, gleichwohl zumindest näherungsweise abschätzen zu können, greift die KNA hier auf Marktpreise oder sofern diese offensichtlich verzerrt oder gar nicht vorhanden sind - auf Schattenpreise sowie Preisäquivalente zurück. Dem Kriterium der monetären Meßbarkeit verdankt wohl in erster Linie der Humankapitalansatz (siehe hierzu ausführlich Weisbrod, 1961; Mushkin, 1962; Mooney, 1977, S. 50ff.) seine Attraktivität im Rahmen der praxisbezogenen KNA. Der Humankapitalansatz bewertet die Projektwirkungen mit jenen monetären Beiträgen, wie sie in die Sozialproduktsberechnung eingehen. Entsprechend bestimmt er auch den Wert eines Menschen über die Produktivität des Vermögenswertes Humankapital mit dem Wert seiner Arbeit. Schlagen sich die Projektwirkungen jedoch bei Individuen nieder, die nicht im Erwerbsleben stehen, (z.B. bei Rentnern und Pensionären, aber auch bei Kleinkindern, Schülern und Arbeitslosen), so vermag der Humankapitalansatz keine sinnvolle Bewertung zu liefern. Unter wohlfahrtstheoretischen Aspekten kann die KNA insofern tendenziell nicht auf das Konzept der Zahlungsbereitschaft verzichten, denn sonst begibt sie sich ihres normativen Anspruchs. Der Zahlungsbereitschaftsansatz behält auch im Rahmen der praxisbezogenen KNA noch die Funktion, die wohlfahrtsanalytische Orientierung vorzugeben.

\subsubsection{Das Nutzenspektrum pharmazeutischer Innovation}

Bei einer pharmazeutischen Innovation besteht das Untersuchungsziel der KNA somit darin, ihre Effekte unter gesamtwirtschaftichen Aspekten mit den entsprechenden Wirkungen zu vergleichen, die ohne diese Erfindung auftreten. Dabei dient im konkreten Falle die beste bisher vorhandene pharmakologische Technologie als Bezugssystem bzw. als normative Meßlatte für die Beurteilung der Innovation ${ }^{18)}$. Während sich die Kostendifferenzen zwischen einer pharmazeuti-

18) Die KNA übernimmt mit dieser Vergleichsbasis aus allokationstheoretischer Sicht zwangsläufig bestehende Ineffizienzen. Diese Einschränkung des Opportunitätskosten-

Eberinzips willelches in letzter Konsequenz einen Kosten-Nutzenvergleich aller denkbaren 
schen Innovation und ihrer besten bisher angewandten Alternative zumeist vergleichsweise gut abschätzen lassen, wirft schon die Erfassung - und noch mehr die numerische Bewertung - des differentiellen Nutzenspektrums erhebliche und teilweise sogar unlösbare Probleme auf. Zunächst herrscht schon bei der Typisierung der Nutzenarten selbst in der einschlägigen Literatur eine Vielfalt sich überschneidender Klassifikationen und Definitionen vor (vgl. Anderson/Settle, 1977, S. 20 ff.; Cullis/West, 1991, S. 171ff.; Musgrave/Musgrave/Kullmer, 1990, S. 177ff.). Sodann stellen die meisten dieser Schemata und Termini nicht auf Probleme des Gesundheitswesens oder gar auf solche pharmazeutischer Innovationen ab. Da der Nutzen eines medizinischen Vorhabens neben einer möglichen Outputerhöhung vornehmlich in der Ersparnis jener Aufwendungen besteht, die ohne dieses Projekt erfolgt bzw. notwendig gewesen wären (vgl. Klarman, 1965, S. 367), existieren hier besonders enge Wechselwirkungen zwischen Nutzen- und Kostenseite, die nicht selten spiegelbildlich zueinander stehen.

Unbeschadet allfälliger Abgrenzungsprobleme interessieren im Kontext pharmazeutischer Innovation vornehmlich die folgenden vier dualen Kategorien von Nutzenarten:

- reale und pekuniäre

- finale und intermediäre

- direkte und indirekte sowie

- tangible und intangible.

Die KNA berücksichtigt nur reale Nutzen bzw. Wirkungen, welche über die Versorgung mit Gütern und Diensten die gesellschaftliche Wohlfahrt erhöhen, und keine pekuniären Effekte. Bei letzteren handelt es sich um projektinduzierte Veränderungen der relativen Preise auf nachgeordneten Märkten (vgl. Musgrave/Musgrave/Kullmer, 1990, S. 177f.), die zwar für einzelne Wirtschaftssubjekte mit individuellen Gewinnen und Verlusten einhergehen, sich aber auf gesellschaftlicher Ebene per saldo ausgleichen. Ähnliches gilt für Transferzahlungen, die durch das Projekt ausgelöst oder vermieden werden. Pekuniäre Effekte beeinflussen daher per saldo nicht die gesellschaftliche Wohlfahrt, d.h. sie besit-

Projektalternativen fordert, erscheint in praxi schon aus Informationsgründen unvermeidlich. 
zen unmittelbar19) keine allokativen, sondern lediglich Verteilungswirkungen. Die KNA erfaßt üblicherweise keine solchen distributiven Effekte, sofern diesen nicht im Rahmen der Projektwirkungen eine ganz besondere Rolle zukommt, was aber bei pharmakologischen Innovationen nur selten der Fall sein dürfte.

Finale Nutzen entstehen durch Projektwirkungen, welche die individuelle Wohlfahrt unmittelbar erhöhen. Intermediäre Effekte erlauben dagegen per se keine individuelle Konsumtion, sondern gehen erst als Zwischenprodukte in nachfolgende Güter und Dienste ein. Die positiven Wirkungen von Arzneimittelinnovationen fallen im Bereich der Therapie praktisch ausschließlich als finale Nutzen an. Sie tragen nämlich direkt dazu bei, Lebensjahre zu retten bzw. die Lebenserwartung zu erhöhen, irreparable Gesundheitsschäden zu verhindern und damit auch die Lebensqualität zu steigern, Krankenhausaufenthalte einzuschränken, Ausgaben für ambulante Behandlung, Arzneien sowie Heil- und Hilfsmittel einzusparen, langfristige Berufs- und Erwerbsunfähigkeit zu vermindern und die Dauer temporärer Arbeitsunfähigkeit zu senken.

Im Gegensatz zu finalen Nutzen erlauben intermediäre Effekte für sich betrachtet keine individuelle Konsumtion, sie gehen erst als Zwischenprodukte in nachfolgende, wohlfahrtsstiftende Güter und Dienste ein. Intermediären Charakter besitzen im Gesundheitswesen grundsätzlich diagnostische Leistungen, denn sie erzeugen in der Regel nicht unmittelbar und auch nicht per se, sondern erst über die sich anschließende Therapie Wohlfahrtseffekte. Eine Diagnose, die keine therapeutische Umsetzung erfährt, vermag unbeschadet ihres analytischen Niveaus zumeist keinen Nutzen zu stiften. Eine diagnostische Untersuchung kann allerdings in speziell gelagerten Fällen auch unabhängig von therapeutischen Maßnahmen die individuelle Wohlfahrt unmittelbar steigern, wenn die Patienten und/oder ihre Angehörigen das diagnostizierte Ergebnis, z.B. das Nichtvorhandensein einer Krankheit, in Form von "Sicherheitskonsum" wie ein Endprodukt konsumieren (vgl. Wille, 1986, S. 105f.).

Bei einer Klassifikation der diversen Kosten- und Nutzenarten steht die Unterscheidung zwischen direkten (oder primären) und indirekten (oder sekundären) Effekten häufig im Mittelpunkt (vgl. Wille, 1989, S. 545ff.). Da jedoch beide Arten von Projektwirkungen im Grunde gleichberechtigt in die KNA eingehen,

19) Diese Verteilungswirkungen können im Zeitablauf zwar ihrerseits wieder Allokationseffekte auslösen, solche Kausalketten lassen sich in praxi aber kaum nachverfolgen. 
besitzt diese Trennung letztlich nur eine systematisierende Funktion. Letztere kann allerdings über eine Art Checkliste dazu beitragen, auch weniger augenfällige Effekte systematisch aufzuspüren und damit der Vernachlässigung von projektinduzierten Wohlfahrtswirkungen vorzubeugen. Dabei sollte eine outputorientierte Klassifikation u.E. vorrangig an jenen Nutzenströmen ansetzen, welche den Patienten als den primären Adressaten der Gesundheitsversorgung durch den Konsum medizinischer Leistungen zufließen (vgl. Anderson/Settle, 1977, S. 22). In diesem Sinne beinhalten direkte Nutzen jene Wohlfahrtssteigerungen, welche aus dem unmittelbaren Konsum des projektbezogenen Outputs resultieren. Aus diesem Projektkonsum entstehen dann mittelbar bzw. abgeleitet die indirekten Nutzen, d.h. diese werden erst durch die direkten Effekte ausgelöst. Direkte Nutzen pharmazeutischer Innovationen können z.B. als Verringerung der Krankheitsintensität und Reduktion der Morbiditätsdauer und schließlich als Steigerung der Lebensqualität und Gewinn an Lebensjahren bzw. Erhöhung der Lebenserwartung anfallen. Die dadurch ausgelösten indirekten Nutzen umfassen z.B. die Vermeidung von Berufs- und Erwerbsunfähigkeit, die Senkung temporärer Arbeitsunfähigkeit, die Erträge aus einer höheren Arbeitsproduktivität, den Fortfall künftiger Arztbesuche und häuslicher Pflegeleistungen, die Einsparung von Arzneimitteln sowie Heil- und Hilfsmitteln und schließlich auch einen Zugewinn an Freizeit beim Patienten und seinen Angehörigen.

Bei der Unterscheidung zwischen tangiblen und intangiblen Effekten dient die Meßbarkeit der Projektwirkungen als Selektionskriterium. Tangible Nutzen lassen sich grundsätzlich, z.B. mit Hilfe von Markt- oder Schattenpreisen, in monetären oder anderen standardisierten Einheiten messen und, sofern sie dieselbe Dimension aufweisen, auch vergleichen. Im Gegensatz dazu entziehen sich intangible Nutzen, wie z.B. ein erhöhtes Sicherheitsgefühl, geringere Befürchtungen und Sorgen, Trauer, eine Schmerzmilderung sowie ein Zuwachs an Freude und Entspannung, einer sinnvollen kardinalen Bewertung. Im Einzelfall hängt die jeweilige Einstufung in tangible und intangible Projektwirkungen u.a. von der Ausgestaltung der Rechts- und Gebührenordnung (z.B. bei der Festsetzung von Schmerzensgeld), von der verfügbaren Meßmethodik und wohl auch von der Vorliebe des Analytikers für allfällige Quantifizierungen ab. In diesem Kontext besteht die zentrale Aufgabe einer KNA u.E. nicht darin, medizinisch unbestimmte oder ethisch delikate Outputs "um jeden Preis" in monetären Einheiten zu messen, sondern das gesamte Spektrum der Projektwirkungen als Informationsgrundlage für die Entscheidungsfindung offenzulegen. Da es sich bei den 
intangiblen Effekten nach Einschätzung der Betroffenen um gewichtige Projektwirkungen handeln kann, sollte die KNA sie in keinem Falle vernachlässigen, sondern qualitativ bzw. in verbaler Form berücksichtigen.

Da die Unterscheidung zwischen tangiblen und intangiblen Effekten mit der Meßbarkeit ein eigenständiges systematisches Kriterium aufweist, lassen sich die betreffenden Wirkungen separat den direkten und indirekten Nutzeneffekten zuordnen. Wie auch Abbildung 2 illustriert, gibt es demnach sowohl tangible direkte (z.B. Reduktion der Morbiditätsdauer) und tangible indirekte (Vermeidung von Arbeitsunfähigkeit) Nutzen, als auch intangible direkte (z.B. Schmerzmilderung beim Patienten) und intangible indirekte (geringere Sorgen und Anpassungslasten von Angehörigen) Nutzen. 
Abbildung 2: Das Nutzenspektrum pharmazeutischer Innovationen

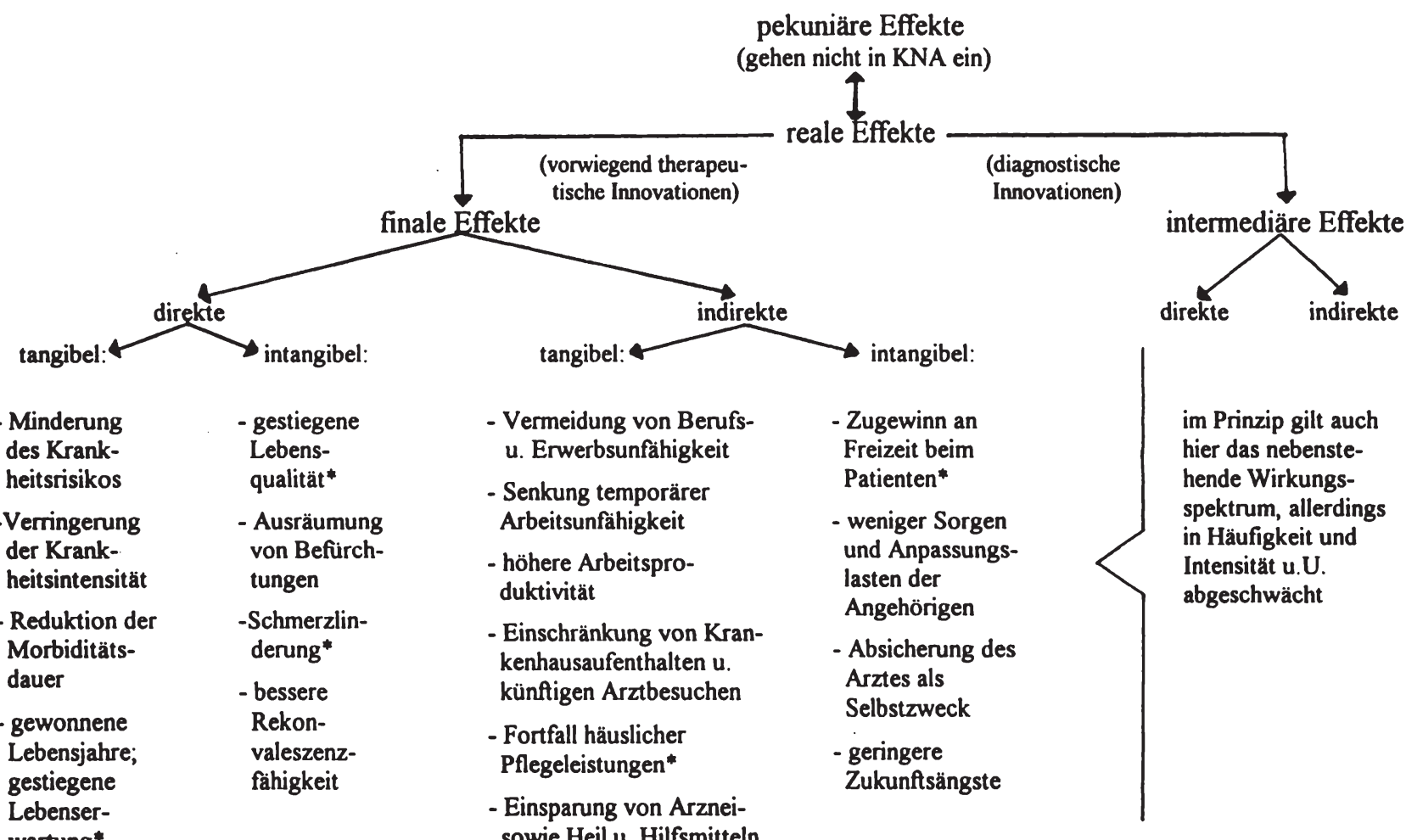

wartung* sowie Heil u. Hilfsmitteln

* Diese Wirkungen befinden sich im Grenzbereich zwischen tangiblen und intangiblen Effekten 


\section{Das Arzneimittel im System gesundheitlicher Leistungserstellung}

\subsection{In- und Outputebenen der Gesundheitsproduktion}

Unbeschadet ihrer Existenzberechtigung läßt die Ausgabenbetrachtung für sich alleine noch keine Schlüsse über die Endprodukte gesundheitlicher Leistungserstellung und damit über die gesellschaftlichen Wohlfahrtseffekte der betreffenden Aufwendungen zu. Finanzielle Mittel bilden zwar häufig eine notwendige Voraussetzung für die Aufgabenerfüllung im Gesundheitswesen, aber "there is no one to one relationship between the amount of money spent on social programs and the benefits to society" (Sawhill, 1969, S. 478). Bei der Frage nach konkreten Gesundheitszielen vermag die ökonomische Wohlfahrtstheorie, die auf der Grundlage gegebener individueller Präferenzen nach Effizienzkriterien bzw. Optimalitätsbedingungen für abstrakte Zielsysteme sucht, kaum mehr eine Hilfestellung zu leisten. Im Mittelpunkt ihres Forschungsinteresses stehen Probleme der Aggregierbarkeit individueller Präferenzfunktionen sowie der Widerspruchsfreiheit gesellschaftlicher Wohlfahrtsfunktionen, während sie den Weg, der von den Ausgaben zur konkreten Zielrealisierung führt, als blackbox behandelt. Es fällt offensichtlich leichter "to define a theoretical criterion for economic efficiency in health care than to show what is and what is not an efficient use of resources in practice" (Abel-Smith, 1984, S. 3). Ohne Kenntnis konkreter Gesundheitsziele bleibt, von augenfälliger Verschwendung abgesehen, zwangsläufig auch die Frage nach der Effzienz und Effektivität von Gesundheitsausgaben weitgehend offen.

Eine erste Orientierungshilfe für den Zielcharakter von Gesundheitsausgaben leisten die medizinischen Behandlungsziele, die vorrangig darauf abstellen (vgl. Schwartz, 1987, S. 19):

- den vermeidbaren Tod zu verhindern bzw. das Leben möglichst zu verlängern,

- Krankheit und die mit ihr verbundenen Funktionsverluste und Befindlichkeitsstörungen zu verhüten, zu heilen und zu lindern, sowie

- die menschliche Würde und Freiheit auch in Krankheit und Tod zu wahren. 
Diese Charakterisierung der Zieldimension von Gesundheitsausgaben deutet bereits an, daß sich das "Gut Gesundheit" einer direkten Beobachtung und eindimensionalen Messung entzieht und bestenfalls mit Hilfe partieller Indikatoren oder konstruierter Gesundheitsindizes abbilden oder umschreiben läßt (vgl. Leu et al., 1986, S. 160).

Die funktionalen Beziehungen, welche zwischen den Gesundheitsausgaben und den medizinischen Behandlungszielen existieren, wollen wir im folgenden anhand eines hierarchisch aufgebauten Ziel-Mittel-Schemas etwas eingehender analysieren. Abbildung 3 verbindet stufenweise mehrere In- und Outputebenen und dient in diesem Kontext lediglich dazu, den Zielcharakter und die Operationalität bzw. Prütbarkeit der jeweiligen Ebenen zu verdeutlichen. Es handelt sich hier nicht um die vollständige Spezifizierung einer medizinischen Produktionsfunktion, etwa im Sinne einer idealtypischen Programmstruktur, denn die Realisierung von bestimmten Indikatoren einer Ziel-Mittel-Ebene stellt in instrumentaler Hinsicht häufig lediglich eine notwendige, aber noch keine hinreichende Bedingung dar, um gewisse Werte auf der hierarchisch unmittelbar höher gelagerten zu verwirklichen.

Die Arzneimittelausgaben, die als monetäre Inputs in das Gesundheitssystem fließen, befinden sich wie die anderen Ausgaben für medizinische Behandlung auf der untersten Ebene dieser Ziel-Mittel-Hierarchie. Mit den Behandlungsausgaben erwerben die Ausgabenträger, die hier im Auftrage und auf Rechnung der GKV handeln, sachliche und personelle Kapazitäten (z.B. Arzneimittel, Heil- und Hilfsmittel, Röntgengeräte, Ärzte, Krankenschwestern), um mit diesen Produktionsmitteln das medizinische Produkt bzw. Angebot zu erstellen. Das Arzneimittel bildet insofern einen Produktionsfaktor, der in Kombination mit anderen Behandlungsarten dazu beiträgt, das "Gesundheitsprodukt" bzw. medizinische Angebot zu erzeugen. Die Ausgabenplafonds selbst beinhalten zunächst noch keine Hinweise darüber, welche physischen Kapazitäten später aus ihnen erwachsen. Selbst einer Klassifikation der Gesundheitsausgaben nach Behandlungsarten läßt sich, ohne Kenntnis der entsprechenden Preisindizes, nicht entnehmen, inwieweit z.B. veranschlagte Mehrausgaben auf der nächsten Stufe zu einer Erhöhung der Produktionsmittel, d.h. der Menge, führen oder durch steigende Preise absorbiert werden. 
Abbildung 3: Ziel- und Mittelebenen von Gesundheitsindikatoren

\begin{tabular}{|c|c|c|c|c|}
\hline $\begin{array}{l}\text { Ziel-Mittel- } \\
\text { Ebene }\end{array}$ & $\begin{array}{l}\text { Beitrag zur } \\
\text { Gesundheits- } \\
\text { produktion }\end{array}$ & $\begin{array}{l}\text { Indikatoren- } \\
\text { typ }\end{array}$ & Beispiele & \begin{tabular}{|l} 
mögliche \\
Ursachen für \\
Ineffizienzen und \\
Ineffektivitäten
\end{tabular} \\
\hline \multirow{3}{*}{$\begin{array}{l}\text { (5) Wirkungs- } \\
\text { ebene } \\
\text { (4) Ebene der } \\
\text { Inanspruch- } \\
\text { nahme }\end{array}$} & $\begin{array}{l}\text { wohlfahrts- } \\
\text { relevanter } \\
\text { Lebens- } \\
\text { bereich }\end{array}$ & $\begin{array}{l}\text { nicht zu } \\
\text { konkretisie- } \\
\text { ren }\end{array}$ & $\begin{array}{l}\text { Steigerung des } \\
\text { Gesundheitszustandes, } \\
\text { moderne Gesund- } \\
\text { heitsvorsorge, be- } \\
\text { darfsgerechtes An- } \\
\text { gebot an medizi- } \\
\text { nischen Leistungen }\end{array}$ & $\begin{array}{l}\text { Fehleinschätzung } \\
\text { der Präferenzen } \\
\text { der Konsumenten } \\
\text { (nicht prüfbar zu } \\
\text { formulieren) }\end{array}$ \\
\hline & $\begin{array}{l}\text { konkretisierte } \\
\text { operationale } \\
\text { Wirkungsziele }\end{array}$ & $\begin{array}{l}\text { Resultatindi- } \\
\text { katoren auf } \\
\text { individueller } \\
\text { Ebene }\end{array}$ & $\begin{array}{l}\text { Mortalitäts- und } \\
\text { Morbiditätsindizes, } \\
\text { Indizes der } \\
\text { Lebenserwartung }\end{array}$ & $\begin{array}{l}\text { fehlender Zielbe- } \\
\text { zug der Maßnah- } \\
\text { men, mangelnder } \\
\text { Zielerreichungs- } \\
\text { grad derselben }\end{array}$ \\
\hline & $\begin{array}{l}\text { konkretisierte } \\
\text { operationale } \\
\text { Ausbrin- } \\
\text { gungsziele }\end{array}$ & $\begin{array}{l}\text { Nutzungsindi- } \\
\text { katoren }\end{array}$ & $\begin{array}{l}\text { Anzahl der in An- } \\
\text { spruch genommenen } \\
\text { Impfungen, diagnosti- } \\
\text { sche Untersuchungen } \\
\text { sowie ambulanten und } \\
\text { stationären Behand- } \\
\text { lungen }\end{array}$ & $\begin{array}{l}\text { fehlender Ziel- } \\
\text { bezug, mangelnde } \\
\text { Nachfrage, } \\
\text { Überkonsumtion }\end{array}$ \\
\hline $\begin{array}{l}\text { (3) Angebots- } \\
\text { ebene }\end{array}$ & $\begin{array}{l}\text { fertiggestelltes } \\
\text { konsumierba- } \\
\text { res Produkt, } \\
\text { verfugbares } \\
\text { und erreichba- } \\
\text { res Angebot }\end{array}$ & $\begin{array}{l}\text { Angebots- } \\
\text { bzw. } \\
\text { Leistungs- } \\
\text { indikatoren }\end{array}$ & $\begin{array}{l}\text { Angebot an } \\
\text { Impfungen, } \\
\text { diagnostischen } \\
\text { Untersuchungen sowie } \\
\text { ambulanten und } \\
\text { stationären } \\
\text { Behandlungen }\end{array}$ & $\begin{array}{l}\text { ineffiziente } \\
\text { Produktion: } \\
\text { - technisch } \\
\text { bedingt } \\
\text { - infolge fehlen- } \\
\text { der Motivation }\end{array}$ \\
\hline \multirow{2}{*}{$\begin{array}{l}\text { (2) Ausstat- } \\
\text { tungsebene } \\
\text { (1) Ausgaben- } \\
\text { bzw.Finan- } \\
\text { zierungs } \\
\text { ebene }\end{array}$} & $\begin{array}{l}\text { personelle und } \\
\text { sachliche } \\
\text { Kapazitäten }\end{array}$ & $\begin{array}{l}\text { physische } \\
\text { Input- oder } \\
\text { Ausstattungs- } \\
\text { indikatoren }\end{array}$ & $\begin{array}{l}\text { Ärzte, Kranken- } \\
\text { schwestern, } \\
\text { Krankenhäuser, } \\
\text { Röntgengeräte, } \\
\text { Arzneimittel }\end{array}$ & $\begin{array}{l}\text { unwirtschaftlicher } \\
\text { Einsatz der mone- } \\
\text { tären Mittel, } \\
\text { Steigerungen } \\
\text { spezieller Preis- } \\
\text { indizes }\end{array}$ \\
\hline & $\begin{array}{l}\text { Ausgaben } \\
\text { bzw. } \\
\text { monetäre } \\
\text { Inputs }\end{array}$ & $\begin{array}{l}\text { monetäre } \\
\text { Inputindika- } \\
\text { toren }\end{array}$ & $\begin{array}{l}\text { Gesundheitsausgaben } \\
\text { nach } \\
\text { - Ausgabenträger } \\
\text { - Ausgabenarten } \\
\text { - Leistungsarten }\end{array}$ & $\begin{array}{l}\text { Zuwiderhand- } \\
\text { lungen beim Voll- } \\
\text { zug, strafbare } \\
\text { Verfehlungen }\end{array}$ \\
\hline
\end{tabular}


Obgleich die sachlichen und personellen Kapazitäten im Vergleich zu den Ausgaben schon auf einer höheren Ebene rangieren ${ }^{20)}$, gehören sie insgesamt gesehen noch voll zum Inputbereich. Sie verkörpern noch nicht das eigentliche Produkt, d.h. das konsumierbare Angebot, sondern sollen dieses als physische Inputs erst erzeugen. Auch im Hinblick auf die medizinischen Behandlungsziele bildet das fertiggestellte Produkt (z.B. das Angebot an diagnostischen Untersuchungen sowie ambulanten und stationären Behandlungen) in unserer Ziel-Mittel-Hierarchie die unterste Ebene, der unter Angebotsaspekten ein gewisser Outputcharakter zukommt. Die Existenz dieses Angebots garantiert aber noch nicht seine Nutzung oder gar positive Effekte auf die Behandlungsziele. Insofern klafft zwischen dieser untersten Outputebene und den Gesundheitszielen noch eine beträchtliche Lücke.

Der Outputcharakter nimmt zu, wenn die Wirtschaftssubjekte das medizinische Angebot nutzen und damit die Ebene der Ausbringungsziele ("output objectives") erreicht wird. Das Angebot trifft hier auf die Nachfrage bzw. die Bedürfnisse der Patienten, und die Wohlfahrtsanalyse kann sich bei der Allokation der meisten Güter, die der Markt- und Preismechanismus koordiniert, mit dieser Stufe begnügen, denn die Konsumenten äußern mit ihrer Nachfrage ihre Präferenzen bzw. ihre Zahlungsbereitschaft.

Ein Konzept, welches allein auf die Nutzung abstellt und die Wirkung der betreffenden Outputs ausklammert, reicht aber bei den meisten Gesundheitsleistungen nicht aus, denn die Konsumenten entrichten hierfür kein spezielles Entgelt ${ }^{21}$ ) und sehen sich insofern auch nicht gezwungen, ihre Zahlungsbereitschaft zu offenbaren. Unabhängig von der individuellen Zahlungsbereitschaft vermögen Ausbrin-

20) Da hier Zielaspekte im Vordergrund des Interesses stehen, klammern wir die betriebsinternen Produktionsprozesse aus.

21) Das gilt sowohl beim Sachleistungs- als auch beim Kostenerstattungsprinzip, sofern hier kein Selbstbehalt greift. Bei der Inanspruchnahme von Gesundheitsleistungen im Rahmen von Krankenversicherungssystemen liegt im Prinzip keine individuelle, sondern lediglich eine gruppenmäßige Äquivalenz (bezogen auf den Kreis der jeweils Versicherten) vor. Gleichwohl stellen die Gesundheitsleistungen im Prinzip keine öffentlichen Güter dar, denn es besteht bei ihnen grundsätzlich sowohl Ausschließbarkeit als auch Rivalität. Nur wenige Gesundheitsleistungen, wie z.B. Impfungen gegen ansteckende Krankheiten, weisen zu einem Teil Elemente öffentlicher Güter auf, aber auch hier existiert ein, meist dominanter, Teil mit privatem Gutscharakter. Das Trittbrettfahrerproblem resultiert im Rahmen der GKV nicht aus den Eigenschaften der Gesundheitsgüter, sondern aus den Modalitäten des Versicherungssystems. 
gungs- bzw. Nutzungsindikatoren aber nicht verläßlich über die Wohlfahrts- bzw. Zieleffekte zu informieren, die mit der Inanspruchnahme dieser Leistungen einhergehen. Eine gestiegene Nutzung von Gesundheitsleistungen sichert noch nicht per se eine Realisierung der angestrebten medizinischen Behandlungsziele, denn die betreffenden Maßnahmen können auch weitgehend wirkungslos bleiben und im Extremfall den Gesundheitsstatus der Patienten sogar noch verschlechtern.

Angesichts der begrenzten Aussagefähigkeit von Ausbringungsindikatoren besteht im Sinne einer zielorientierten Analyse noch die Möglichkeit, die Wohlfahrtseffekte von Gesundheitsausgaben auf der Wirkungsebene zu bestimmen. Den Wirkungszielen ("impact objectives", "target variables", "final outputs") fällt dabei die Aufgabe zu, die medizinischen Behandlungsziele in operationaler und prüfbarer Form widerzuspiegeln und z.B. als Mütter- und Säuglingssterblichkeiten bei der Geburt, Dauer von Rekonvaleszenzen sowie Früherkennungen von Krankheiten abzubilden. Über den Endproduktcharakter und die Wohlfahrtsrelevanz dieser "Resultatindikatoren auf individueller Ebene" (Leipert, 1978, S. 104) sollte allerdings allgemeiner Konsens herrschen. Die Wirkungsziele rangieren in unserer Ziel-Mittel-Hierarchie zwischen den "intermediären Outputebenen", gegenüber denen sie Zielcharakter besitzen, und den über ihnen postierten Ebenen der gesellschaftlichen Leitbilder und wohlfahrtsrelevanten Lebensbereiche ("goals", "general values"). Im Vergleich zu den beiden höher postierten Outputebenen kommt den Wirkungszielen zwar nur Mittelcharakter zu, aber andererseits entziehen sich sowohl die "wohlfahrtsrelevanten Lebensbereiche" als auch die sog. Leitbilder einer Operationalisierung und Prüfbarkeit. Die Wirkungsziele bilden in deduktiver Hinsicht die erste bzw. höchste Ebene der Zielhierarchie, die grundsätzlich operationale Outputindikatoren aufweist und insofern auch eine Prüfbarkeit erlaubt, und repräsentieren gleichzeitig, d.h. induktiv betrachtet, jene konkretisierten Outputs, welche den ausgeprägtesten Zielcharakter besitzen. Diese Ebene steht deshalb berechtigterweise im Mittelpunkt der empirisch orientierten gesundheitsökonomischen Wohlfahrts- bzw. Zielanalyse.

\subsection{Dimensionen gesundheitlicher Outcome-Indikatoren}

Die verschiedenen Dimensionen gesundheitlicher Wirkungsziele klingen bereits im Gesundheitsbegriff der Weltgesundheits-Organisation (1946, S. 14) an, die Gesundheit als einen "state of complete physical, mental, and social well-being and not merely the absence of desease or infirmity" definiert. Obgleich dieses

Eberhard Wille, Angelika Mehnert and Jan Philipp Rohweder - 978-3-631-75615-7 
Begriffskonzept Gefahr läuft, unrealisierbare Ansprüche an die Gesundheitsversorgung zu wecken, deutet es auf die sektorübergreifenden Abhängigkeiten der gesundheitlichen Wirkungsziele hin. Letztere hängen nämlich neben der Gesundheitsversorgung auch von Maßnahmen bzw. Zuständen im Bereich des Umweltschutzes, des Verkehrs, des Erziehungswesens, der Arbeitsbedingungen und nicht zuletzt von dem persönlichen Lebensstil des Einzelnen ab (ähnlich Butler, 1992, S. 143). Bei ihrem Versuch, diesem Gesundheitsideal möglichst nahe zu kommen, sehen sich die Gesundheitspolitik und die anderen involvierten sektoralen Politiken allerdings selbst bei optimaler Planung und Koordination mit natürlichen, vorwiegend biologischen und psychischen Grenzen konfrontiert. So endet selbst das "gesündeste Leben" mit dem Tod und ging zuvor unvermeidlich mit einem gewissen $\mathrm{Ma} ß$ an Schmerzen, Trauer und Leid einher. Dabei zerfließen nicht selten die Übergänge zwischen Befindlichkeitsstörung und Krankheit, zumindest spiegelt nicht jede Befindlichkeitsstörung einen verminderten Gesundheitszustand wider, der nach medizinischer Therapie verlangt. Schließlich nimmt die körperliche und geistige Leistungsfähigkeit mit zunehmendem Alter ab, so daß sich die Gesundheitsversorgung sinnvollerweise nicht an einem zeitlosen Ideal, sondern an der altersabhängigen biologischen Norm orientieren sollte.

Die gesundheitlichen Wirkungsziele bzw. Outcome-Indikatoren erstrecken sich somit nicht nur auf die Länge des Lebens, sondern auch auf die Lebensqualität in dieser Zeit (vgl. Henderson/McGuire/Mooney, 1988, S. 21). Dabei beinhaltet die Lebensqualität ein breites Spektrum von Fähigkeiten und deren Wahrnehmung und beeinflußt auf diese Weise die Leistungsfähigkeit und die Zufriedenheit der Individuen. Unter diesem Aspekt beschränkt sich Krankheit nicht im engen medizinischen Sinne auf die pathologische Abweichung realer Werte physiologischer Variablen von bestimmten Normwerten, sondern kann sich auch in der Beeinträchtigung des normalen gesellschaftlichen Rollenverhaltens äußern (vgl. Neipp, 1987, S. 8). Die in Tabelle 10 aufgelisteten Dimensionen der Lebensqualität verdeutlichen einen entsprechend weiten Ansatz, der nicht nur die Krankheit selbst, sondern auch die mit ihr einhergehenden Beeinträchtigungen einschließt (ähnlich Zweifel/Zysset-Pedroni, 1992, S. 42) 22 ).

22) Entsprechend versucht der "Quality-Adjusted Life Years-Ansatz", die gesamte Verbesserung des Gesundheitszustandes im Hinblick auf die Lebensquantität und -qualität auf individueller Ebene in einem aggregierten Outcomeindikator bzw. Gesundheitsindex zusammenzufassen. Siehe hierzu u.a. Torrance/Feeny, 1989; Mehrez/Gafni, 1989; Wagstaff, 1991 und Weisbrod, 1992. 
Tabelle 10: Dimensionen der Lebensqualität

\begin{tabular}{|l|l|}
\hline \multicolumn{1}{|c|}{ Dimensionen } & \multicolumn{1}{|c|}{ Beispiele } \\
\hline Physische Funktionsfähigkeit & $\begin{array}{l}\text { Mobilität, Selbstpflege, Fähigkeit zur Ausübung } \\
\text { alläglicher Aktivitäten, Schmerz, physische Symptome }\end{array}$ \\
\hline Psychische Funktionsfähigkeit & Depression, Zorn, Hilflosigkeit, Zukunftserwartung \\
\hline Kognitive Funktionsfähigkeit & $\begin{array}{l}\text { Erinnerungsvermögen, Aufnahmefähigkeit, } \\
\text { Urteilsvermögen }\end{array}$ \\
\hline Soziale Funktionsfähigkeit & $\begin{array}{l}\text { Teilnahme an sozialen Aktivitäten, sexuelle } \\
\text { Funktionsfähigkeit, Familienbeziehungen, } \\
\text { Freizeitaktivitäten }\end{array}$ \\
\hline Allgemeines Wohlbefinden & $\begin{array}{l}\text { Allgemeiner Gesundheitszustand, } \\
\text { Wahrnehmungsvermögen, } \\
\text { Allgemeines Zufriedenheitsniveau }\end{array}$ \\
\hline
\end{tabular}

Quelle: Nach Luce/Elixhauser ,1990, S. 109.

Mit diesem weiten Konzept der Lebensqualität korrespondieren auch die Erreichbarkeitsindikatoren, die in Abbildung 3 zwischen den Wirkungszielen und den fertiggestellten Produkten rangieren und sich nicht per se, d.h. ohne Würdigung des jeweiligen Falles, einer bestimmten Ebene dieses Ziel-MittelSchemas zuordnen lassen. Bei den fertiggestellten Produkten handelt es sich zunächst um nicht konsumiertes bzw. genutztes Angebot, das in der Regel noch nicht wohlfahrtssteigernd wirkt. Andererseits können die Wirtschaftssubjekte als potentielle Nachfrager bereits in den verbesserten Zugangsmöglichkeiten zu bestimmten Gesundheitsleistungen eine Erhöhung ihrer Lebensqualität empfinden. Sie konsumieren dann "das Wissen um die jederzeitige Nutzungsmöglichkeit" (Leipert, 1978, S. 103) wie ein Endprodukt, so daß die Option einer Nutzung hier den Rang eines Wirkungszieles erreicht. Die OECD sieht entsprechend in der Nutzungsmöglichkeit, die das konsumierbare Angebot eröffnet, "an 
element of well-being in itself" und hält die "accessibility to various services" sogar für "as important as actual use" (OECD 1976, S. 19).

Die Erreichbarkeitsindikatoren bergen zwar bei extensiver Interpretation die Gefahr in sich, als Alibi für fehlgeplantes Angebot und damit verbundener Ineffektivität zu dienen, besitzen aber gerade im Gesundheitswesen in vielen Fällen ihre prinzipielle Berechtigung. So stellen die ständige Verfügbarkeit von Krankenbetten auf Intensivstationen, die Entfernung bis zum nächsten Arzt bzw. Krankenhaus sowie die Schnelligkeit eines möglichen Eingreifens von Unfallund Rettungsdiensten fast klassische Erreichbarkeitsindikatoren dar. In gleicher Weise bietet die private Haus- und Reiseapotheke, in den Medien häufig allzu pauschal als pharmazeutischer "Hausmüll" angeprangert, bei sinnvoller Zusammenstellung und Terminierung die Voraussetzung für einen solchen Optionskonsum. Tritt ein Schadensfall ein, kann die verbesserte Erreichbarkeit dazu verhelfen, therapeutische Maßnahmen unverzüglich einzuleiten und unter Umständen, z.B. bei leichten Infekten, einen Arztbesuch zu erübrigen.

Daneben kann bereits das Wissen um die Existenz eines wirksamen Heilmittels die Angst vor der entsprechenden Krankheit mindern und damit die Wohlfahrt nicht nur von erkrankten, sondern auch von gesunden Menschen erhöhen. $\mathrm{Ob}$ und inwieweit die Verbesserung der Erreichbarkeit den Outputcharakter von Wirkungszielen annimmt oder lediglich auf der Ebene des konsumierbaren Angebots verbleibt, hängt in praxi von der subjektiven Wahrnehmung dieser Outputs und den jeweiligen Präferenzen ab. Die Erreichbarkeitsindikatoren erhalten ihre wohlfahrtstheoretische Fundierung als Wirkungsziele somit durch individuelle Präferenzen in Form eines Sicherheitsbedürfnisses potentieller Patienten.

\subsection{Das Medikament als Teil medizinischer Behandlung}

\subsubsection{Beziehungen zwischen den Behandlungsarten}

Wie oben unter 4.1 dargelegt, befinden sich alle Behandlungsausgaben als monetäre Gesundheitsinputs auf der untersten Ebene der Ziel-Mittel-Hierarchie und vermögen nicht für sich betrachtet, sondern lediglich über das fertiggestellte Produkt, in das sie einfließen, Nutzen zu stiften. Die mit Hilfe dieser Ausgaben finanzierten sachlichen und personellen Kapazitäten stellen in der Regel ebenfalls noch nicht das konsumierbare Angebot, sondern erst physische Produktionsmittel

Eberhard Wille, Angelika Mehnert and Jan Philipp Rohweder-978-3-631-75615-7 
dar, denn zumeist beschränkt sich eine medizinische Behandlung nicht auf eine einzige Leistungsart. Ausnahmen bilden lediglich ambulante Behandlungen, die ohne den Einsatz von Medikamenten sowie Heil- und Hilfsmitteln erfolgen, und vice versa die Selbstmedikation. Für die medizinische Produktionsleistung erscheint die Behandlung des Arztes, die entsprechende Ausgaben verursacht, ebenso unentbehrlich wie das Medikament, das mit Arzneimittelausgaben einhergeht23). Da nur die Produktionsleistung im ganzen die Wohlfahrt steigern kann, besteht unter Zielaspekten, d.h. im Sinne medizinischer Aufgabenerfüllung, kein $A n l a ß$, zwischen den verschiedenen Produktionsfaktoren, welche dieses Gut erzeugen, bzw. den korrespondierenden Ausgabenarten zu privilegieren oder zu diskriminieren. Dies bedeutet, daß alle Behandlungsarten, von der "sprechenden Medizin" über Maßnahmen im Krankenhaus bis zu Medikamenten oder Heil- und Hilfsmitteln, a priori die gleiche Wohlfahrtsrelevanz besitzen. Aus dem gleichen Grunde reicht die isolierte Betrachtungsweise einer Behandlungsart nicht aus, um unter Zielaspekten fundierte Aussagen abzuleiten.

Zwischen den einzelnen Behandlungsarten existieren im Hinblick auf die Gesundheitsversorgung vielfältige Verflechtungen, so daß sich für eine Verbesserung medizinischer Behandlung drei grundsätzliche Möglichkeiten anbieten, zwischen denen ihrerseits wieder enge Wechselwirkungen bestehen. Einmal geht es um die Erhöhung von Effizienz und Effektivität innerhalb der einzelnen Behandlungsarten, sodann bei komplementären Beziehungen zwischen diesen Bereichen um eine zielorientierte Koordination und schließlich bei Vorliegen von Substitutionalität um die optimale Aufteilung der Ressourcen auf die konkurrierenden Verwendungen. Die augenfällige Parallelität im Wachstum der Ausgaben für die Behandlung durch Ärzte und der Arzneimittelausgaben deutet auf eine komplementäre Produktionsbeziehung dieser beiden Behandlungsarten bei der ambulanten Versorgung hin.

Liegen substitutive Beziehungen zwischen den einzelnen Behandlungsarten vor, so hängt ihr effizientes Einsatzverhältnis bei gegebenen Gesundheitszielen bzw. Orientierungsdaten von den jeweils möglichen Verfahren gesundheitlicher Leistungserstellung und den relativen Preisen der Produktionsfaktoren ab. Gegenüber dem Krankenhaussektor dürften konkurrierende Leistungsanbieter in vielen Fällen

23) Dieser Zusammenhang gilt materiell auch für den stationären Bereich, obwohl die amtliche Statistik die Arzneimittelausgaben hier nicht getrennt ausweist. 
preisliche Wettbewerbsvorteile besitzen, so daß eine Substitution von stationären durch ambulante Leistungen und die Verlagerung der medizinischen Versorgung vor allem älterer Menschen von Akutkrankenhäusern auf spezialisierte Pflegeheime oder gar in den Bereich der häuslichen Kranken- und Altenpflege 24) ohne Minderung der Behandlungsziele zu spürbaren Ausgabeneinsparungen führen könnten. Diese bisher höchst unzureichend ausgeschöpften Substitutionsmöglichkeiten beruhen primär auf Aufgabenverlagerungen zwischen den Behandlungsarten und eröffnen insofern erhebliche Effizienzverbesserungen des Gesamtsystems, ohne dabei tiefer in die spezifischen Koordinationsprozesse innerhalb eines Leistungsbereichs vorzudringen. Die Substitution von stationären durch ambulante Behandlungen führt, selbst wenn dabei der Arzneimitteleinsatz unverändert bleibt, tendenziell zu einem steigenden Ausgabenanteil für Medikamente in der amtlichen Statistik, da diese die Arzneimittelausgaben nur im ambulanten, aber nicht im stationären Bereich als eigenständige Behandlungsart klassifiziert.

Um bei substitutiven Beziehungen zumindest Tendenzaussagen über das effiziente Einsatzverhältnis der Behandlungsarten ableiten zu können, bedarf es, wie bereits oben angedeutet, entsprechender Informationen über die Entwicklung der relativen Preise dieser Produktionsfaktoren. Unter der Prämisse, daß eine Substitution die Resultatindikatoren bzw. Orientierungsdaten nicht negativ beeinflußt, verlangt die Effizienznorm eine stärkere Betonung jenes Produktionsfaktors, zu dessen Gunsten sich die relativen Preise verändern. Andernfalls gilt es, die mit der Substitution verbundene Outputminderung und die durch sie mögliche Ausgabeneinsparung gegeneinander abzuwägen. Zudem erlauben Kenntnisse über die Entwicklung spezifischer Preisindizes von Behandlungsarten möglicherweise vor allem in Verbindung mit anderen Daten - Rückschlüsse auf die Funktionsfähigkeit der betreffenden Märkte bzw. Koordinationsmechanismen. Schließlich lassen sich auch die Erfolgsaussichten einer staatlichen Einflußnahme auf die Preispolitik, wie z.B. die Setzung von Festbeträgen im Arzneimittelbereich, im Hinblick auf die Eingrenzung des Ausgabenwachstums nur abschätzen, wenn Hinweise über die Preis- und Mengeneffekte der jeweiligen Behandlungsausgaben vorliegen.

24) Zu Akutkrankenhäusern vgl. Wachtel, 1984, S. 286; Rüschmann, 1986, S. 195 und zu häuslicher Kranken- und Altenpflege vgl. Lagergren, 1985, S. 357; Bundesärztekammer, 1986, S. 128. 


\subsubsection{Die Preis- und Mengenentwicklung von Behandlungsarten}

Um bei den verschiedenen Behandlungsarten die Entwicklung der Relativpreise $\mathrm{zu}$ analysieren und anschließend Preis- und Mengeneffekte voneinander zu trennen, bedarf es zunächst der Auswahl adäquater Preisindizes. Da es bisher kein allgemein akzeptiertes Konzept zur Ermittlung von Gesundheitsoutputs gibt, fehlt eine notwendige Voraussetzung für die in theoretischer Hinsicht wünschenswerte direkte Preisbereinigung der Endprodukte. Mangels einer solchen sog. Outputdeflationierung verbleibt als Ausweg eine Inputbereinigung, die an jenen Ausgaben ansetzt, welche in die Gesundheitsversorgung fließen. Sodann sieht sich die Preisbereinigung von Behandlungsausgaben mit dem Problem konfrontiert, daß die betreffenden Ausgaben kaum über die individuelle Zahlungsbereitschaft der Konsumenten bzw. Patienten informieren, da diese für die empfangenen Leistungen kein spezielles Entgelt entrichten bzw. keine finanzielle Last im Sinne einer individuellen Äquivalenz tragen. Diese teilweise methodisch unüberwindbaren Hindernisse beeinträchtigen zweifellos die Aussagekraft einer Deflationierung von Behandlungsausgaben, welche insofern nur Tendenzen der realen Entwicklung aufzuzeigen vermag (siehe ausführlicher Ulrich, 1988, S. 60ff.; Ulrich/Wille, 1989 , S. 364ff.).

Mit diesen Einschränkungen können die Analyse der Relativpreise und die Deflationierung der Behandlungsausgaben mit Hilfe der folgenden Preisindizes erfolgen, welche die Entwicklung der betreffenden Warenkörbe wohl am besten repräsentieren:

- Preisindex für Dienstleistungen von Ärzten: für die Behandlung durch Ärzte und für die Behandlung durch Zahnärzte;

- Preisindex für Dienstleistungen der Krankenhäuser: für die stationäre Behandlung;

- Preisindex des Einzelhandels mit pharmazeutischen, kosmetischen und ähnlichen Erzeugnissen aus Apotheken: für die Arzneimittel.

Für die Preisbereinigung der ambulanten und stationären Behandlung stehen aus der amtlichen Statistik lediglich die beiden o.a. Deflatoren zur Verfügung. Obgleich sie Teilindizes aus dem Preisindex für die Lebenshaltung aller privaten Haushalte darstellen, baut ihre Ermittlung nicht nur auf den privaten Verbrauchsbudgets, sondern überwiegend auf Angebotsfaktoren auf. Insofern eignen sich diese beiden Deflatoren für eine Preisbereinigung der entsprechenden GKV-AusEberhard Wille, Angelika Mehnert and Jan Philipp Rohweder - 978-3-631-75615-7 
gaben besser, als dies aufgrund ihrer Herkunft zunächst erscheinen mag. In gleicher Weise beschränkt sich die Konstruktion der Preisindizes für Arzneimittel im Rahmen der Lebenshaltung nicht auf die Selbstmedikation - was einer strengen Interpretation des Konzeptes der Lebenshaltung entsprechen würde -, sondern versucht den gesamten pharmazeutischen Markt möglichst repräsentativ zu erfassen.

Zur Deflationierung der GKV-Arzneimittelausgaben könnten neben dem hier gewählten Deflator aus dem Index der Einzelhandelspreise auch zwei Verbrauchsgüter-Preisindizes ("für die Gesundheitspflege ohne Rezeptgebühr" oder "für Medikamente") als adäquate Preisindizes dienen. $\mathrm{Da}$ die Zeitreihen dieser drei Preisindizes nahezu synchron verlaufen und ihre Wachstumsraten im Beobachtungszeitraum nur geringfügig differieren, hängen die folgenden empirischen Befunde nicht von der Wahl eines speziellen bzw. willkürlichen Deflators für die Arzneimittelausgaben ab. Für den von uns verwandten "Preisindex des Einzelhandels mit pharmazeutischen, kosmetischen u.a. Erzeugnissen aus Apotheken" spricht schon prima vista das Faktum, daß Arzneimittel und Verbandstoffe einen Anteil von $95 \mathrm{vH}$ am Apothekenumsatz einnehmen (vgl. ABDA, 1993a, S. 39).

Für die beiden Behandlungsarten "Heil- und Hilfsmittel" sowie "Zahnersatz" bietet die amtliche Statistik keine Preisindizes, die eine noch vertretbare Aussagefähigkeit bzw. Nähe zum relevanten Warenkorb besitzen. Eine Preisbereinigung des Zahnersatzes scheitert an einem geeigneten Deflator für die Material- und Laboraufwendungen, während einer adäquaten Deflationierung der Heil- und Hilfsmittel bisher vor allem das heterogene Spektrum dieser Behandlungsart entgegensteht.

In Tabelle 11 findet sich für die Deflationierung der stationären Behandlung neben einer offiziellen bzw. unbereinigten Version ein bereinigter Preisindex für die Dienstleistungen der Krankenhäuser. Der unbereinigte Preisindex erstreckte sich bis 1980 lediglich auf den Krankenhausaufenthalt bzw. Pflegekosten-Tagessatz und berücksichtigte erst danach explizit Operationsleistungen, was die Wachstumsrate dieser Maßzahl tendenziell vermindert. Da die unbereinigte Version somit einen Strukturbruch aufweist, schließt der bereinigte Preisindex die Operationsleistungen in hypothetischer Form ab 1970 durchgehend ein. 
Tabelle 11: Der Preisstruktureffekt im Bereich medizinischer Behandlung

\begin{tabular}{|l|c|}
\hline \multicolumn{1}{|c|}{ Preisindizes } & Wachstumsrate \\
& $1970-1992$ \\
\hline Lebenshaltung aller privaten Haushalte & 129,2 \\
\hline Dienstleistungen von Ärzten & 165,0 \\
\hline Dienstleistungen der Krankenhäuser & 350,8 \\
\hline Dienstleistungen der Krankenhäuser, bereinigt & 235,7 \\
\hline $\begin{array}{l}\text { Einzelhandel mit pharmazeutischen, kosmetischen } \\
\text { u.ä. Erzeugnissen aus Apotheken }\end{array}$ & 89,5 \\
\hline GKV-Behandlungsleistungen & 169,1 \\
\hline
\end{tabular}

1) Veränderung im angegebenen Zeitraum in $\mathrm{vH}$.

Quelle: Zusammengestellt und errechnet aus: Statistisches Bundesamt, Preise und Preisindizes für die Lebenshaltung 1978 bis 1992, Stuttgart und Mainz 1979 bis 1993.

Die in Tabelle 11 aufgelistete Preisentwicklung verdeutlicht, daß die Wachstumsrate des Preisindexes für Arzneimittel mit 89,5 vH spürbar unter den entsprechenden Steigerungsraten für die ambulante und stationäre Behandlung liegt. Die für Dienstleistungen von Ärzten ermittelte Rate $(165,0 \mathrm{vH})$ rangiert dabei zwischen jener für Arzneimittel einerseits und für Dienstleistungen der Krankenhäuser andererseits. Die beträchtliche Differenz zwischen der unbereinigten (350,8 $\mathrm{vH})$ und der bereinigten $(235,7 \mathrm{vH})$ Variante des Preisindexes für Dienstleistungen der Krankenhäuser geht zunächst darauf zurück, daß an diesem Index die Operationsleistungen ab 1980 einen Wägungsanteil von über $40 \mathrm{vH}$ besitzen und dessen Wachstumsrate somit spürbar prägen. Da das Honorar für eine Blinddarmoperation, hier als pars pro toto von Operationsleistungen, in den Jahren 1980 bis 1984 allenfalls geringe, teilweise sogar "negative" Steigerungsraten aufwies, schwächt die fiktive Rückverlagerung dieser Entwicklung das Wachstum dieses Preisindexes stark ab. Daher dürtten der bereinigte Index die Preisentwicklung im stationären Sektor tendenziell unter- und die unbereinigte Version diesen Verlauf grundsätzlich überzeichnen. Die Differenz zwischen den Steigerungsraten beider Indizes mag auch das Qualitätsproblem verdeutlichen, mit dem sich eine 
Deflationierung im dienstleistungsintensiven Krankenhausbereich konfrontiert sieht (vgl. Wille, 1988, S. 24f.).

Eine Aufspaltung der Ausgabengrößen in eine Preis- und eine Mengenkomponente zeigt, daß im Zeitraum von 1970 bis 1992 nur bei den Arzneimitteln die Mengenkomponente mit 72,6 zu 27,4 vH überwog (Tabelle 12). Auf der Grundlage des unbereinigten Preisindexes verzeichnet die stationäre Behandlung die niedrigste Mengenkomponente. Bei einer Deflationierung mit Hilfe des bereinigten Preisindexes übersteigt die Mengenkomponente im stationären Sektor jene des ambulanten Bereichs für den Zeitraum von 1970 bis 1992, während es sich in den Jahren 1970 bis 1975 umgekehrt verhielt.

Tabelle 12: Preis- und Mengenkomponente von Behandlungsleistungen

\begin{tabular}{|c|c|c|c|c|c|c|c|c|}
\hline $\begin{array}{r}\text { Behand- } \\
\text { lungsart }\end{array}$ & \multicolumn{2}{|c|}{$\begin{array}{c}\text { ambulante } \\
\text { Behandlung }\end{array}$} & \multicolumn{2}{|c|}{$\begin{array}{c}\text { stationäre } \\
\text { Behandlung }\end{array}$} & \multicolumn{2}{|c|}{$\begin{array}{c}\text { stationäre } \\
\text { Behandlung, } \\
\text { bereinigt }\end{array}$} & \multicolumn{2}{|c|}{ Arzneimittel } \\
\hline & Menge & Preis & Menge & Preis & Menge & Preis & Menge & Preis \\
\hline $1970-1975$ & 44,5 & 55,5 & 19,6 & 80,4 & 34,2 & 65,8 & 71,6 & 28,4 \\
\hline $1970-1992$ & 39,2 & 60,8 & 22,0 & 78,0 & 41,6 & 58,4 & 72,6 & 27,4 \\
\hline
\end{tabular}

Quelle: Zusammengestellt und errechnet aus: Der Bundesminister für Arbeit und Sozialordnung, 1970 bis 1992 , und 1993b, S. $92 \mathrm{ff}$.

Die Bereinigung der Ausgabenentwicklung mit Hilfe von Preisindizes stellt ein statistisches Verfahren dar, welches nicht unmittelbar auf normative Aussagen abzielt. Insofern können von vornherein weder Preiseffekte als Belege für Ineffizienzen noch Mengeneffekte als Indikatoren der Wohlfahrtsentwicklung gelten. Diese Relativierung folgt auch zwingend aus unserem Ziel-Mittel-Schema (siehe oben unter 4.1), welches die Mengeneffekte von Behandlungsarten ebenfalls dem Inputbereich zuordnet. Die Preisbereinigung informiert allerdings über eine globale Ursache von Ausgabenerhöhungen und vermag auf diese Weise die wirtschaftspolitische Entscheidungsgrundlage zu verbessern. Da die Festbeträge Eberhard Wille, Angelika Mehnert and Jan Philipp Rohweder - 978-3-631-75615-7 
schon von ihrer Konzeption her nicht auf die Mengenentwicklung einzuwirken vermögen, standen die Hoffnungen des GRG, im Arzneimittelbereich einen mengenmäßigen Struktureffekt zu erzielen, von Beginn an auf brüchigem Fundament. 
Eberhard Wille, Angelika Mehnert and Jan Philipp Rohweder - 978-3-631-75615-7 Heruntergeladen von PubFactory am05/04/2021 12:53:36PM via Victoria University of Wellington 


\section{Innovation und Imitation im Arzneimittelbereich}

\subsection{Zum Wettbewerb in der pharmazeutischen Industrie}

Forschende pharmazeutische Unternehmen konkurrieren sowohl weltweit miteinander, als auch auf einzelnen nationalen Märkten. Dabei lassen sich zwei Stoßrichtungen unterscheiden: zum einen stehen forschende Unternehmen untereinander im Wettbewerb, zum anderen konkurrieren sie mit Generika-Herstellern. Während der Forschungswettbewerb maßgeblich im internationalen Rahmen stattfindet, ist der Nachahmerwettbewerb meist auf einzelne Länder beschränkt (vgl. Boroch/Cassel, 1993, S. 114).

Der Innovationswettbewerb ermöglicht es den Unternehmen, flexibel auf Änderungen $\mathrm{zu}$ reagieren und sich durch neue und bessere Produkte oder Verfahren Vorteile am Markt zu verschaffen, die ihnen selber in Form von höheren Gewinnen und Marktanteilen sowie einer produkt- oder firmenspezifischen Reputation, aber auch den Nachfragern zugute kommen. Dieser Markterfolg ruft vornehmlich nach Ablauf des Patentschutzes Nachahmer auf den Plan, die an diesen Vorteilen partizipieren möchten und dadurch die Verbreitung der Innovation beschleunigen und den ursprünglichen Marktvorteil zunichte machen können. Daraus resultieren wiederum Anreize zum Innovationswettbewerb. Dies zeigt, daß der Wettbewerb im Markt für pharmazeutische Produkte dynamischer und nicht statischer Natur ist (siehe Moore/Newman, 1989, S. 24).

Die Pharmaunternehmen finanzieren ihre Forschungs- und Entwicklungstätigkeit überwiegend selbst. Da die Entwicklungskosten, die an den F\&E-Kosten den größten Anteil ausmachen, im Hinblick auf ein Innovationsvorhaben mittlerweile bei über 400 Mio. DM bis zur Markteinführung liegen - mit steigender Tendenz -, sind nur relativ große Unternehmen auf diesem Sektor vertreten. Um diese Kosten zu decken und profitabel zu arbeiten, bieten sie weltweit an (vgl. Burstall 1990, S. 20). Die Zahl der mittelständischen forschenden Unternehmen sinkt. In Deutschland sind allein in den achtziger Jahren 13 Firmen in Konzernbesitz übergegangen, weitere geschlossen worden. Insofern scheint die Bedeutung der kleineren und mittleren Unternehmen für die Intensivierung des heimischen Wettbewerbs rückläufig. 
Der Zeitraum, in dem die Unternehmen ein Produkt international (in Japan, den USA und drei europäischen Ländern) am Markt placieren konnten, hat sich seit den siebziger Jahren fast halbiert (vgl. Centre for Medicines Research, 1992, S. 11). Doch nicht nur die Vermarktung der innovativen Produkte verläuft immer stärker im internationalen Rahmen - $50 \mathrm{vH}$ der Verkäufe der europäischen und amerikanischen Unternehmen finden nicht im Ursprungsland statt (vgl. Centre for Medicines Research, 1992) -, auch die F\&E-Investitionen dieser Unternehmen werden zu knapp $30 \mathrm{vH}$ im Ausland vorgenommen (vgl. Halliday et al., 1992, S. 142). Interessanterweise tätigen die japanischen Unternehmen über $90 \mathrm{vH}$ ihrer Verkäufe und ihrer F\&E-Ausgaben in Japan selbst (vgl. Centre for Medicines Research, 1992). Da sie ihre Investitionen in Europa zwischen 1988 und 1990 verdoppelten, wird der Wettbewerbsdruck durch japanische Unternehmen aber künftig wohl zunehmen (vgl. Halliday et al., 1992).

Weltweit verlangsamte sich das Tempo der Forschung und Entwicklung in den vergangenen 15 Jahren. Erfolgten 1975 noch 75 Ersteinführungen neuer pharmazeutischer Wirkstoffe, waren es 1990 nurmehr 39. Dabei verzeichnen die europäischen Staaten, vor allem Frankreich, Italien und Deutschland, absolut und relativ einen deutlichen Rückgang. Während dieser in Frankreich und Italien bereits zu Beginn dieses Zeitraums zu beobachten war, setzte er in Deutschland in der zweiten Hälfte ein. Hier sank die Zahl der New Chemical Entities (NCEs) von 42 (1980-1985) auf 22 (1986-1990), d.h. um knapp 50 vH. Die USA konnten trotz sinkender absoluter Zahlen ihren Anteil an den Gesamteinführungen halten. Nur in Japan stieg die Anzahl der Ersteinführungen (vgl. Reis-Arndt, 1993). Dies deutet darauf hin, daß die Wettbewerbsfähigkeit der europäischen Unternehmen tendenziell sinkt.

\subsection{Zur Bedeutung von Innovation und Imitation}

Die Funktion, die Arzneimittel bei der Erhöhung von Effizienz und Effektivität der Gesundheitsversorgung einnehmen, weist bereits auf einen grundlegenden Unterschied zwischen innovativen und imitierenden Produkten hin. Während die Effizienz das Verhältnis zwischen dem fertiggestellten Produkt bzw. konsumierbaren Angebot und den Ausgaben mißt, setzt die Effektivität auf einer höheren Zielebene die Wirkungsziele mit diesem Angebot - oder den monetären Inputs in Beziehung (vgl. Wille, 1986). Insoweit Originalpräparate medizinischen Fortschritt verkörpern, steigern sie unmittelbar die Effektivität im Gesundheitswesen, Eberhard Wille, Angelika Mehnert and Jan Philipp Rohweder - 978-3-631-75615-7 
indem sie dazu verhelfen, entweder bestimmte gesundheitliche Wirkungsziele bzw. medizinische Orientierungsdaten mit einem geringeren Mitteleinsatz zu realisieren oder mit dem bisherigen Aufwand ein höheres Zielniveau zu erreichen (siehe Müller/Schöneich, 1992, zur Kosteneffizienz medikamentöser Therapie bei Schizophrenie und Drummond et al., 1988, S. 18 zum Einsparungspotential bei Magen-Darm-Geschwüren). Auch die Entwicklung neuer Antibiotika mit stärkerer antibakterieller Wirkung kann Kosten senken (vgl. Pichler, 1991). Direkte Wohlfahrtssteigerungen bei der Gesundheitsversorgung, wie z.B. durch Erfolge bei der Krebsbekämpfung und bei Autoimmunkrankheiten, lassen sich nur durch innovative Arzneimittel erzielen. Dies gilt auch für die Entdeckung einer innovativen Therapieform durch bereits bekannte Wirkstoffe, die bisher noch nicht medizinisch eingesetzt wurden (Erstindikation) oder nur für einen anderen medizinischen Zweck (Zweitindikation). Hierbei eröffnet die Verwendung neuer Trägersubstanzen wie Liposomen vielfältige Möglichkeiten (siehe Rubas/ Schreier, 1991).

Im Unterschied zu innovativen Arzneimitteln beeinflussen imitierende Produkte, wie Analogpräparate und Generika, nicht die gesundheitlichen Wirkungsziele, ihnen fällt vielmehr die Aufgabe $\mathrm{zu}$, bei schon existierenden Produkten über Preissenkungen die Effizienz der Gesundheitsversorgung zu verbessern. Imitierende Produkte können die Opportunitätskosten von Gesundheitsleistungen im Arzneimittelsektor vermindern und auf diese Weise über die alternative Verwendung der eingesparten Mittel indirekt wohlfahrtsteigernd wirken.

Eine Zwischenstellung nehmen "Me-too-"Präparate ein. Sie gelten als innovativ im Sinne des Patentrechts, beruhen aber nicht auf genuin neuen Wirkstoffen, sondern auf Molekülvariationen bereits bekannter NCEs. So führen sie nicht unbedingt zu neuen Wirkungsweisen, können aber z.B. durch Verringerung von Nebenwirkungen oder Tagesdosen, anders als reine Imitationen, die Effektivität steigern. Betrachtet man die schrittweisen Veränderungen, die durch Weiterentwicklung der NCEs bewirkt werden können, und die jede für sich genommen möglicherweise eher klein ausfallen, über einen längeren Zeitraum, können in ihrer Summe erhebliche Entwicklungsfortschritte zutage treten. Andererseits müssen neue Wirkstoffe nicht zwangsläufig zu neuen oder qualitativ besseren Therapieformen führen. In diesem Fall wirken sie wie Nachahmerpräparate und können qualitativ nur in Preiswettbewerb mit bereits bestehenden Mitteln treten. 
Während imitierende Arzneimittel die höheren Outputebenen im Gesundheitswesen nicht tangieren, können von innovativen Originalpräparaten vielschichtige positive externe Effekte ausgehen. Ein neuer Impfstoff gegen eine ansteckende Krankheit nützt z.B. nicht nur - wenn auch vorwiegend - den Geimpften, sondern über eine Reduktion der Ansteckungsgefahr auch jenen Mitbürgern, welche diese Impfung nicht erhalten. In ähnlicher Weise dürfte schon das Wissen um die Existenz eines wirksamen Heilmittels gegen Krebs oder AIDS die Angst vor der entsprechenden Krankheit mindern und damit die Wohlfahrt nicht nur von erkrankten, sondern auch von gesunden Menschen erhöhen.

Obgleich diese Aktivitäten überwiegend den Unternehmenszielen dienen, erzeugen forschende pharmazeutische Unternehmen über Beratung und Fortbildung der Ärzte, über die Kommunikation mit Wissenschaftlern, über Publikationen in den Medien und über die begleitende Evaluation der eigenen Produkte positive externe Effekte. Die in diesem Zusammenhang anfallenden Informationen diffundieren im gesamten Gesundheitswesen und versetzen z.B. den niedergelassenen Arzt in die Lage, sein medizinisches Wissen hinsichtlich Diagnose und Therapie zu erweitern. In diesem Kontext läßt sich freilich trefflich darüber streiten, wo die genaue Grenze zwischen "wissenschaftlicher Information" und "Werbung" verläuft. Gegen die grundsätzliche Existenz positiver Kommunikationseffekte spricht auch nicht die Tatsache, daß einzelne Unternehmen in der Vergangenheit hier nicht selten in exzessiver Form um die Gunst der Ärzte warben.

Unabhängig davon vermag ein forschendes Unternehmen aber auch gesellschaftlich wünschenswerte informative Softwareleistungen nicht zu vermarkten, da es im Gegensatz zu den meisten anderen Bereichen, wie z.B. der Computerindustrie, bisher keine technische Möglichkeit gibt, diese Leistungen an eine Hardware zu knüpfen. Da diese Softwareleistungen die Eigenschaften der Nicht-Ausschließbarkeit und der Nicht-Rivalität aufweisen, stehen sie allen potentiellen Anwendern entgeltlos zur Verfügung. Die forschenden Unternehmen erbringen daher auch nach Ablauf des Patentschutzes - und hierin liegt die Besonderheit zu anderen Märkten - noch Leistungen, die ihre imitierenden Konkurrenten als "free rider" nutzen können.

Die Wirkungen der Arzneimittelforschung beschränken sich aber keineswegs auf den Gesundheitssektor, worauf gerade die Biotechnologie als neue "Schlüsseltechnologie" aufmerksam macht: "Die Molekularbiologie von heute ist die Medizin von Morgen" (siehe Scholz, 1992, S. 15). Es bestehen vielmehr enge 
Komplementaritäten zu Innovationen im Landwirtschafts- und Umweltbereich. Pharmazeutische Erfindungen auf dem Gebiet der Gentechnologie dürften insofern auch die Agrar- sowie Umweltforschung stimulieren und vice versa. Diese wechselseitigen Forschungsspillovers eröffnen für die Zukunft auf recht weiter Basis Innovations- und wohl auch Beschäftigungschancen.

Aber auch in der pharmazeutischen Forschung selber wächst der Stellenwert der Biotechnologie rapide. Vor allem in den USA wurden in den letzten Jahren in Folge der fortschreitenden Genforschung eine Reihe von Gentechnologie-Unternehmen gegründet. Die zunehmende Kenntnis über Aufbau und Wirkungsweise von Genen trägt zu umwälzenden Veränderungen der Forschungs- und Entwicklungsmethoden in Richtung der Konstruktion synthetischer Wirkstoffmoleküle bei, die längerfristig den bisher praktizierten langwierigen und kostenträchtigen trial-and-error-Prozeß zumindest zum Teil ablösen können. Schon jetzt besteht die Möglichkeit, Organismen mit therapeutisch erwünschten Eigenschaften herzustellen. Aus diesem Grunde wird mit einem Hochschnellen der Zulassungsanträge für neue Wirkstoffe noch in den neunziger Jahren gerechnet (vgl. Scherer, 1993, S. 100).

Innovationen bei den verschiedenen Behandlungsarten verschieben im Zeitablauf auch das effiziente Einsatzverhältnis der Produktionsmittel, denn sie können sowohl die relativen Preise dieser Faktoren als auch die Möglichkeiten der Leistungserstellung verändern. So kann eine Innovation im Arzneimittelsektor sowohl ambulante Behandlungen sowie Heil- und Hilfsmittel ersetzen als auch in Verbindung mit ihnen stationäre Aufenthalte reduzieren (vgl. Müller/Schöneich, 1992). Insoweit ein innovatives Arzneimittel eine Krankheitsphase und die mit ihr verbundene medikamentöse Therapie verringert, finden auch Verdrängungsprozesse innerhalb des Arzneimittelsektors statt. Dabei gehen Substitutionen anderer Behandlungsarten durch innovative Arzneimittel bei gegebenem (meist sogar gestiegenem) Gesundheitsoutcome beinahe zwangsläufig mit Ausgabeneinsparungen einher, was vor allem für Verlagerungen vom stationären in den ambulanten Sektor gilt. Solche innovationsinduzierten Kostensenkungen fallen u.a. an, wenn neue diagnostische Verfahren die Anzahl von (überflüssigen) Krankenhauseinweisungen vermindern (vgl. Wille, 1987) und im stationären Bereich die Verweildauer reduzieren oder eine medikamentöse Behandlung chirurgische Eingriffe ersetzt (zu einem relevanten Beispiel siehe Weisbrod, 1984; Bapst et al., 1986). 
Im Vergleich zu den meisten anderen Erfindungen im Gesundheitswesen besitzen innovative Arzneimittel schließlich den Vorzug, als homogene Produkte egalitär zu wirken (vgl. Kaufer, 1979, S. 37). Sofern die benötigten Wirkungssubstanzen in hinreichendem Umfange vorliegen, stehen neue Medikamente allen Bevölkerungsschichten schon bald nach ihrer Zulassung zum gewünschten Zeitpunkt und in gleicher Qualität zur Verfügung. Im Gegensatz dazu bieten Neuerungen im Bereich der ambulanten und stationären Behandlung wesentlich geringere Diffusionsmöglichkeiten, so daß, wie z.B. bei Organtransplantationen, nicht selten lange Wartezeiten bestehen oder für einen längeren Zeitraum nur eine beschränkte Anzahl von Ärzten Leistungen einer bestimmten Qualität erbringt.

\subsection{Bestimmungsfaktoren für die Standortwahl}

$\mathrm{Ob}$ und wo Innovationen stattfinden, hängt vom ökonomischen, politischen und gesellschaftlichen Umfeld ab. Hierbei spielt der rechtliche Rahmen eine wichtige Rolle. Dazu zählt Länge und Ausmaß des Patentschutzes, Zulassungsanforderungen und -verfahren sowie die Reglementierung von Forschungsinhalten und -umfang (z.B. bei der Gentechnologie). Diese sogenannten Kostenfaktoren der Standortbestimmung spielen eine große Rolle, weil sie bei forschenden Pharmaherstellern einen großen Anteil am gesamten Betriebsaufwand ausmachen und in Abhängigkeit vom Standort stark variieren. Für 1990 wurden die Entwicklungskosten für ein pharmazeutisches Produkt in den USA auf \$231 Mio geschätzt. Je die Hälfte bildeten direkte F\&E-Ausgaben und Kapitalkosten. Aber auch eine Preis- oder Gewinnregulierung und die staatliche Steuerung der Nachfrage stellen wichtige Bestimmungsfaktoren dar.

Trotz zunehmend multinationaler Unternehmensstrukturen ist der Heimmarkt von beachtlicher Bedeutung, da er mit $50 \mathrm{vH}$ den größten Länderumsatzanteil ausmacht (siehe Punkt 5.1). Im Wettbewerb mit anderen Unternehmen ist es aber unerläßlich, sich nicht auf den Heimvorteil zu verlassen, sondern auch die Vorteile anderer Märkte zu nutzen und auf Veränderungen der Rahmenbedingungen flexibel zu reagieren. Für die Wettbewerbsfähigkeit besitzt neben den o.g. institutionellen Bestimmungsfaktoren auch die Verfügbarkeit von Ressourcen einschließlich des Humankapitals sowie der Umfang innovativer Kapazitäten Bedeutung (vgl. Boroch/Cassel, 1993 und Sheen, 1992). 
Innerhalb Europas beträgt die Patentlaufzeit einheitlich 20 Jahre ab Anmeldung und entspricht damit weitgehend der japanischen. Seit 1992 ist auch der inhaltliche Schutzumfang für pharmazeutische Produkte EU-einheitlich geregelt. In den USA beträgt die Laufzeit 17 Jahre ab Patenterteilung. Durch das stetige Anwachsen der Entwicklungs- und Zulassungszeiten in den letzten 20 Jahren nahm die effektiv nutzbare Schutzfrist jedoch auf ca. 8-11 Jahre ab (vgl. Scherer, 1993, S. 100; ähnlich Reis-Arndt, 1993, S. 17). Während die USA im Jahre 1984 und Japan vier Jahre später mit Patentverlängerungsgesetzen der Erosion der effektiven Patentlaufzeit entgegenwirkten, schuf die EG erst mit Wirkung vom 2.1.1993 ein ergänzendes Schutzzertifikat, das die Dauer des effektiven Schutzes der der beiden Staaten wieder angleicht (vgl. EWG-Verordnung Nr. 1768/92). In allen Regelungen beträgt die maximale Verlängerungszeit fünf Jahre, wobei eine effektive Schutzdauer von 15 (USA 14) Jahren nicht überschritten werden darf25). Da dieses Zertifikat in Deutschland erst für Erzeugnisse, die ab 1988 zugelassen wurden, beantragt werden kann, besteht hier für früher zugelassene Innovationen im internationalen Vergleich ein Schutz-Lag26).

Dem Patentschutz kommt für den Nachahmerwettbewerb erhebliche Bedeutung zu. Je kürzer der Zeitraum zwischen Zulassung und Ablauf des Patentschutzes in einem Land ist, desto eher können Generika dort auf den Markt kommen. Dies verbessert, wie bereits ausgeführt, die Effizienz der medizinischen Versorgung, kann aber andererseits den Finanzierungsspielraum für weitere F\&E einengen, vor allem, wenn es sich um einen großen Absatzmarkt handelt. Längerfristig können diese Entwicklungen zu Effektivitätseinbußen führen, weil sie Forschungsanstrengungen auf die ökonomisch sicherere Me-too-Forschung lenken oder von der Erforschung kleinerer Indikationsgebiete (sog. orphan drugs), die zu keiner groBen Nachfrage führen, Abstand nehmen läßt (vgl. Cassel, 1990, S. 49 und Kaufer, 1985, S. 3). Betrachtet man die Tatsache, daß der Heimmarkt auch der größte Teilmarkt ist, so bietet ein langer Patentschutz dort ein relativ größeres Refinanzierungspotential. Große Schutzunterschiede über längere Zeiträume dürften daher zu Standortverlagerungen führen.

25) Dem waren Frankreich und Italien 1991 mit nationalen Zertifikatsregelungen vorausgeeilt, deren Laufzeiten die jetzt gültige noch übertrafen. Seit Inkrafttreten der EWGVerordnung können solche nationalen Zertifikate nicht mehr ausgestellt werden.

26) Hierbei beansprucht Deutschland zusammen mit Dänemark ein späteres Zulassungsdatum als den in der Verordnung vorgesehenen Stichtag 1.1.1985. Im Gegensatz dazu haben Belgien und Italien den frühestmöglichen Termin, 1.1.1982, gewählt. 
Wie der Patentschutz wirken sich auch die Anforderungen an Zulassungsunterlagen auf den Wettbewerb zwischen Nachahmern und Originalherstellern aus. Anders als beim Patentschutz existieren hier jedoch größere nationale Unterschiede. Der Schutz vor Zweitanmeldern ist mit dem Recht des Erstanmelders, die Bezugnahme innerhalb der ersten zehn Nachzulassungsjahre zu untersagen, in Deutschland sehr groß, in anderen EU-Ländern beträgt die Dauer sechs (Dänemark, Großbritannien) bzw. ebenfalls zehn Jahre. Die USA gewähren Zweitanmeldern bereits nach fün Jahren ein Bezugnahmerecht. Wie Abbildung 9 verdeutlicht, verliert die lange europäische Einsichtsperre für den Originalanbieter jedoch in Anbetracht der mittlerweile geltenden Schutzzertifikatsregelung an Bedeutung, da sie nur noch dann wirksam vor Nachahmern schützt, wenn Patentrestlaufzeit plus Zertifikatlaufzeit zehn Jahre nicht erreichen, was nur selten der Fall sein dürfte (vgl. Abbildung 4).

Unterschiede bestehen auch hinsichtlich der Bioäquivalenz, die in den USA (vgl. Grabowski/Vernon, 1986, S. 195), nicht aber in Deutschland nachgewiesen sein muß. Das kann dazu führen, daß ein Generikum trotz identischer Zusammensetzung wie das Originalpräparat aufgrund von Unterschieden in der Galenik weniger oder auch stärker wirksam sein kann. Für die geforderte Substitution eines verschriebenen Arzneimittels durch ein (billigeres) Generikum durch die Apotheke ist aber Bioäquivalenz sowohl unter therapeutischen als auch unter Wettbewerbsaspekten eine unabdingbare Voraussetzung27).

Im Hinblick auf die Ausstattung mit Humankapital und innovativen Kapazitäten bietet Deutschland einen attraktiven Standort. Den zwar relativ hohen Arbeitskosten stehen ein hohes fachliches Niveau und damit ein nicht gering zu schätzendes Innovationskapital gegenüber, welches vor allem forschenden Unternehmen zugute kommt. Unsicherheit über den Umfang, in dem dieses Potential eingesetzt werden kann, durch schleppende Genehmigungsverfahren und unklare Rahmenbedingungen insbesondere im Zusammenhang mit der aufkommenden Gen- und Biotechnologie, führte aber bereits zu ersten Verlagerungen dieser Forschungsgebiete ins Ausland. Dabei zeigte sich, da $ß$ mit den Forschungseinrichtungen auch ein Teil der Forscher abwanderte, was zur Ausdünnung der hiesigen innovativen

27) Dieser Tatsache trägt das GRG teilweise Rechnung, indem es unterschiedliche Bioverfügbarkeiten bei der Gruppenbildung berücksichtigt, "sofern sie für die Therapie bedeutsam sind" (§ 35 Abs. 1 SGB V). 
Abbildung 4: Einfluß der Verwertungssperre nach Paragraph 24a AMG und des EU-Zertifikates auf die Schutzfrist am Markt

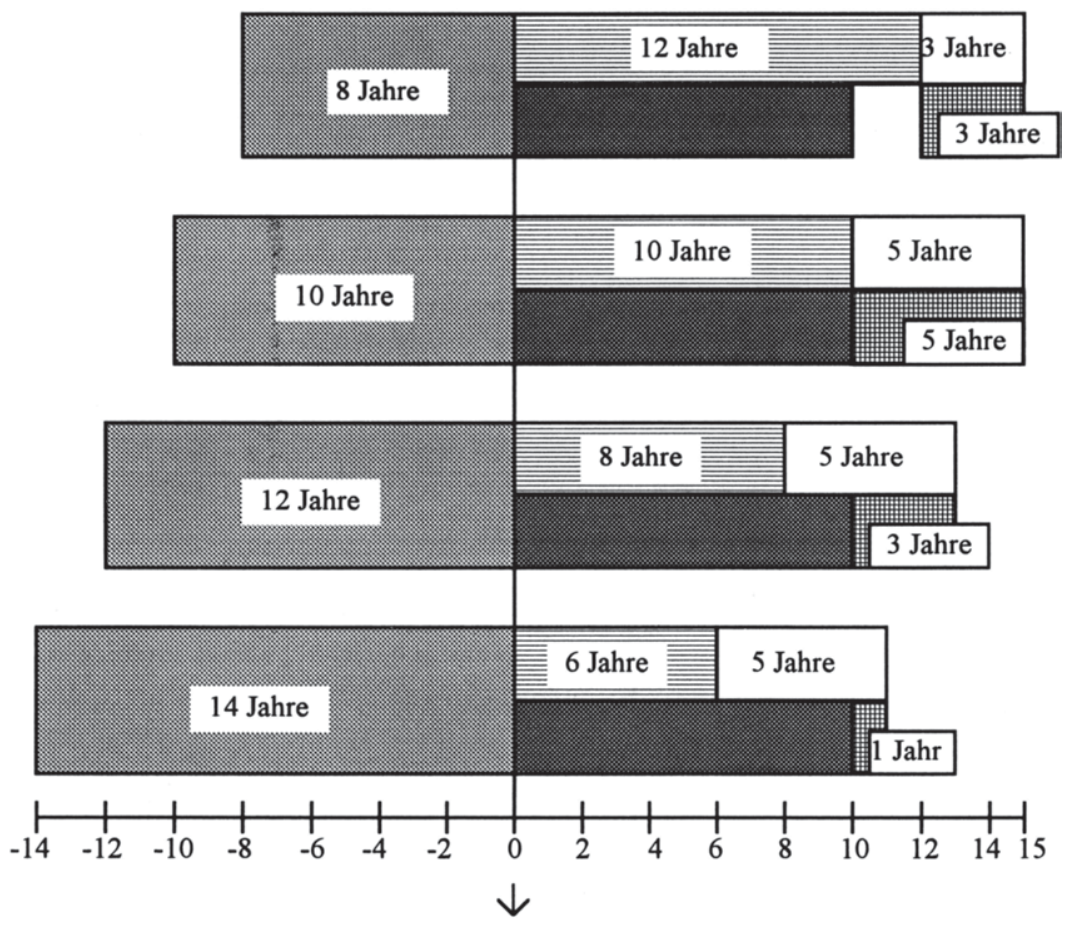

Erste Zulassung in einem EU-Mitgliedsstaat

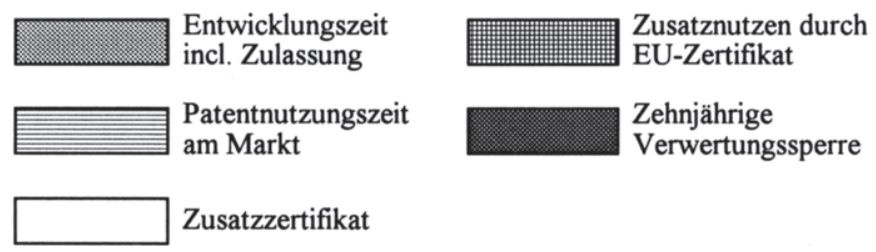

Quelle: Boehringer Mannheim GmbH, 1993. 
Kapazität beitrug. In Anbetracht der steigenden Bedeutung dieser neuen Technologien und der mit ihnen verbundenen Spillovers kann die Fortführung dieser Entwicklung zu Wettbewerbsnachteilen nicht nur für die forschende pharmazeutische Industrie, sondern auch für den mit ihr in Berührung stehenden Agrar- und Umweltbereich führen (siehe Sheen, 1992, zum Problem der lokalen Spezifizität des Wissenstransfers).

Nachfrageseitige Regulierungen und Eingriffe in die Preisbildung beeinflussen vor allem den Absatz. Hier ist an Fixpreise, Gewinnbegrenzungen und Erstattungsobergrenzen oder Indemnitätstarife zu denken. Weitere Steuerungsmöglichkeiten bieten Positiv- und Negativlisten. Mit Inkrafttreten des GSG gewann auch die Budgetierung von Ausgabenpositionen an Bedeutung. In der Ausgestaltung dieser Bereiche sind die nationalen Unterschiede am ausgeprägtesten. Während alle Regulierungsformen darauf abzielen, zur Kostendämpfung im Gesundheitswesen beizutragen, differieren sie in ihrer Wirkungsweise für die pharmazeutischen Unternehmen. Dies gilt sowohl für die Industrie innerhalb eines Landes als auch im Hinblick auf den internationalen Wettbewerb.

Aus ordnungspolitischer Sicht stellt die staatliche Preisfestsetzung den stärksten Eingriff in die Marktautonomie dar. Er bedeutet die Ausschaltung eines unternehmerischen Aktionsparameters. Vor allem die südlichen europäischen Länder kennen keine freie Herstellerpreisbildung ${ }^{28}$ ), sondern bestimmen den Preis aufgrund von cost-plus-Verfahren oder Referenzpreisen, was zu einem im europäischen Vergleich teilweise stark unterdurchschnittlichen Preisniveau geführt hat ${ }^{29)}$. Oftmals differieren zugestandene Preise je nach dem, ob das Produkt ganz oder überwiegend im Inland hergestellt wurde. Insbesondere letzteres führte vor allem in Italien zu einer großen Übernahmewelle und wurde vom Europäischen Gerichtshof 1987 untersagt. In ähnlicher Weise sind Preisänderungen genehmigungspflichtig und können (z.B. in Belgien und Frankreich) durch Export-, F\&E-, Investitions- oder Beschäftigungszusagen positiv beeinflußt werden (vgl. ABDA, 1991, S. 57; Burstall, 1990, S. 74). Auch in diesem Fall dient die Preispolitik gleichzeitig der Förderung der heimischen Industrie.

28) Die Preise für nicht erstattungsfähige Arzneimittel können i.d.R. frei gesetzt werden.

29) Die Differenzen der Apothekenabgabepreise beruhen neben den unterschiedlichen Herstellerabgabepreisen auch auf von Land zu Land verschiedenen Handelsspannen und Mehrwertsteuersätzen. 
Die Reaktion der Unternehmen auf eine solche Politik hängt u.a. von der Größe des Marktes ab. Auf einem kleinen Markt können durch die verkaufte Menge keine großen Deckungsbeiträge erwirtschaftet werden. Im Falle Griechenlands führte dies dazu, daß Firmen sogar neu zugelassene Produkte nicht vermarkteten (vgl. ABDA, 1991, S. 38). Auf größeren Märkten, wie z.B. in Frankreich, macht die Menge, zumal bei Skalenerträgen in der Produktion und im Marketing, die niedrigen Stückdeckungsbeiträge z.T. wett. Ist das Unternehmen auf dem Weltmarkt präsent, besitzt es derzeit die Möglichkeit, durch Preisdifferenzierung auf anderen Märkten entsprechend höhere Preise zu verlangen ${ }^{30)}$. Ist es aber vor allem auf den Heimmarkt angewiesen, so geht diese Politik wie in Frankreich mit einem Rückgang an kostspieliger, aber aussichtsreicher Forschungstätigkeit einher, der durch die sinkenden NCE-Zahlen dokumentiert wird; der Forschungsschwerpunkt liegt auf Produktvariationen (vgl. Hart/Reich, 1990, S. 270f.).

Große Preisunterschiede bieten Anreize für Parallel- und Reimporte, die sich vor allem bei noch patentgeschützten Originalpräparaten lohnen, weil diese noch keiner Konkurrenz durch Nachahmerprodukte unterliegen. Materiell handelt es sich hierbei um einen Import ausländischer Regulierung, da das Preisniveau dieser Importe nicht auf einen marktwirtschaftlichen Wettbewerb zurückgeht, bei dem Unternehmen mit unterschiedlicher Leistungsfähigkeit miteinander konkurrieren, sondern auf staatlichen Dirigismen beruht (vgl. Oberender, 1986, S. 369).

Bei wirkstoffgleichen Arzneimitteln unterschritten die Preise der imitierenden Konkurrenz bis zum GRG spürbar jene der Originalhersteller. Die geringe Preisempfindlichkeit der Arzneimittelnachfrage, die in einem mangelnden Anreizsystem wurzelt, beschnitt aber in der Vergangenheit die Erfolgsaussichten des Imitationswettbewerbs, der auf den Preis als Aktionsparameter setzte. Eine Reaktion bestand in der gezielten Beeinflussung der ärztlichen Verordnungsweise durch Transparenz- und Preisvergleichslisten. Diese Aktivitäten wirken letztlich wie eine Subventionierung der imitierenden Unternehmen, denn diese erhalten von anderen Stellen, die hierfür die Kosten tragen, quasi ihren Werbeaufwand alimentiert (vgl. Wille, 1988, S. 32). Später versuchten die politisch Verantwortlichen via Festbeträge und Selbstbeteiligung die Nachfrage zu sensibilisieren.

30) Dies führt indirekt zu einer Subventionierung des Gesundheitswesens der Niedrigpreisländer durch die Hochpreisländer. 
Allerdings gilt es zu bedenken, daß "dort, wo der Arzneimittelfortschritt gewichtig ist... die Preiselastizität der Nachfrage auch ohne jedwede Krankenversicherung sehr gering" ist (Kaufer, 1985, S. 6).

Anders als die Herstellerpreisregulierung setzen Festbeträge auf der Nachfrageseite an. Formal sind sie unabhängig von Hersteller- oder Apothekenabgabepreisen und geben lediglich an, in welcher Höhe die Krankenkasse bzw. der Gesundheitsdienst die Kosten für das verschriebene Arzneimittel trägt. De facto resultieren die Erstattungspreise aber häufig aus mit Abschlägen versehenen administrierten Preisen, und dort, wo die Preissetzung frei ist, beeinflussen sie Angebotspreise und -verhalten. So führte die Einführung der Festbeträge in Deutschland zur Senkung der Apothekenpreise auf Festbetragsniveau und brachte z.T. erhebliche Umsatzeinbußen bei solchen Originalpräparaten mit sich, deren Preise nicht entsprechend gesenkt wurden (siehe dazu Punkt 6.1.2). In Belgien hatte das teilweise sehr niedrige Erstattungspreisniveau zur Folge, daß Unternehmen von der Vermarktung ihrer Produkte dort Abstand nahmen (vgl. ABDA, 1991, S. 11). Inwieweit innovative Produkte von solchen Regelungen betroffen sind, hängt, wie auch bei der Herstellerpreissetzung, von der Ausgestaltung ab.

Ergänzend existieren in vielen Staaten Listen verordnungs- (und erstattungs-) fähiger Arzneimittel (Positivlisten) oder von der Erstattung ausgenommener Medikamente (Negativlisten). Ökonomisch beinhaltet der Ausschluß von der Positivliste bzw. das Setzen auf die Negativliste einen Erstattungspreis von Null.

Nicht nur die Preise, auch die Nachfragemengen stehen als Regulierungsparameter zur Disposition. Meist erfolgt die Mengenregulierung indirekt über eine Budgetierung. Diese erfolgt in Frankreich bei den Unternehmen, die bei der Beantragung eines neuen Produktes als erstattungsfähiges Arzneimittel einen projektiven Sollumsatz angeben müssen. Bei einer Überschreitung droht Listenausschluß, was die Hersteller in der Vergangenheit zu Preissenkungen veranlaßte. Insofern wirken die Mengen als Preisregulativ, wobei die starke Nachfrage nach dem innovativen Produkt zu niedrigeren Preisen führt.

\subsection{Alternative Finanzierungsformen von Forschung und Entwicklung}

Die forschenden Unternehmen finanzieren ihren Innovationsaufwand über den Preis ihrer Produkte. Im Gegensatz zu anderen dynamischen und forschungsin- 
tensiven Bereichen wie z.B. der Luftfahrt und der Mikroelektronik erhalten sie keine staatliche Subventionen. Die Finanzierung der Forschung und Entwicklung erfolgte in Deutschland bis zur Einführung des GRG mit Hilfe einer Mischkalkulation, bei der nicht nur die patentgeschützten, sondern möglichst viele Produkte einen Beitrag zu den F\&E-Kosten leisteten. Dieses Verfahren verschaffte den großen Unternehmen einen Vorsprung, da diese aufgrund ihrer breiteren Produktpalette bessere Streumöglichkeiten besaßen. Es hatte den volkswirtschaftlichen Effekt, daß Innovationen relativ zu den älteren, nicht mehr patentgeschützten Produkten, tendenziell "zu billig" waren. Spiegelbildlich waren die älteren Produkte teurer als es eine Grenzkostenkalkulation der Produktionskosten dieser älteren Produkte erfordern würde, was auch aus der Preisdifferenz zu Generika ersichtlich war.

Die Einführung der Festbeträge, die einen gleichen Erstattungspreis für Originalund Nachahmerpräparat vorsehen, erschwerte diese Mischfinanzierung. Da patentgeschützte, neuartige Erzeugnisse von den Festbeträgen ausgenommen sind, steigt deren Bedeutung im Rahmen der F\&E-Finanzierung. Vom Ansatz her sollen sich neue Produkte selbst finanzieren, indem die Entwicklungsausgaben dieser Produkte, aber auch aller nicht zur Marktreife gelangten Erzeugnisse nun über den Preis der marktfähigen Innovationen amortisiert werden. Dieses Ziel wird durch verlängerte Patentschutzfristen unterstützt. Insofern könnte der Übergang von der mischfinanzierten zur unmittelbaren innovationsabhängigen Arzneimittelforschung Anreize setzen, die Forschung zu intensivieren und weniger für Produkte zu werben, für die bereits preiswertere, pharmakologisch gleichwertige Alternativen existieren.

Großbritannien versucht mit seinem System der Gewinnregulierung Forschungskosten zu berücksichtigen, die Preissetzung den Unternehmen zu überlassen und zwischen großen und kleinen Unternehmen zu differenzieren. Das Pharmaceutical Prices Regulation Scheme (PPRS) betrifft daher nur solche Unternehmen, deren Jahresumsatz mit dem National Health Service (NHS) $£ 500.000$ überschreitet. Diese müssen dem Gesundheitsministerium jährlich testierte Abschlüsse vorlegen, die 20 größten Unternehmen mit einem NHS-Umsatz von über $£ 4$ Mio. halbjährlich Bilanzen und Kalkulationsschemata, zusätzlich Projektionen über die nächstjährigen Umsätze (vgl. ABDA, 1991, S. 43; Hancher, 1990, S. 207). Aufgrund dieser Daten handelt das Gesundheitsministerium mit den Unternehmen einen individuellen Gewinnrahmen aus, der zwischen 17 und $21 \mathrm{vH}$ des für das NHS eingesetzten bilanzierten Kapitals beträgt. Überschreitungen, die auf EffiEberhard Wille, Angelika Mehnert and Jan Philipp Rohweder - 978-3-631-75615-7 
zienzsteigerungen oder neue Produkte zurückzuführen sind und $50 \mathrm{vH}$ des Zielgewinns nicht überschreiten, dürfen zurückbehalten werden, andere werden mit dem für das nächste Jahr vereinbarten Gewinn verrechnet (vgl. Hancher, 1990, S. 208). Einige Kostenarten unterliegen besonderen Kontrollen: Der Anteil der berücksichtigten Informations- und Werbeausgaben an den NHS-Ausgaben ist nach allgemeinen Kriterien wie dem NHS-Umsatz und der Anzahl der Produkte festgelegt, darüber hinausgehende Ausgaben werden dem Gewinn zugerechnet. Allerdings dürfen forschende Unternehmen zusätzlich bis zu $£ 1$ Mio. in zwei Jahren für die Bekanntmachung und Verkaufsförderung neuer Wirkstoffe (NCE) ausgeben. Bei der Berücksichtigung der F\&E-Kosten spielt neben den weltweiten (d.h. nicht nur den im Inland angefallenen) F\&E-Aufwendungen auch die firmenspezifische Produktpalette und somit der Anteil innovativer Präparate eine Rolle. Generika sind vom PPRS ausgenommen. Für sie gibt das Gesundheitsministerium Höchstpreise vor. Bei freiverkäuflichen und bei nicht vom NHS erstatteten Produkten ist die Preisbildung frei.

Im letzten Punkt gleicht das französische dem britischen System. Auch in Frankreich unterscheidet man bei der Preissetzung zum einen zwischen erstattungsfähigen und nicht erstattungsfähigen - letztere unterliegen keiner Preisbindung-, zum anderen zwischen Generika und Originalpräparaten. Anders als in Großbritannien wird jedoch auch für neue Produkte unter Heranziehung von Herstellungskosten, Tagesbehandlungskosten und ausländischen Referenzpreisen ein Erstattungspreis festgesetzt. Die Preise für Generika liegen bis zu $50 \mathrm{vH}$ unter den Preisen der jeweiligen Originalpräparate, was zu einem scharfen Preiswettbewerb führte, der Originalanbieter veranlaßte, mit eigenen preisgünstigen Generika an den Markt zu gehen (ABDA, 1991, S. 30).

In beiden Systemen bleibt der Grundsatz der F\&E-Finanzierung durch laufende Erträge erhalten, doch zeigt sich, gemessen an der Zahl neuer Wirkstoffe, daß das britische System mehr Innovationen hervorbrachte. Insofern wohnt dem französischen System die Tendenz inne, statt eigene Innovationen zu finanzieren, diese aus dem Ausland zu möglichst geringen Preisen zu importieren. Noch offensichtlicher ist dieses Verhalten in Ländern erkennbar, die keine eigene Forschung betreiben. Die Trittbrettfahrerstrategie in Bezug auf pharmazeutische Innovationen, die sich dahinter verbirgt, baut zunächst auf der Hypothese auf, daß jene Länder, welche bis heute einen hohen Innovationsstandard aufrechterhalten, nicht ähnlich handeln, da sonst die Arzneimittelforschung weltweit zum Erliegen käme. 
dern die Erfolgsaussichten dieser Strategie in dem Maße abnehmen, wie die Zahl ihrer Anwender zunimmt. Die erschwerte Finanzierung über Preise fördert eine Monopolisierung, die den dann noch bestehenden Unternehmen eine gegenüber heute wesentlich verbesserte Wettbewerbs- und Verhandlungsposition verschaff, so daß diese sich dann wohl kaum gezwungen sehen, ihre Innovationen zu Dumpingpreisen zu exportieren. 
Eberhard Wille, Angelika Mehnert and Jan Philipp Rohweder - 978-3-631-75615-7 Heruntergeladen von PubFactory am05/04/2021 12:53:36PM via Victoria University of Wellington 


\section{Forschungsanreize vor dem Hintergrund gesundheits- politischer Regulierungen}

\subsection{Das Gesundheits-Reformgesetz}

\subsubsection{Die gesetzlichen Regelungen}

Wie der entsprechende Gesetzentwurf vom 3.5.1988 schon eingangs betont, soll die Reform die Voraussetzungen dafür schaffen, "die seit Jahren ansteigenden Beitragssätze in der gesetzlichen Krankenversicherung (GKV) zu senken und dauerhaft zu stabilisieren" (Fraktionen der CDU/CSU und FDP, 1988, S. 1). Die Reform strebte insgesamt, d.h. nach Ablauf einer Einführungsfrist bzw. für das Jahr 1992 ein jährliches "Einsparvolumen" von 14,06 Mrd. DM an. Von diesen frei werdenden Mitteln sollten u.a. 6,4 Mrd. DM zur Finanzierung der häuslichen Pflegehilfe dienen und 6,94 Mrd. DM den Versicherten und Arbeitgebern, vornehmlich in Form von Beitragssatzsenkungen, zugute kommen (ebenda, S. 274f.). Für den Arzneimittelbereich bezifferte der Gesetzentwurf die erwarteten Einsparungen auf über 2,8 Mrd. DM, wovon alleine 2,0 Mrd. DM auf die Effekte aus der Festbetragsregelung entfielen. Die Festbeträge verfolgen gemäß $\S 35$ Abs. 5 SGB V das Ziel, sowohl die "Wirtschaftlichkeitsreserven auszuschöpfen" als auch "einen wirksamen Preiswettbewerb auszulösen".

Nach $\S 35$ Abs. 1 SGB V bestimmt der Bundesausschuß der Ärzte und Krankenkassen, für welche Gruppen von Arzneimitteln Festbeträge festgesetzt werden können. Diese Gruppen sollten ursprünglich Arzneimittel mit

(1) denselben Wirkstoffen,

(2) pharmakologisch-therapeutisch vergleichbaren Wirkstoffen, insbesondere mit chemisch verwandten Stoffen,

(3) pharmakologisch-therapeutisch vergleichbarer Wirkung, insbesondere Arzneimittelkombinationen

zusammenfassen. Unterschiedliche Bioverfügbarkeiten wirkstoffgleicher Arzneimittel sind $\mathrm{zu}$ berücksichtigen, sofern sie therapeutische Bedeutung besitzen. 
Ausgenommen von diesen Gruppen bleiben Arzneimittel "mit patentgeschützten Wirkstoffen, deren Wirkungsweise neuartig ist und die eine therapeutische Verbesserung, auch wegen geringerer Nebenwirkungen, bedeuten". Vor der Entscheidung des Bundesausschusses verfügen Sachverständige der medizinischen und pharmazeutischen Wissenschaft und Praxis sowie der Arzneimittelhersteller und der Berufsvertretungen der Apotheker über die Gelegenheit zur Stellungnahme.

Die Spitzenverbände der Krankenkassen setzen gemeinsam und einheitlich den jeweiligen Festbetrag auf der Grundlage von rechnerischen mittleren Tages- oder Einzeldosen oder anderen geeigneten Vergleichsgrößen fest. Ein Festbetrag für Arzneimittel mit denselben Wirkstoffen konnte zunächst erst drei Jahre nach der ersten Zulassung eines wirkstoffgleichen Arzneimittels festgesetzt werden. Die Festsetzung von Festbeträgen soll sich gemäß $§ 35$ Abs. 5 SGB V an "möglichst preisgünstigen Versorgungsmöglichkeiten" ausrichten und deshalb "grundsätzlich von den preisgünstigen Apothekenabgabepreisen in der Vergleichsgruppe" ausgehen. Die Festbeträge sind mindestens einmal im Jahr zu überprüfen und in "geeigneten Zeitabständen an eine veränderte Marktlage anzupassen". Existierte für ein Arzneimittel ein Festbetrag, so finanzierte die Krankenkasse zunächst, d.h. bis Ende 1992 bzw. bis zur Geltung des GSG, die Kosten bis zur Höhe dieses Betrages. Für andere Arzneimittel trug sie die vollen Kosten abzüglich der vom Versicherten zu leistenden Zuzahlung. Letztere sollte bis Ende 1991 3,- DM je Mittel betragen - jedoch nicht mehr als dessen Kosten -, und für die Zeit ab dem 1.1.1992 sah § 31 Abs. 3 SGB V ursprünglich eine Zuzahlung von $15 \mathrm{vH}$, jedoch höchstens 15,- DM je Mittel vor.

Neben den von der Versorgung grundsätzlich ausgeschlossenen sog. Bagatellarzneimitteln kann eine Ausdehnung der Negativliste um solche Medikamente erfolgen, "die ihrer Zweckbestimmung nach üblicherweise bei geringfügigen Gesundheitsstörungen verordnet werden" ( $\$ 34$ Abs. 2 SGB V). Während diese Regelungen weitgehend dem damals schon geltenden Recht entsprachen, ermöglicht $\S 34$ Abs. 3 SGB V auch den Ausschluß von "unwirtschaftlichen Arzneimitteln". Als unwirtschaftlich gelten insbesondere jene Präparate, die für das Therapieziel oder die Risikominderung nicht erforderliche Bestandteile enthalten, deren Wirkung sich wegen der Vielzahl der enthaltenen Wirkstoffe nicht mit ausreichender Sicherheit beurteilen läßt oder für deren therapeutische Nutzen kein Nachweis vorliegt. 
§ 84 SGB V beauftragt die Partner der Gesamtverträge, d.h. die Kassenärztlichen Bundesvereinigungen und die Bundesverbände der Krankenkassen, arztgruppenspezifisch jeweils Richtgrößen für das Volumen verordneter Arzneimittel zu vereinbaren. Diese Vereinbarungen sollten die Entwicklung der Zahl und der Altersstruktur der behandelten Personen sowie die Preiswürdigkeit der Verordnungen berücksichtigen. Den arztgruppenspezifischen Richtgrößen fiel die Aufgabe zu, die früheren Höchstbeträge für Arzneimittel zu ersetzen. Sie zielten jedoch, wie der Gesetzentwurf erläutert (Fraktionen der CDU/CSU und FDP, 1988, S. 193), nicht auf "eine Budgetierung des Verordnungsvolumens für den einzelnen Arzt" ab. Der Gesetzestext ließ letztlich offen, ob sich die Richtgrößen nur auf die Mengenkomponente von Arzneimitteln erstrecken, was als Ergänzung zu den preisbezogenen Festbeträgen konzeptionell eigentlich nahe lag, oder auch monetäre Elemente beinhalten.

Bei Überschreitung der Richtgrößen sah schon das GRG bzw. § 106 Abs. 2 SGB $\mathrm{V}$ in alter Fassung eine arztbezogene Wirtschaftlichkeitsprüfung der kassenärztlichen ${ }^{31)}$ Versorgung vor. Es obliegt den Landesverbänden der Krankenkassen und den Kassenärztlichen Vereinigungen, gemeinsam die entsprechenden Prüfungsverfahren zu vereinbaren. Diese Vertragspartner bilden auch bei den Kassenärztlichen Vereinigungen Prüfungs- und Beschwerdeausschüsse, denen jeweils Vertreter der Ärzte und der Krankenkassen paritätisch angehören. Der Prüfungsausschuß entscheidet auf Antrag der Krankenkasse oder der Kassenärztlichen Vereinigung ${ }^{32}$ ), ob ein Verstoß gegen das Wirtschaftlichkeitsgebot vorliegt und welche Maßnahmen gegebenenfalls folgen. "Dabei sollten gezielte Beratungen weiteren Maßnahmen in der Regel vorangehen" ( $\$ 106$ Abs. 5 SGB V). Gegen die Entscheidung der Prüfungsausschüsse können die betroffenen Ärzte die Beschwerdeausschüsse anrufen. Dabei besaß eine solche Anrufung ursprünglich grundsätzlich, d.h. auch im Falle einer Überschreitung der Richtgrößen, aufschiebende Wirkung.

Der an der kassenärztlichen (jetzt: "vertragsärztlichen") Versorgung teilnehmende Arzt soll gemäß $§ 73$ Abs. 5 SGB V die Preisvergleichsliste beachten und auf dem Verordnungsblatt vermerken, ob die Apotheke ein preisgünstigeres wirk-

31) In dem durch das GSG geänderten Text heißt es jetzt "vertragsärztliche Versorgung".

32) Im geänderten Text:"auf Antrag der Krankenkasse, ihres Verbandes oder der Kassenärztlichen Vereinigung" (siehe § 106 SGB V). 
stoffgleiches Arzneimittel anstelle des verordneten abgeben darf 33). Verordnet der Arzt ein Arzneimittel, das den Festbetrag überschreitet, hat er den Versicherten auf die Pflicht zur Übernahme der Mehrkosten hinzuweisen. In den Fällen, in denen der Arzt ein Arzneimittel nur unter seiner Wirkstoffbezeichnung verordnet oder eine Substitution durch ein wirkstoffgleiches zuläßt, verpflichtet $\S 129$ Abs. 1 SGB V die Apotheken, ein preisgünstiges Medikament abzugeben. Daneben besteht auch die Verpflichtung zu Abgabe von preisgünstigen importierten Arzneimitteln. Ein Rahmenvertrag soll in diesem Kontext vorsehen, daß die Apotheken bei "gröblichen und wiederholten Verstößen gegen diese Vorschriften" von der Versorgung der Versicherten bis zur Dauer von zwei Jahren ausgeschlossen werden können. Da die Arzneimittelausgaben der GKV unter Einschluß der Selbstbeteiligung der Versicherten fast $70 \mathrm{vH}$ des gesamten Apothekenumsatzes ausmachen (vgl. ABDA, 1993a, S. 40), läuft diese Sanktion praktisch auf den wirtschaftlichen Ruin einer Apotheke hinaus.

\subsubsection{Auswirkungen auf GKV und Arzneimittelmarkt}

In fiskalischer Hinsicht vermochte das GRG die Ausgabenentwicklung innerhalb der GKV nur für gut ein Jahr einzudämmen, denn schon im Jahre 1990 kehrte die alte Wachstumsdynamik wieder zurück ${ }^{34}$ ). So stiegen die GKV-Ausgaben pro Mitglied (einschl. Rentner) im Jahre 1991 um 10,6 vH an, während die entsprechenden beitragspflichtigen Einnahmen nur um 4,7 vH zunahmen (siehe auch oben unter 3.1 Abbildung 1). Dieser Trend setzte sich dann im Jahre $1992 \mathrm{mit}$ einem Ausgabenzuwachs von 8,7 vH und einem Anstieg der beitragspflichtigen Einnahmen von 5,2 vH fort ${ }^{35}$ ). Im Zuge dieses Auseinanderklaffens von Einnahmen- und Ausgabenentwicklung erreichte das Gesamtdefizit der GKV im Jahre 1992 das "Rekordniveau" von 9,1 Mrd. DM, und der durchschnittliche Beitragssatz kletterte zum 1.1.1993 auf die Höchstmarke von 13,4 vH (vgl. Der Bundesminister für Arbeit und Sozialordnung, 1993b; Müller, 1993). Dieses fiskalische

33) Dies bedeutet eine Einschränkung bzw. Auflockerung des sog. Autsimileverbotes.

34) Dabei enthielten die GKV-Ausgaben des Jahres 1988 noch erhebliche Vorzieheffekte ("Blümbauch"), die der Sachverständigenrat für die Konzertierte Aktion im Gesundheitswesen (1990, S. 48) auf 3,5 bis 4,1 Mrd. DM schätzte.

35) Unsere Ausfürungen beziehen sich hier nur auf die alten Bundesländer. Von der deutschen Wiedervereinigung gingen bisher fiskalisch gesehen keine entscheidenden Auswirkungen auf die GKV aus. 
Scheitern des GRG bildete wohl mit den entscheidenden Anlaß für das nur vier Jahre später folgende GSG.

Wie Tabelle 13 ausweist, trugen die verschiedenen Behandlungsarten im Zeitraum von 1980 bis 1992 in unterschiedlicher Intensität zum Wachstum der GKVAusgaben bei. Die Arzneimittel, deren Anteil an den GKV-Ausgaben von 1970 bis 1980 noch sank (siehe oben unter 2.2 Tabelle 4 und unter 2.3 Tabelle 7), stiegen ab 1980 überproportional an. Gleiches gilt für die Aufwendungen für stationäre Behandlung sowie Heil- und Hilfsmittel, wohingegen die Ausgaben für ambulante Behandlung durch Ärzte und durch Zahnärzte innerhalb der GKVAusgaben anteilsmäßig zurückgingen.

Tabelle 13: Durchschnittliche Wachstumsraten der GKV-Ausgaben nach Behandlungsarten (1970 - 1992)

\begin{tabular}{|l|c|c|}
\hline \multicolumn{1}{|c|}{ Behandlungsart } & $\begin{array}{c}\text { durchschnittliche } \\
\text { Wachstumsrate in \% } 1) \\
1980-1988\end{array}$ & $\begin{array}{c}\text { durchschnittliche } \\
\text { Wachstumsrate in \%1) } \\
1980-1992\end{array}$ \\
\hline Behandlung durch Ärzte & 4,9 & 5,7 \\
\hline Behandlung durch Zahnärzte & 4,4 & 5,2 \\
\hline stationäre Behandlung & 6,5 & 6,8 \\
\hline Arzneimittel & 6,8 & 7,0 \\
\hline Heil- und Hilfsmittel & 8,4 & 7,4 \\
\hline Zahnersatz & 6,1 & 3,1 \\
\hline insgesamt 2 ) & 5,8 & 6,2 \\
\hline
\end{tabular}

1) Arithmetisches Mittel der Veränderungsraten über die entsprechenden Jahre.

2) Ausgaben der GKV für Gesundheit ohne die nichtaufteilbaren, sonstigen Aufwendungen.

Quelle: Zusammengestellt und errechnet aus: Der Bundesminister furr Arbeit und Sozialordnung, $1980-1993$ und $1993 \mathrm{~b}$. 
Insgesamt gesehen gelang es dem GRG offensichtlich nicht, das Wachstum der Arzneimittelausgaben wie gewünscht einzugrenzen. Dieses Ergebnis überrascht prima vista insofern, als von der Festbetragsregelung durchaus relevante, anfangs in Teilbereichen sogar spektakuläre Einflüsse auf den Arzneimittelmarkt ausgingen. Zunächst löste die Festbetragsregelung im betreffenden Verordnungssegment auf breiter Front Preissenkungen aus, die im Jahre 1990 zu einer geschätzten Nettoentlastung 36) der GKV von ca. 500 Mill. führten (vgl. Sachverständigenrat für die Konzertierte Aktion im Gesundheitswesen, 1991, S. 68ff.). Die am 1.1.1991 gültigen 72 Festbeträge betrafen ein Umsatzvolumen von 5,5 Mrd. DM und deckten damit bereits über $25 \mathrm{vH}$ der gesamten GKV-Arzneimittelausgaben ab. Hersteller von Originalpräparaten, die mit ihrem Preis bei renommierten Produkten, wie z.B. Adalat, Voltaren und Lexotanil, zunächst über dem Festbetrag lagen, erlitten empfindliche Umsatzverluste (vgl. Zerche, 1992, S. 71ff.). Insofern sahen sich nahezu alle Anbieter von Originalpräparaten schon Mitte 1990 gezwungen, ihre Preise auf Festbetragsniveau abzusenken.

Infolge dieser Preissenkungen kam es auf dem Arzneimittelmarkt insofern zu einer gespaltenen Preisentwicklung, als die Preise im Festbetragssegment durchschnittlich zurückgingen, im Nicht-Festbetragssegment aber im Durchschnitt anstiegen (vgl. Reichelt, 1989, S. 702). Für die Umsatzentwicklung der Arzneimittelausgaben spielte, wie Tabelle 14 belegt, die Preiskomponente insgesamt nur eine untergeordnete Rolle (so auch der Sachverständigenrat für die Konzertierte Aktion im Gesundheitswesen, 1992, S. 63). Neben der Verordnungszahl bewirkte vor allem die Strukturkomponente das starke Wachstum der Arzneimittelausgaben. Die Strukturkomponente mißt jenen Teil der Umsatzänderungen, der auf einen Wechsel zu anderen Arzneimitteln als sog. Intermedikamenteneffekt oder bei identischen Arzneimitteln zu größeren Packungen, teureren Darreichungsformen und Wirkstärken als sog. Intramedikamenteneffekt zurückgeht (vgl. Ulrich, 1988, S. 83ff.; Schwabe/Paffrath, 1993, S. 16).

Die Festbetragsregelung setzt für die Preisbildung von Arzneimitteln eine Richtbzw. Orientierungsgröße, welche über Preissenkungen und/oder Produktsubstitutionen für die GKV Ausgabeneinsparungen auslösen soll. Die Erfolgsaussichten dieser Maßnahmen hängen in starkem Maße von dem Einfluß ab, den die Preis-

36) Die Nettoentlastung ergibt sich hier als Bruttoentlastung vermindert um die Eigenbeteiligung der Versicherten in Höhe von 3,- DM pro verordnetem Arzneimittel, welche bei Festbetragsarzneimitteln nach dem GRG zunächst entfiel. 
entwicklung auf das Ausgabenwachstum ausübt. Bei einer Aufspaltung der Ausgabengrößen in eine Preis- und eine Mengenkomponente bilden die Arzneimittelausgaben aber die einzige Behandlungsart, bei der die Mengenkomponente deutlich überwiegt (siehe oben 4.3.2 Tabelle 12). Die Festbetragsregelung stößt bei ihrem Versuch, das Wachstum der Arzneimittelausgaben einzudämmen insofern auf konzeptionelle Grenzen, als sie keine Maßnahme gegen die Mengenentwicklung vorsieht, die im Arzneimittelbereich vorherrscht. Darüber hinaus läuft sie Gefahr, die Mengenausweitung noch zu stimulieren, denn für Arzneimittel, deren Preis den Festbetrag nicht überstieg, übernahm die Krankenkasse bis zum GSG die gesamten Kosten, d.h. es entfiel dann sogar die frühere Rezeptgebühr in Höhe von 2,- DM je Mittel. Lediglich bei Arzneimitteln, für die kein Festbetrag existierte, leistete der Versicherte generell eine Zuzahlung. Die Festbetragsregelung, die nur an der Preiskomponente ansetzt, zielt letztlich an der bisher dominanten Einflußgröße des Ausgabenwachstums im Arzneimittelbereich vorbei.

Tabelle 14: Komponenten der Ausgabenentwicklung

\begin{tabular}{|c|c|c|c|c|c|c|}
\hline \multirow{2}{*}{ Jahr } & \multirow{2}{*}{$\begin{array}{c}\text { Umsatzent- } \\
\text { wicklung }\end{array}$} & $\begin{array}{c}\text { Zahl der } \\
\text { Verord- } \\
\text { nungen } 1)\end{array}$ & Preise & insgesamt 1 ) & $\begin{array}{c}\text { Intermedi- } \\
\text { kamenten- } \\
\text { effekt }\end{array}$ & $\begin{array}{c}\text { Intramedi- } \\
\text { kamenten- } \\
\text { effekt }\end{array}$ \\
\hline 1987 & 6,8 & 3,7 & 0,7 & 2,3 & 0,4 & 1,9 \\
\hline 1988 & 8,5 & 4,1 & 1,4 & 2,7 & 0,8 & 1,9 \\
\hline 1989 & 0,8 & $-3,5$ & 1,0 & 2,9 & 0,0 & 2,9 \\
\hline 1990 & 6,5 & 5,3 & $-0,1$ & 1,3 & $-0,4$ & 1,7 \\
\hline 1991 & 10,8 & 3,8 & 1,5 & 5,1 & 2,5 & 2,7 \\
\hline 1992 & 9,8 & 3,2 & 2,0 & 4,3 & 1,8 & 2,5 \\
\hline
\end{tabular}

1) In Prozent.

Quelle: Schwalbe/Paffrath, 1988 - 1993.

Zudem führte das Nebeneinander von Medikamenten mit und ohne Festbeträge zu der medizinisch wie ökonomisch fragwürdigen Konsequenz, daß die Patienten 
herkömmliche Medikamente überwiegend zum Null-Tarif erhielten, für solche, die therapeutischen Fortschritt verkörpern, aber Zuzahlungen leisten mußten.

Nicht nur die Ausklammerung der Mengenkomponente, sondern auch die Wahl einer unzutreffenden Vergleichsbasis und die Vernachlässigung von naheliegenden Verhaltensreaktionen tendieren zu einer Überschätzung des Einsparungspotentials, welches die Festbeträge bewirken können. Zunächst fand, wie bereits oben unter 2.1.1 erwähnt, eine spürbare Verdrängung von Originalpräparaten durch billigere Imitationsprodukte bereits vor Einführung der Festbeträge statt. Die Verlängerung dieses Trends bildet die methodisch adäquate Vergleichsbasis zur Abschätzung jener fiskalischen Effekte, welche kausal auf die Festbetragsregelung zurückgehen. Bereits vor dieser Reform standen zahlreiche Hersteller von Originalpräparaten vor der Notwendigkeit, zur Rückgewinnung von Marktanteilen die Preise deutlich zu senken. Die Einführung von Festbeträgen mag als Initialzündung für Preissenkungen auf breiter Basis gewirkt haben, die aber in vielen Fällen - wenn auch wohl nicht in diesem Ausmaß - kurze Zeit später ohnenhin erfolgt wären.

Wie nahezu jeder staatliche Eingriff führt auch die Festbetragsregelung bei den Betroffenen zu Verhaltensreaktionen, die eine realistische Abschätzung ihrer Effekte zumindest qualitativ in Rechnung stellen sollten. So finanzierten die Hersteller von Originalpräparaten ihren relativ arbeitsintensiven Innovationsaufwand zuvor überwiegend mit Hilfe einer Mischkalkulation, bei der nicht nur die patentgeschützten, sondern möglichst viele Produkte einen Beitrag zur Finanzierung der Forschungskosten leisteten. Die Festbetragsregelung regt die forschenden Unternehmen zur Erhaltung ihrer Innovationsfähigkeit nun an, kompensatorische Preiserhöhungen vorzunehmen, wozu z.B. die Markteinführung von patentgeschützten Präparaten oder nicht imitierbarer Produkte Chancen bieten. Solche Kompensationsmöglichkeiten stehen sicherlich nicht jedem Unternehmen, und vor allem nicht kurzfristig, offen, mindern aber sicherlich auf mittlere Frist einen Teil des veranschlagten Einsparungspotentials. Obgleich die Festbetragsregelung je nach wettbewerblicher Konstellation auch die Erträge bestimmter Generika-Produzenten empfindlich minderte, führte sie auf dem Markt für wirkstoffgleiche Arzneimittel schwergewichtig zu Umsatz- und Gewinneinbußen der forschenden Unternehmen. Dabei traf der plötzliche Übergang auf die Festbetragsregelung die ein- 
zelnen forschenden Unternehmen in höchst unterschiedlichem Maße ${ }^{37}$ ). Die festbetragsbedingten Umsatz- und Gewinneinbußen hingen u.a. davon ab, ob ein Unternehmen

- eine hohe Exportquote aufwies,

- in Länder mit oder ohne staatlich regulierten Pharmamarkt exportierte,

- einen hohen Umsatzanteil von nicht mehr patentgeschützten wirkstoffgleichen Medikamenten besaß,

- über eine große Zahl patentgeschützter Produkte und vor allem patentfähiger, marktreifer Innovationen verfügte,

- einen partiellen Ausgleich durch einen verstärkten Absatz nicht rezeptpflichtiger Medikamente erreichen konnte und

- nur Arzneimittel produzierte oder auch auf anderen Märkten Kompensationsmöglichkeiten fand.

\subsection{Das Gesundheitsstrukturgesetz}

\subsubsection{Maßnahmen im Arzneimittelbereich}

Da das GRG die fiskalischen Erwartungen nicht erfüllte, strebte das GSG schon für das Jahr 1993 eine finanzielle Nettoentlastung der GKV von 10,11 Mrd. DM an (vgl. Fraktionen der CDU/CSU, SPD und FDP, 1992, S. 159f.). Alle Beteiligten versprachen sich von den vorgesehenen Maßnahmen schon im Jahre 1993 eine Stabilisierung des durchschnittlichen Beitragssatzes. "Vor allem bei wirksamer Umsetzung der strukturellen Maßnahmen erscheinen ab 1994 auch wieder Beitragssatzsenkungen möglich" (ebenda, S. 161). Für den Arzneimittelbereich sah der Gesetzentwurf finanzielle Entlastungen von insgesamt 3,36 Mrd. DM vor. Davon entfielen 1,5 Mrd. DM auf das Preismoratorium, 0,56 Mrd. DM auf das Arzneimittelbudget und 1,3 Mrd. DM auf Zuzahlungen.

37) Zur Auswirkung von Festbetragsregelungen auf die deutsche pharmazeutische Industrie siehe NERA, 1993a, S.88. 
Um das Volumen der GKV-Arzneimittelausgaben zu begrenzen, vereinbaren die Landesverbände der Krankenkassen und die Verbände der Ersatzkassen gemeinsam und einheitlich mit der Kassenärztlichen Vereinigung für das jeweils folgende Kalenderjahr ein Arzneimittelbudget als Obergrenze für die entsprechenden Ausgaben. Diese Budgets sind erstmalig für das Jahr 1994 auf der Grundlage des Budgets von 1993 zu beschließen. Bei ihrer Fortschreibung sollen Veränderungen (1) der Zahl und der Altersstruktur der Versicherten, (2) der Preise der Arznei-, Verband- und Heilmittel, (3) der gesetzlichen Leistungspflicht der Krankenkassen und (4) der bestehenden Wirtschaftlichkeitsreserven und Innovationen Berücksichtigung finden. Übersteigen die Ausgaben in einer bestimmten Periode diese Budgets, dann muß die Kassenärztliche Vereinigung im folgenden Kalenderjahr für einen Ausgleich sorgen. Andernfalls verringern sich die Gesamtvergütungen um den übersteigenden Betrag (Art. 1 Nr. 42 GSG; $§ 84$ Abs. 1 SGB V).

Art. 29 Abs. 1 GSG legt das Arzneimittelbudget für das Jahr 1993 mit bestimmten $\mathrm{Zu}$ - und Abschlägen auf das Ausgabenvolumen des Jahres 1991 fest. Das Arzneimittelbudget für die alten Bundesländer liegt bei etwa 24,12 Mrd. DM38). Überschreiten die tatsächlichen Ausgaben dieses Arzneimittelbudget, haftet zunächst die Kassenärztliche Bundesvereinigung bis zu einer Höhe von 280 Mio DM. Die Aufteilung dieses Ausgleichsbetrages auf die einzelnen Kassenärztlichen Vereinigungen richtet sich nach ihrem Anteil am übersteigenden Betrag. Einen weiteren Überschreitungsbetrag bis zu einer Gesamthöhe von 560 Mio. DM, d.h. maximal 280 Mio. DM, muß dann die pharmazeutische Industrie gegenüber den Krankenkassen ausgleichen. Dieser Ausgleich erfolgt durch eine entsprechende Verlängerung der Geltungsdauer des Preismoratoriums (Artikel 29 Abs. 3 u. 4 GSG).

Die Vertragspartner können das Arzneimittelbudget frühestens ab 01.01.1994 aussetzen, sofern sie einheitliche arztgruppenspezifische Richtgrößen für das Volumen der je Arzt verordneten Leistungen getroffen haben (siehe ausführlicher Glaeske, 1993). Die für die Wirtschaftlichkeitsprüfungen nach $\S 106$ SGB V vereinbarten arztgruppenspezifischen und indikationsbezogenen Richtgrößen

38) Bei der Ermittlung des Sollbudgets für 1993 wurden die Arzneimittel-Istausgaben von 1991 (24,47 Mrd. DM) um die erhöhten Patientenzuzahlungen, die Preissenkungen durch das Preismoratorium ud die Effekte weiterer Festbeträge sowie um die Mehrwertsteuererhöhung, die Zunahme der Ärztezahl und die Neuaufnahme empfängnisverhütender Mittel in den Leistungskatalog bereinigt. Siehe im Detail Rostalski, 1993. 
gelten für das jeweils folgende Kalenderjahr und sollen die Zahl und die Altersstruktur der Versicherten, bestehende Wirtschaftlichkeitsreserven und die Preiswürdigkeit der verordneten Leistungen berücksichtigen (Art. 1 Nr. 42 GSG; § 84 Abs. 3 u. 4 SGB V). Überschreiten die jeweiligen Ausgaben eines Vertragsarztes diese Richtgrößen um mehr als $15 \mathrm{vH}$, so findet zwingend eine Prüfung seines Verordnungsverhaltens statt. Bei einer Überschreitung um über $25 \mathrm{vH}$ trägt der Vertragsarzt den Mehraufwand, soweit dieser nicht auf Praxisbesonderheiten beruht. Die Vertragspartner können diese Prozentsätze frühestens zum 01.01.1995 neu festlegen (Art. 63 GSG; § 106 SGB V).

Für die neuen Bundesländer gelten Budgets erstmalig für das Jahr 1994. Sie entsprechen den verdoppelten Ausgaben des ersten Halbjahres 1992, bereinigt um den Rechnungsabschlag von $20 \mathrm{vH}$ und unter Berücksichtigung der oben für die Fortschreibung der Budgets aufgeführten vier Vorgaben (Art. 1 Nr. 169 GSG; § 311a SGB V; Art. 29 Abs. 7 GSG).

Die Zuzahlung der Patienten zu den Arzneimitteln wurde neu geregelt. Für das Jahr 1993 richtet sich der Selbstbehalt nach dem Apothekenabgabepreis und beträgt bei Medikamenten bis 30,- DM 3,- DM, bei Medikamenten zwischen 30,DM und 50,- DM 5,- DM und bei Medikamenten über 50,- DM 7,- DM. Ab dem 01.01.1994 orientiert sich die Höhe der entsprechenden Zuzahlung an der Packungsgröße. Die Zuzahlung schließt jetzt im Gegensatz zur früheren Regelung auch das Festbetragssegment ein (Art. 1 Nr. 18; § 31 Abs. 2, 3 u. 4 SGB V).

Der Bundesminister für Gesundheit erläßt durch eine Rechtsverordnung mit Zustimmung des Bundesrates eine Liste verordnungsfähiger Fertigarzneimittel. Sie tritt an die Stelle der bisherigen Negativliste des $\S 34$ SGB V, die vor allem sog. Bagatellarzneimittel umfaßte. Grundlage für diese Positivliste bildet eine wirkstoffbezogene Vorschlagsliste des Instituts "Arzneimittel in der Krankenversicherung", die erstmalig bis zum 30.06.1995 zu beschließen ist. Das Institut setzt sich aus 11 unabhängigen Sachverständigen zusammen, die der Bundesausschuß der Ärzte und Krankenkassen mit Zustimmung des Bundesministeriums für Gesundheit für die Dauer von vier Jahren beruft. Handelt es sich um Arzneimittel nach $\S 49$ des Arzneimittelgesetzes, hat das Institut innerhalb von drei Monaten nach der Bekanntmachung seiner Zulassung über die Aufnahme zu entscheiden. Andernfalls ist das Arzneimittel bis zu einer gegenteiligen Entscheidung verordnungsfähig. Die Rechtsverordnung selbst ist erstmalig bis zum 31.12.1995 zu erlassen. Danach besitzt der Patient nur noch einen Anspruch auf Versorgung mit 
Arzneimitteln aus der Positivliste. Der Vertragsarzt kann jedoch auch andere Arzneimittel zu Lasten der GKV verschreiben, wenn er dies auf einem gesonderten Verordnungsblatt mit maschinenlesbarer Kennzeichnung schriftlich begründet (Art. 1 Nr. 21 u. Nr. 49 GSG; § 34a u. § 92a SGB V).

Artikel 30 Abs. 1 GSG legt fest, daß die Herstellerabgabepreise apothekenpflichtiger Fertigarzneimittel, für die am 01.01.1993 kein Festbetrag galt, in den Jahren 1993 und 1994 höchstens 95 vH der am 01.05.1992 geltenden Preise bei verschreibungspflichtigen Medikamenten betragen dürfen. Bei apothekenpflichtigen Medikamenten, die nicht der Verschreibungspflicht unterliegen, dürfen die Preise analog höchstens $98 \mathrm{vH}$ betragen. Für Arzneimittel, die zwischen dem 02.05.1992 und dem 31.12.1992 erstmals in den Markt eingeführt wurden, bilden die Markteinführungspreise die Bezugsgröße für die Preissenkung. Die Preise für Medikamente, die nach dem 31.12.1992 auf den Markt kommen, dürfen in den Jahren 1993 und 1994 nicht erhöht werden. Das Preismoratorium führt somit für dieses Marktsegment eine staatlich administrative Herstellerpreisbindung ein, die zunächst bis zum 31.12.1994 gilt. Es trifft auch solche Medikamente, die nicht zu Lasten der GKV verordnet werden, so daß auch die privaten Krankenversicherer und die Selbstmedikation von dieser staatlich verordneten Preissenkung profitieren.

Das GSG beläßt es zwar bei den bisherigen Festbetragsgruppen, das Festbetragssegment 3 des $\S 35$ SGB V faßt nun jedoch Arzneimittel "mit therapeutisch vergleichbarer Wirkung, insbesondere Arzneimittelkombinationen" zusammen 39). Da sich diese Festbetragsstufe zuvor auf Arzneimittel mit "pharmakologischtherapeutisch vergleichbarer Wirkung" bezog, lockert diese Änderung die Bedingungen für die Festbetragsbildung auf dieser Stufe auf. Der Verzicht auf die pharmakologische Vergleichbarkeit erleichtert die jeweilige Gruppenbildung. Ausgenommen von der Festbetragsbildung bleiben "Arzneimittel mit patentgeschützten Wirkstoffen, deren Wirkungsweise neuartig ist und die eine therapeutische Verbesserung, auch wegen geringerer Nebenwirkungen, bedeuten". Im Sinne dieser Regelung gilt ein Wirkstoff dann als neuartig, "solange derjenige Wirkstoff, der als erster dieser Gruppe in Verkehr gebracht worden ist, unter Patentschutz steht" (Art. 1 Nr. 22 GSG; § 35 Abs. 1 Satz 4

39) Die Festbetragsgruppe 1 erstreckt sich auf Arzneimittel mit "denselben Wirkstoffen" und die Festbetragsgruppe 2 auf solche mit "pharmakologisch-therapeutisch vergleichbaren Wirkstoffen, insbesondere mit chemisch verwandten Stoffen". 
SGB V). Dies bedeutet, daß nach Ablauf des Patentschutzes des ersten innovativen Arzneimittels auch patentgeschützte Arzneimittel, sofern sie zu der gleichen Wirkstoffgruppe gehören, grundsätzlich der Festbetragsbildung unterliegen.

Zudem entfällt der bisherige Abs. 4 des $\S 34$ SGB V, der für die Festsetzung von Festbeträgen für Arzneimittel mit "denselben Wirkstoffen" (Gruppe 1) eine Wartezeit von 3 Jahren nach Ablauf des Patentschutzes vorsah. Festbeträge für Medikamente mit denselben Wirkstoffen können somit nun mit der ersten Zulassung eines wirkstoffgleichen Arzneimittels und nicht erst drei Jahre danach festgesetzt werden.

\subsubsection{Absehbare Auswirkungen}

Eine empirisch orientierte Analyse des GSG kann sich derzeit (Oktober 1993) nur auf einen statistisch ausgewerteten Beobachtungszeitraum von 6 Monaten stützen, was für eine fundierte Beurteilung fraglos bei weitem nicht ausreicht. Nach hohen Defiziten im Jahre 1992 erzielte die GKV in den alten Bundesländern im ersten Halbjahr 1993 bei einem Zuwachs der Grundlohnsumme von ca. 4,7 vH und einem Ausgabenrückgang pro Mitglied von 2,7 vH einen finanziellen Überschuß von 2,6 Mrd. DM (vgl. Bundesministerium für Gesundheit, 1993 und Müller, 1993). Nach den derzeit absehbaren Tendenzen können die Kassen zumindest im Jahre 1993 ihre Beitragssätze stabil halten und ihre durch das Rekorddefizit in 1992 aufgebrauchten finanziellen Reserven wieder etwas auffüllen. Aufgrund der bis Ende 1995 geplanten fast flächendeckenden Budgetierung aller Behandlungsarten besitzt das GSG im Vergleich zum GRG größere Erfolgsaussichten, das Wachstum der GKV-Ausgaben zu begrenzen. Ob dies für eine mehrjährige Stabilisierung der Beitragssätze ausreicht, hängt aber auch von der künftigen gesamtwirtschaftlichen Entwicklung $a b$, die vornehmlich über die Beschäftigungssituation die Einnahmen der GKV determiniert.

Zur angestrebten Stabilisierung der GKV-Ausgaben trugen die Aufwendungen für Arzneimittel im ersten Halbjahr 1993 weit überproportional bei. Die Apothekenumsätze mit der GKV gingen im Vergleich zum ersten Halbjahr 1992 in den alten Bundesländern um $21 \mathrm{vH}$ zurück, wobei diese Umsatzeinbrüche regional zwischen $14 \mathrm{vH}$ in Berlin-West und $38 \mathrm{vH}$ in der Pfalz stark schwankten (vgl. 
ABDA, 1993b) ${ }^{40)}$. Bei einer Fortsetzung dieser Entwicklung würden die GKVArzneimittelausgaben das gemäß Art. 29 Abs. 1 GSG vorgegebene Budget um ca. 3,8 Mrd. DM unterschreiten. Aufgrund des stabilisierenden Einflusses der Nachfrage im Bereich der Selbstmedikation verzeichnete der gesamte westdeutsche Apothekenmarkt in diesem Zeitraum "nur" einen Umsatzrückgang von 12,7 vH. Da kompensierende Effekte größeren Ausmaßes im Exportgeschäft ausblieben, sank die gesamtdeutsche pharmazeutische Produktion in diesen 6 Monaten um 9,9 vH (vgl. BPI, 1993c, S. 1).

Im Hinblick auf die GKV-Arzneimittelausgaben fiel der Umsatzrückgang im Vergleich zur Entwicklung der Verordnungszahlen deutlich stärker aus. So blieben in den ersten 3 Monaten des Jahres 1993 die Umsätze um $24 \mathrm{vH}$, die Verordnungszahlen aber lediglich um $17 \mathrm{vH}$ hinter den Werten des Vorjahresquartals zurück (vgl. Klauber/Selke, 1993, S. 469f.) ${ }^{41}$ ). Die entscheidenden Ursachen für diese Abweichungen bilden zum einen die durch das Preismoratorium verfügte Preissenkung und zum anderen die stark angestiegene Verschreibung von Generika bzw. Imitationsprodukten. Im Zuge dieser Entwicklung ging das deutsche Arzneimittelpreisniveau im EU-Vergleich von 128,4 vH im Jahre 1988 auf 105 vH zum 01.01.1993 zurück (siehe Tabelle 15) und dürfte, folgt man dieser Berechnung, inzwischen wohl schon voll im EU-Durchschnitt liegen. Wegen der methodischen Probleme, welche solche internationalen Vergleiche aufwerfen (siehe auch Andersson, 1993), läßt sich im Hinblick auf die entsprechenden Niveauwerte zwar trefflich um ein paar Prozentpunkte streiten, die relative Entwicklung des bundesdeutschen Arzneimittelpreisniveaus spiegelt Tabelle 15 aber zweifellos zutreffend wider.

Wie schon eingangs unter 1. erwähnt, beschleunigte das GSG den Trend eines steigenden Verordnungs- und Umsatzanteils von Zweitanmelderprodukten. Auch innerhalb der Generika verordneten die Ärzte, vornehmlich aus Unsicherheit über die Auswirkungen des Arzneimittelbudgets und/oder aus Furcht vor Wirtschaft-

40) Hierbei gilt es allerdings zu berücksichtigen, daß jene KV-Bezirke, welche die Arzneimittelausgaben am stärksten reduzierten (z.B. Pfalz, Saarland, Koblenz), im Referenzjahr 1991 überdurchschnittlich hohe Umsätze verzeichneten.

41) Für das erste Halbjahr 1993 ermittelt das Wissenschaftliche Institut der Ortskrankenkassen (1993) einen Rückgang der Arzneiverordnungen von $17 \mathrm{vH}$ und ein Absinken der GKV-Arzneimittelumsätze von 22,4 vH. Dabei zeigt die Zahl der Arzneiverordnungen im Halbjahresverlauf einen Aufwärtstrend. 
lichkeitsprüfungen, in der Regel das preiswerteste Medikament. Die Verordnung relativ teurer, innovativer Arzneimittel scheuten dagegen auch "Ärztegruppen, die bisher innovationsfreundlich waren" (Kossow/Trauboth, 1993, S. 47). Während die forschenden Unternehmen überwiegend kräftige Umsatzeinbußen erlitten, bescherte das GSG vielen Generika-Herstellern einen Umsatz-Boom.

Tabelle 15: Das Arzneimittelpreisniveau in der EU (EU-Durchschnitt = 100)

\begin{tabular}{|l|r|r|r|r|c|}
\hline Land & 1988 & 1989 & 1990 & 1991 & $\left.1992^{1}\right)$ \\
\hline Belgien & 88,6 & 91,0 & 92,6 & 100,5 & 116 \\
\hline Dänemark & 128,1 & 131,1 & 136,7 & 143,4 & 133 \\
\hline Deutschland & 128,4 & 123,5 & 116,6 & 110,5 & 105 \\
\hline Frankreich & 71,5 & 69,0 & 66,9 & 63,8 & 63 \\
\hline Griechenland & 73,8 & 80,0 & 80,0 & 85,5 & 85 \\
\hline Großbritannien & 115,9 & 123,1 & 125,6 & 124,6 & 123 \\
\hline Irland & 130,5 & 129,8 & 132,2 & 129,8 & 133 \\
\hline Italien & 79,1 & 83,1 & 89,4 & 96,1 & 96 \\
\hline Luxemburg & 97,1 & 95,6 & 93,5 & 94,5 & 97 \\
\hline Niederlande & 131,9 & 127,7 & 129,9 & 134,1 & 148 \\
\hline Portugal & 67,5 & 61,7 & 57,9 & 57,7 & 67 \\
\hline Spanien & 71,6 & 70,8 & 76,6 & 83,7 & 94 \\
\hline
\end{tabular}

1) Stand: 1.1.1993.

Quelle: Zusammengestellt aus ABDA, 1991 und 1993a. 
So nahm im GKV-Arzneimittelmarkt z.B. der Umsatz von Boehringer Mannheim, Boehringer-Ingelheim und Glaxo im 2. Quartal 1993 gegenüber dem Vorjahr um $35,4 \mathrm{vH}$ bzw. $30,2 \mathrm{vH}$ und 28,2 vH ab, während die Generika-Produzenten Ratiopharm und Hexal-Pharma entsprechende Umsatzsteigerungen von 12,3 vH bzw. 11,9 vH verbuchen konnten (vgl. Wissenschaftliches Institut der Ortskrankenkassen, 1993). Im gesamten Arzneimittelmarkt sank von Januar bis August 1993 der Gesamtumsatz um 12,1 vH und z.B. der Umsatz von Boehringer Mannheim um 26,1 vH, von Bristol-M. Squibb um 21,6 vH, von Glaxo um 16,2 vH, von Boehringer Ingelheim um 13,2 vH und von Bayer um 11,2 vH. Dagegen stieg im gleichen Zeitraum der Umsatz von Hexal-Pharma um 54,4 vH und jener von Ratiopharm um 10,9 vH, wobei das letztere Unternehmen zum umsatzstärksten auf dem deutschen Arzneimittelmarkt avancierte (vgl. Bayer-Statistik, 1993). Im Gegensatz zum GRG, als die meisten forschenden Unternehmen Umsatzverluste im Festbetragssegment durch Preiserhöhungen am Restmarkt und Mengenausweitungen ausgleichen konnten, zeichnen sich derzeit für sie keine derartigen Kompensationsmöglichkeiten ab.

Eine Mischfinanzierung, die auch nach dem GRG noch teilweise möglich war, erscheint nun unter den Bedingungen des GSG weitgehend ausgeschlossen. Für diese These spricht zudem die ständige relative Ausdehnung des Festbetragsmarktes, der zum 01.01.1993 mit einem Umsatzvolumen von 9,1 Mrd. DM bereits $45 \mathrm{vH}$ der gesamten Arzneimittelausgaben ausmachte und in naher Zukunft noch um ca. 3,5 Mrd. DM zunehmen dürfe (vgl. Spitzenverbände der Krankenkassen, 1993, S. 18f.). Vor diesem Hintergrund müssen die Erstanbieter versuchen, den gesamten Innovations- und Entwicklungsaufwand in die Preiskalkulation für neue innovative Produkte einfließen zu lassen. Wenn sie während der Patentrestlaufzeit den gesamten Forschungsaufwand über die Preise ihrer patentgeschützten Arzneimittel miterlösen, können sie nach Ablauf der Patente im Preiswettbewerb mit den Nachahmern bestehen. Nur insoweit es den Herstellern von Originalpräparaten gelingt, am Markt eine solche "Hochpreispolitik" durchzusetzen, d.h. die Ärzte solche Präparate trotz Arzneimittelbudget oder arztgruppenspezifischer Richtgrößen auch verordnen, bleibt ihre bisherige Innovationsfähigkeit erhalten.

Über die Auswirkungen, die dieser abrupte Abfall der GKV-Arzneimittelausgaben für den Gesundheitszustand und die Wohlfahrt der Patienten mit sich brachte, lassen sich derzeit - und möglicherweise auch grundsătzlich - keine fundierten Aussagen machen. Eine Aufspaltung der Verordnungsrückgänge nach IndikaEberhard Wille, Angelika Mehnert and Jan Philipp Rohweder - 978-3-631-75615-7 
tionsgebieten zeigt, daß die Ärzte überwiegend nicht nach dem Gießkannenprinzip reduzieren, sondern durchweg nach medizinischen Kriterien selektieren. So erlitten im ersten Halbjahr 1993 mit den Venentherapeutika $(-34,9 \mathrm{vH})$, den Urologika $(-32,3 \mathrm{vH})$, den durchblutungsfördernden Mitteln $(-29,9 \mathrm{vH})$, den Vitaminen $(-29,1 \mathrm{vH})$ und den Mineralstoffpräparaten $(-28,2 \mathrm{vH})$ jene Indikationsgruppen die stärksten Verordnungsverluste, die der Arzneiverordnungs-Report ' 92 "vollständig oder in Teilen zu den umstrittenen Arzneimittelgruppen zählt" (Wissenschaftliches Institut der Ortskrankenkassen, 1993).

Die obige Feststellung schließt freilich in vielen Fällen erhebliche Wohlfahrtsverluste auf der Seite der Patienten keineswegs aus, denn letztere erhielten in diesem Prozeß keine Chance, ihre Wertschätzung gegenüber bestimmten Medikamenten, z.B. über eine Selbstbeteiligung, differenziert zum Ausdruck zu bringen. Selbst die Vorsitzenden Kassenärztlicher Vereinigungen beklagen in diesem Kontext, daß das GSG zu einer erheblichen Störung des Arzt-Patienten-Verhältnisses führte, denn der Arzt geriet bei seinen Arzneimittelverordnungen nicht selten in die Position des Leistungsverweigerers (siehe FAZ vom 06.05.1993, S. 16, ähnlich Brenner, 1993). Zudem bildet die Bewertung des Arzneimittelreports, der bestimmte Arzneimittelgruppen als "in Teilen umstritten" bezeichnet, ein äußerst vages Kriterium, das seine Selektion gleich zweifach relativiert. Anders formuliert bedeutet dies nämlich, daß die betreffenden Medikamente teilweise auch unstrittig helfen können. Sofern a priori ein solcher Unbestimmtheitsbereich existiert, gehören die betreffenden Entscheidungen aber vor Ort in die Kompetenz des behandelnden Arztes, denn nur er verfügt hier über die adäquate Informationsbasis. Jede andere Regelung läuft auf eine paternalistische Anmaßung von letztlich nicht vorhandenem instrumentalem Wissen hinaus. Anders verhält es sich nur, wenn die Wirksamkeit eines Medikamentes im Urteil pharmakologischer und medizinischer Experten bisher ohne Nachweis blieb.

Über diese mehr atmosphärischen Störungen hinaus führte das Arzneimittelbudget auch zu einigen nachweisbaren medizinischen bzw. gesundheitspolitischen Verwerfungen. Teilweise verordneten die Ärzte billigere Medikamente mit geringerer Wirksamkeit bzw. stärkeren negativen Nebenwirkungen, was vor allem für den Bereich der Antibiotikatherapie gilt (vgl. Gabler-Sandberger/Heinzl, 1993). So traten in einem medizinisch fragwürdigen Umfange ältere Antibiotika, die wie z.B. die Tetracycline gegen einige häufige und bedeutsame Keime erhebliche Resistenzen entwickeln, an die Stelle potenter, moderner Antibiotika, wie z.B. ovaler Cephalosporine, neuer Makrolide und Chinolone. Sodann nahmen die 
Überweisungen von Praktischen Ärzten und Internisten zu Fachärzten bei GKVPatienten gegenüber dem Vorjahreszeitraum signifikant zu (vgl. Graf v.d. Schulenburg/Schöffski, 1993). In diesem Zusammenhang fällt auf, daß diese Überweisungen gerade bei arzneimittelintensiven Indikationsgebieten, wie z.B. Hypertonie und Parkinson, überdurchschnittlich anstiegen. Ob das Arzneimittelbudget auch die Krankenhauseinweisungen in ăhnlicher Weise beeinflußte (so Graf v.d. Schulenburg/Schöffski, 1993), erscheint derzeit noch umstritten. 


\section{Ergebnisse und Schlußfolgerungen in Thesen}

(1) Die forschende pharmazeutische Industrie in Deutschland steht derzeit vor allem vor folgenden Herausforderungen:

- Der Anteil der Zweitanmelderpräparate am GKV-Gesamtmarkt nahm seit Anfang der achtziger Jahre ständig zu, wobei das GSG diesen Trend noch verstärkte.

- Das Arzneimittelbudget begrenzt den Ausgabenumfang, so daß die forschenden Unternehmen strukturelle Umsatzeinbußen im generikafähigen Markt kaum mehr über Niveaueffekte des Gesamtmarktes kompensieren können.

- Weltweite Kostendämpfungsmaßnahmen im Gesundheitswesen erschweren es zunehmend, Umsatzverluste im heimischen Markt über das Auslandsgeschäft auszugleichen.

- Sofern der bevorstehende EU-Binnenmarkt keine Deregulierungen erzwingt oder die nationalen Regulierungssysteme nicht vereinheitlicht, gleichzeitig aber über die Förderung von Re- und Parallelimporten die räumliche Preisdifferenzierung weiter einengt, entfällt ein bisher relevantes Finanzierungsinstrument.

(2) Diese für die forschenden Unternehmen ungünstigen Tendenzen bestanden teilweise zwar schon in der Vergangenheit, bilden in ihrer Kombination aber ein Novum. Unbeschadet noch vorhandener bzw. unausgeschöpfter Effizienzpotentiale innerhalb der pharmazeutischen Industrie stellt sich bei dieser Konstellation die Frage, ob sich die pharmazeutische Forschung auf mittlere Frist weltweit oder nur in Europa abschwächt und welche Rolle Deutschland künftig als Standort für forschende Arzneimittelfirmen spielt. Die pharmazeutische Industrie in Deutschland exportierte 1992 Waren im Wert von 12,8 Mrd. DM und trug mit einem Ausfuhrüberschuß von einem Drittel des Exportvolumens wie schon in der Vergangenheit überdurchschnittlich zur Aktivierung der Handelsbilanz bei.

(3) Innerhalb der medizinischen Behandlungsarten verursachten im Zeitraum 1970 bis 1992 vornehmlich die stationäre Behandlung, die Heil- und Hilfsmittel sowie der Zahnersatz den starken Anstieg der GKV-Gesundheitsausgaben. Dagegen gingen die Arzneimittelausgaben ebenso wie die Ausgaben für die Behand- 
lung durch Ärzte und durch Zahnärzte in diesem Zeitraum anteilsmäßig zurück. Ab dem Jahre 1980 verzeichnete der Arzneimittelanteil innerhalb der GKV-Ausgaben allerdings eine steigende Tendenz. Bei einem Vergleich mit der Ausgabenentwicklung im Rahmen der PKV fallt vor allem auf, daß sich der Arzneimittelanteil dort von 1970 bis 1992 nahezu halbierte. Dieser Befund nährt unabhängig von allen strukturellen Unterschieden zwischen GKV und PKV Zweifel an der These von der eindeutigen Dominanz angebotsseitiger Determinanten im Rahmen der Arzneimittelversorgung.

(4) Auf der Grundlage eines Vergleiches der GKV-Ausgaben pro Rentner und pro Mitglied besitzen die Arzneimittelausgaben von allen Behandlungsarten die stärkste Rentner- und damit wohl auch Altersabhängigkeit. So beanspruchte im Jahre 1992 eine sog. Rentnerquote von 28,7 vH einen Anteil von 54,3 vH an den Arzneimittelausgaben. Die absoluten GKV-Arzneimittelausgaben pro Rentner übertrafen jene pro Mitglied um fast das 3 fache. Die Rentner verursachten mit durchschnittlich 1.304,- DM deutlich mehr Arzneimittelausgaben als Aufwendungen für die Behandlung durch Ärzte (919,- DM), während es sich bei den Mitgliedern tendenziell umgekehrt verhielt.

(5) Im Zentrum der vergangenen Kostendämpfungsmaßnahmen und Gesundheitsreformen stand eindeutig das Postulat der Beitragssatzstabilität, obwohl dieses nicht per se, sondern nur abgeleitet ein gesamtwirtschaftliches Ziel darstellt. Während verteilungspolitische Gesichtspunkte zumindest als Nebenbedingungen Berücksichtigung fanden, blieben Allokations- bzw. Effizienzaspekte weitgehend unberücksichtigt. Letztere fordern vor allem ein gesundheitsökonomisches Anreizsystem, das die Leistungsfáhigkeit und Innovationsbereitschaft der Leistungsanbieter stimuliert. Hierzu gehören nicht zuletzt verläßliche Rahmendaten, da sie u.a. die Grundlage für risikoreiche pharmazeutische Innovationen und aufwendige Investitionen in Arztpraxen bilden.

(6) Zur Beurteilung der Nützlichkeit einer einzelnen pharmakologischen Innovation bietet sich die Kosten-Nutzen-Analyse an, die im Rahmen einer gesamtwirtschaftlichen Betrachtungsweise die projektbezogenen bzw. -induzierten Nutzen und Kosten einander gegenüberstellt. Dabei vergleicht sie die Effekte der pharmakologischen Innovation mit den entsprechenden Wirkungen, die ohne diese Erfindung auftreten. Als Bezugssystem für die konkrete Beurteilung der Innovation dient zumeist die beste Alternative, d.h. bisher vorhandene pharmakologische Technologie. Im Gegensatz zu Imitationsprodukten, die gegenüber dem 
ursprünglichen Originalpräparat keine zusätzlichen realen Nutzensteigerung in der medizinischen Behandlung zu stiften vermögen, können pharmakologische Innovationen grundsätzlich ein breites Nutzenspektrum erzeugen. Letzteres reicht von gewonnenen Lebensjahren und gestiegener Lebensqualität über eine Senkung der Arbeitsunfähigkeit und eine höhere Arbeitsproduktivität bis zum Zugewinn an Freizeit und geringeren Zukunftsängsten.

(7) Unabhängig von ihrer Existenzberechtigung erlaubt die reine Ausgabenbetrachtung noch keine Aussagen über die Endprodukte und damit die Zielrealisierung gesundheitlicher Leistungserstellung. Auch das mit den Arzneimittelausgaben erworbene Medikament bildet zunächst nur einen Produktionsfaktor, der zumeist in Kombination mit anderen Behandlungsarten zur Verbesserung des Gesundheitszustandes beiträgt. Die immer noch sehr unvollkommenen Kenntnisse über die kausalen Input-Output-Beziehungen gesundheitlicher Leistungserstellung bilden sicherlich einen Grund, wenn auch keine Rechtfertigung für das bisher dominante Ausgaben- bzw. Kostendenken im Gesundheitswesen. Immerhin versuchen neuere Ansätze, wie z.B. das "Quality-Adjusted Life Years-Konzept", die vielschichtigen Dimensionen gesundheitlicher Outcome-Indikatoren zu erfassen und in diesem Kontext über die Lebenszeit hinaus auch die Lebensqualität als physische, psychische, kognitive und soziale Funktionsfähigkeit zu berücksichtigen.

(8) Zwischen den einzelnen Behandlungsarten können im Hinblick auf die medizinische Aufgabenerfüllung komplementäre und substitutive Produktionsbeziehungen bestehen. Liegen substitutive Beziehungen vor, hängt das effiziente Einsatzverhältnis bei gegebenen Gesundheitszielen von den jeweils möglichen Produktions- bzw. Behandlungsverfahren und den relativen Preisen der Produktionsfaktoren $\mathrm{ab}$. Dabei verändern sich innerhalb der Behandlungsarten die relativen Preise eindeutig zugunsten der Arzneimittel, deren Preisindex im Zeitraum von 1970 bis 1992 erheblich geringer anstieg als die Preisindizes für ambulante und stationäre Behandlung. Eine Aufspaltung der Ausgabengrößen in eine Preis- und eine Mengenkomponente zeigt, daß bei den Arzneimitteln im Beobachtungszeitraum mit über $72 \mathrm{vH}$ die Mengenkomponente überwog. Da die Festbeträge nur an der Preiskomponente ansetzen und an der Mengenentwicklung vorbeizielen, fehlte den Einsparungserwartungen des GRG bereits die konzeptionelle Grundlage. 
(9) Forschende Unternehmen konkurrieren vorwiegend auf internationaler Ebene miteinander und zudem auf dem heimischen Markt mit den Generika-Herstellern. Dabei erfüllen der Innovationswettbewerb, der primär auf die Effektivität abzielt, und der Imitationswettbewerb, bei dem die Effizienz im Vordergrund steht, unterschiedliche Funktionen. Während die Effizienz das Verhältnis zwischen dem medizinischen Produkt und den dazu aufgewendeten Ausgaben mißt, setzt die Effektivität auf einer höheren Zielebene die Wirkungsziele bzw. gesundheitlichen Outcomes mit diesem Produkt oder den entsprechenden Ausgaben in Beziehung. Sofern Originalpräparate medizinischen Fortschritt verkörpern, steigern sie die Effektivität im Gesundheitswesen, denn sie verhelfen dann dazu, entweder medizinische Wirkungsziele mit einem geringeren Mitteleinsatz zu verwirklichen oder mit dem bisherigen Ressourcenaufwand ein höheres gesundheitliches Outcomeniveau zu erreichen. Direkte Wohlfahrtssteigerungen bei der Gesundheitsversorgung, wie z.B. Erfolge bei der Krebsbekämpfung und bei Autoimmunkrankheiten, können nur innovative Arzneimittel bewirken.

(10) Imitierende Produkte vermögen nicht die gesundheitlichen Outcomes zu beeinflussen, wohl aber über Preissenkungen die Effizienz der Gesundheitsversorgung zu erhöhen. Analogpräparate und Generika können die Opportunitätskosten der Arzneimitteltherapie senken und über die alternative Verwendung der eingesparten Mittel indirekt wohlfahrtssteigernd wirken. Im Kontext von Innovation und Imitation nehmen die sog. "Me-too-Präparate" insofern eine Zwischenstellung ein, als sie im Sinne des Patentrechts als innovativ gelten, aber nicht auf genuin neuen Wirkstoffen beruhen. Sie können, vor allem im Zuge sukzessiver Entwicklungsfortschritte, die Effektivität erheblich steigern, müssen aber nicht in jedem Fall mit relevanten therapeutischen Effekten einhergehen.

(11) Von innovativen Originalpräparaten gehen teilweise auch gesellschaftliche Nutzen aus, die sich als positive externe Effekte einer unmittelbaren Vermarktung entziehen. So dürfte z.B. schon das Wissen um die Existenz eines wirksamen Heilmittels gegen Krebs oder AIDS die Angst vor der entsprechenden Krankheit mindern und damit nicht nur erkrankten, sondern auch gesunden Menschen Nutzen stiften. Unbeschadet partieller Exzesse erzeugen forschende Pharmaunternehmen über Beratung und Fortbildung der Ärzte, über die Kommunikation mit Wissenschaftlern, über Publikationen und über die begleitende Evaluation der eigenen Produkte positive externe Effekte. Da bei Arzneimitteln im Gegensatz zu den meisten anderen Gütern keine technische Möglichkeit existiert, diese informativen Leistungen an eine Hardware zu knüpfen, können die imitierenden Kon- 
kurrenkten diese Software später als "free rider" nutzen. Schließlich bestehen, vor allem auf dem Gebiet der Biotechnologie, enge Komplementaritäten zwischen pharmazeutischen Innovationen und solchen im Landwirtschafts- und Umweltbereich, so daß pharmazeutische Erfindungen im Bereich der Gentechnologie auch die Agrar- und Umweltforschung stimulieren dürften und vice versa.

(12) Innovationen innerhalb der medizinischen Behandlungsarten können sowohl die Optionen der gesundheitlichen Leistungserstellung als auch die relativen Preise der Produktionsfaktoren verändern. So vermag eine pharmazeutische Innovation sowohl ambulante Behandlungen sowie Heil- und Hilfsmittel als auch in Kombination mit letzteren stationäre Aufenthalte zu ersetzen. Insoweit ein innovatives Arzneimittel eine Krankheitsphase und die mit ihr verbundene medikamentöse Therapie reduziert, löst es auch Substitutionsprozesse innerhalb des Arzneimittelsektors aus. Ausgabeneinsparungen bei gegebenem, meist sogar gestiegenem Gesundheitsoutcome fallen vor allem dann an, wenn ein innovatives Arzneimittel dazu beiträgt, stationäre Aufenthalte in den ambulanten Sektor zu verlagern. Gleichwohl schlagen sich die meisten Innovationen im Gesundheitswesen und damit auch die pharmazeutischen langfristig betrachtet weniger in Ausgabeneinsparungen als in Steigerungen der gesundheitlichen Outcomes nieder. Diese Feststellung mindert sicherlich nicht ihren Wert, beugt aber unrealistischen fiskalischen Erwartungen vor.

(13) Während hinsichtlich des Patentschutzes von Arzneimittelinnovationen auf internationaler Ebene inzwischen weitgehend ähnliche Bedingungen vorherrschen, weichen die nationalen Preisbildungsregelungen noch stark voneinander ab. Viele Länder regulieren die Herstellerpreise von erstattungsfähigen Medikamenten, und die Unternehmen reagieren hierauf mit nationalen Preisdifferenzierungen. Aus dieser Sicht subventionieren die Länder mit relativ freier Preisbildung den Konsum des medizinischen Fortschritts in Ländern mit rigider Preisregulierung. Die Förderung von Re- und Parallelimporten aus diesen Ländern läuft, vor allem bei patentgeschützten Originalpräparaten, letztlich auf einen Import ausländischer Regulierung hinaus. Die betreffenden Preisunterschiede beruhen nämlich nicht auf effizienteren Produktionsverfahren oder intensiverem marktwirtschaftlichem Wettbewerb, sondern ausschließlich auf staatlicher Preisregulierung.

(14) Vor Einführung des GRG finanzierten die forschenden Pharmafirmen ihren Innovationsaufwand vorwiegend über eine sog. Mischfinanzierung, bei der nicht 
nur die patentgeschützten, sondern auch andere Originalpräparate einen Beitrag zur Finanzierung der Forschungskosten leisteten. Die Einführung der Festbeträge erschwerte die Mischfinanzierung und setzte damit Anreize, die Forschungsfinanzierung auf patentgeschützte Arzneimittel, "deren Wirkungsweise neuartig ist und die eine therapeutische Verbesserung" ( $\$ 35$ Abs. 1 SGB V) beinhalten, zu verlagern. Obgleich die Festbetragsregelung auf dem generikafähigen Markt teilweise zu empfindlichen Umsatzeinbußen der forschenden Firmen führte, verfehlte sie, wie letztlich das GRG insgesamt, das anvisierte Einsparungsziel. Die zentrale Ursache für dieses fiskalische Scheitern lag im Arzneimittelbereich wohl darin begründet, daß die Festbetragsregelung die Mengenentwicklung nicht einzudämmen vermochte, sondern sie eher noch stimulierte.

(15) Die bisherigen Erfahrungen sprechen dafür, daß das GSG im Vergleich zum GRG erheblich größere Aussichten besitzt, das Wachstum der GKV-Ausgaben zu begrenzen. Im Arzneimittelbereich verstärkte das GSG den Trend eines steigenden Verordnungs- und Umsatzanteils von Zweitanmelderprodukten und schränkte auf Seiten der forschenden Unternehmen die Möglichkeiten zur Mischfinanzierung weiter ein. Insofern sehen sich die Erstanbieter nun gezwungen, den gesamten Innovations- und Entwicklungsaufwand über die Preise für innovative Produkte zu finanzieren. Diesem Übergang von der Mischfinanzierung zur innovationsabhängigen Forschungsfinanzierung steht aber derzeit das Arzneimittelbudget insofern entgegen, als die Ärzte seinetwegen die Verschreibung von relativ teuren, innovativen Präparaten tendenziell scheuen. Im Unterschied zur Festbetragsregelung, welche die Gewinnerwartungen für neuartige, innovative Produkte kaum tangiert, birgt das Arzneimittelbudget selbst für medizinisch unstrittige Arzneimittelinnovationen erhebliche und teilweise unkalkulierbare Risiken.

(16) Im Zuge von Festbetragsregelung und GSG sank das deutsche Arzneimittelpreisniveau, das noch 1988 innerhalb der EU-Länder mit an der Spitze lag, zwischenzeitlich nahezu auf den EU-Durchschnitt ab. Wie bereits erwähnt, wurzelten die Divergenzen in den europäischen Preisniveaus nicht im unterschiedlichen Leistungsvermögen der jeweiligen Hersteller, sondern in stark voneinander abweichenden Preisbildungssystemen. Um die Trittbrettfahrerposition der Länder mit einer hohen Regulierungsdichte abzubauen, bietet sich als marktkonforme Lösung offensichtlich eine europaweite Deregulierung dieser Preisbildungssysteme an. Solange aber die einzelnen Länder an ihren Preisregulierungen festhalten oder diese gar noch verschärfen, setzt eine erfolgreiche

Eberhard Wille, Angelika Mehnert and Jan Philipp Rohweder - 978-3-631-75615-7 
Arzneimittelforschung in erster Linie einen ergiebigen heimischen Markt voraus. Unter den auf den europäischen Pharmamärkten existierenden Bedingungen schließen sich eine prosperierende Pharmaforschung und ein unterdurchschnittliches nationales Arzneimittelpreisniveau leider aus. 
Eberhard Wille, Angelika Mehnert and Jan Philipp Rohweder - 978-3-631-75615-7 Heruntergeladen von PubFactory am05/04/2021 12:53:36PM via Victoria University of Wellington 


\section{Literaturverzeichnis}

Abel-Smith, B. (1984), Cost Containment in Health Care. A Study of 12 European Countries, London.

ABDA-Bundesvereinigung Deutscher Apothekerverbände (1991), ApothekenReport 42, Frankfurt.

ABDA-Bundesvereinigung Deutscher Apothekerverbände (1993a), ABDABericht 1992/93, Frankfurt und Eschborn.

ABDA-Bundesvereinigung Deutscher Apothekerverbände (1993b), Apothekenumsätze mit der GKV zur Budgetkontrolle nach Artikel 29 GSG, mimeo.

Andel, N. (1977), Nutzen-Kosten-Analysen, in: Handbuch der Finanzwissenschaft, 3. Aufl., Bd. I, Tübingen, S. 475-518.

Anderson, L.G. and Settle, R.F. (1977), Benefit-Cost Analysis: A Practical Guide, Lexington, Toronto.

Andersson, F. (1993), Methodological Aspects of International Drug Price Comparisons, in: Pharmaco economics, Vol. 4, 4, S. 247-256.

Bapst, L.R., Horisberger, B. und Sierp, D. (1986), Kosten-Nutzen-Analyse der medikamentösen Ulkusbehandlung mit Tagamet, in: Horisberger, B. und Eimeren, W. van (Hrsg.), Die Kosten-Nutzen-Analyse. Methodik und Anwendung am Beispiel von Medikamenten, Berlin et al., S. 51-101.

Bayer-Statistik (1993), Die führenden Firmen im Apothekenmarkt, Januar bis August 1993, mimeo.

Berg, H. (1986), Bilanz der Kostendämpfungspolitik im Gesundheitswesen 19771984, Sankt Augustin. 
Birch, S. and Donaldson, C. (1987), Applications of Cost-Benefit Analysis to Health Care. Departures from Welfare Economic Theory, in: Journal of Health Economics, Vol. 6, S. 211-225.

Boehringer Mannheim GmbH (1993), Patentverlängerung durch Schutzzertifikate (SPC), Mannheim, mimeo.

Boroch, W. und Cassel, D. (1993), Die forschende europäische Arzneimittelindustrie im internationalen Güter- und Standortwettbewerb, in: Hamburger Jahrbuch für Wirtschafts- und Gesellschaftspolitik, 38. Jahr, S. 111-124.

BPI (Bundesverband der Pharmazeutischen Industrie, 1987), Pharma Jahresbericht 1986/87, Frankfurt.

BPI (Bundesverband der Pharmazeutischen Industrie, 1993a), Pharma Daten '93, Frankfurt.

BPI (Bundesverband der Pharmazeutischen Industrie, 1993b), Pharma Jahresbericht 1992/3, Frankfurt.

BPI (Bundesverband der Pharmazeutischen Industrie, 1993c), Pharma Marktinformation, $5 / 93$.

Brenner, G. (1993), Arzneimittel-Budget gefährdet Arzt/Patient-Beziehung, in: Der Praktische Arzt, 4/93, S. 11-19.

Bundesärztekammer (1986), Gesundheits- und sozialpolitische Vorstellungen der deutschen Ärzteschaft, Köln.

Bundesministerium für Forschung und Technologie (1993), Bundesbericht Forschung 1993, Bonn.

Bundesministerium für Gesundheit (1993), Gesetzliche Krankenversicherung, vorläufige Rechnungsergebnisse, 1. bis 2. Quartal 1993/1992, Bonn den 09.09.1993. 
Burstall, M.L. (1990), 1992 and the Regulation of the Pharmaceutical Industry, London.

Burstall, M.L. (1991), Europe after 1992: Implication for Pharmaceuticals, in: Health Affairs, Fall, S. 157-171.

Butler, J.R.G. (1992), Welfare Economics and Cost-Utility Analysis, in: Zweifel, P. and Frech III, H.E. (Ed.), Health Economics Worldwide. Developments in Health Economics and Public Policy, Dordrecht et al., S. 143-157.

Cassel, D. (1990), Rahmenbedingungen fuir die Arzneimittelentwicklung der Zukunft aus sozialökonomischer Sicht, in: Fülgraff, G.M. u.a. (Hrsg.), Klinischpharmakologisches Kolloquium IV, Titisee 1989, Freiburg.

Centre for Medicines Research, Ed. (1992), Annual Report 1991-1992, Carshalton.

Commission of the European Communities (1989), The Rules Governing Medical Products in the European Community, Volumes I-III, Luxembourg.

Cornwall, R.R. (1984), Introduction to the Use of General Equilibrium Analysis, Amsterdam et al.

Cullis, J.G. and West, P.A. (1991), The Economics of Health. An Introduction, reprinted, Oxford.

Der Bundesminister für Arbeit und Sozialordnung (1970-1993), Die gesetzliche Krankenversicherung in der Bundesrepublik Deutschland in den Jahren 1970 bis 1992. Statistischer und finanzieller Bericht, verschiedene Jahrgänge, Bonn 1970 bis 1993 .

Der Bundesminister für Arbeit und Sozialordnung (1993b), Gesetzliche Krankenversicherung, in: Bundesarbeitsblatt, 6/1993, S. 92-110.

Deutsche Bundesbank (1986), Die Belastung mit Sozialabgaben seit Beginn der siebziger Jahre, in: Monatsberichte der Deutschen Bundesbank, 38. Jg., 1, S. 1725. 
Drummond, M.F. (1981), Welfare Economics and Cost Benefit Analysis in Health Care, in: Scottish Journal of Political Economy, Vol. 28, S. 125-145.

Drummond, M.F., Stoddart, G.L. and Torrance, G.W. (1987), Methods for the Economic Evaluation of Health Care Programmes, Oxford et al.

Drummond. M.F., Smith, G.T. and Wells, N. (1988), Economic Evaluation in the Development of Medicines, London.

Erbsland, M. und Wille, E. (1993), Die Maßnahmen des Gesundheits-Strukturgesetzes im ambulanten Sektor und ihre Auswirkungen auf den Pharmamarkt, in: ZEW-Wirtschaftsanalysen, Jg.1, Nr. 4, S. 494-515.

EWG-Verordnung Nr. 1768/92 des Rates der Europäischen Gemeinschaften vom 18.06.1992, in: Amtsblatt der Europäischen Gemeinschaften, Reihe L: Rechtsvorschriften, Nr. 182, 35 Jg., 02.07.1992.

Fraktionen der CDU/CSU und FDP (1988), Entwurf eines Gesetzes zur Strukturreform im Gesundheitswesen (Gesundheits-Reformgesetz-GRG), BundestagsDrucksache 11/2237, Bonn den 03.05.1988.

Fraktionen der CDU/CSU, SPD und FDP (1992), Entwurf eines Gesetzes zur Sicherung und Strukturverbesserung der gesetzlichen Krankenversicherung (Gesundheits-Strukturgesetz), Bundestags-Drucksache 12/3608, Bonn den 06.11.1992.

Gabler-Sandberger, E. und Heinzl, S. (1993), Infektionstherapie 1993 und Gesundheitsstrukturgesetz, in: Chemotherapie Journal, 2. Jg., Heft 3, S. 121-126.

Genzel, H. (1987), Sozialstaatliche Anforderungen an das deutsche Gesundheitswesen, in: Ausbildung und Fortbildung in Gesundheitsökonomie. GSF-Bericht $6 / 87$, hrsg. von D. Schwefel et al., München, S. 137-150

Glaeske, G. (1993), Indikationsbezogene Richtgrößen zur Ablösung des Arzneimittelbudgets I und II, in: Die Ersatzkasse, 6/93, S. 240-242 u. 7/93, S. 297 300 . 
Grabowski, H. and Vernon, J. (1986), Longer Patents for Lower Imitation Barriers: The 1984 Drug Act, in: The American Economic Review, Papers and Proceedings, Vol. 76, S. 195-202.

Graf v.d. Schulenburg, J.-M. und Schöffski, O. (1993), Auswirkungen des Gesundheitsstrukturgesetzes auf das Überweisungs- und Einweisungsverhalten von Primärärzten - Eine ökonomische Bewertung aus Sicht der Kostenträger und der Volkswirtschaft-, Oktober 1993, mimeo.

Halliday, R.G., Walker, S.R. and Lumley, C.E. (1992), R \& D Philosophy and Management in the World's Leading Pharmaceutical Companies, in: Journal of Pharmaceutical Medicine, Vol. 2, S. 139-154.

Hancher, L. (1990), Regulating for Competition. Government, Law and the Pharmaceutical Industry in the United Kingdom and France, Oxford.

Hanusch, H. (1987), Nutzen-Kosten-Analyse, München.

Hart, D. und Reich, N. (1990), Integration und Recht des Arzneimittelmarktes in der EG: Eine Untersuchung zum Produkt- und Marktrecht der Gemeinschaft und ausgewählter Mitgliedsstaaten, Baden-Baden.

Hauser, H. und Sommer, J. (1984), Kostendämpfung im Gesundheitswesen in den USA, in Kanada und in der BRD. Ansatzpunkte für die schweizerische Reformdiskussion, Bern und Stuttgart.

Henderson, J., McGuire, A., and Mooney, G. (1988), The Economics of Health Care. An Introductory Text, London et al.

Henke, K.-D. (1986), Möglichkeiten einer Reform der Gesetzlichen Krankenversicherung in der Bundesrepublik Deutschland, in: Gäfgen, G. (Hrsg.), Ökonomie des Gesundheitswesens, Schriften des Vereins für Socialpolitik, N.F. Bd. 159, Berlin, S. 611-630.

Hilken, A. (1989), Innovation und Patentschutz auf dem EG-Arzneimittelmarkt unter besonderer Berücksichtigung des europäischen Wettbewerbsrechts, BadenBaden. 
Horisberger, B. und Eimeren, W. van, Hrsg. (1986), Die Kosten-Nutzen-Analyse. Methodik und Anwendung am Beispiel von Medikamenten, Berlin et al.

Huber, W. (1988), Nachahmerwettbewerb bei Arzneimitteln. Eine markttheoretische und empirische Analyse, Bayreuth.

Institut "Finanzen und Steuern" (1993), Das Sozialbudget der Bundesrepublik Deutschland - Westdeutscher Rückblick und gesamtdeutscher Ausblick -, "Grüner Brief", Nr. 313, Bonn.

Jung, K. (1989), Neues Kapitel in der Krankenversicherung, in: Bundesarbeitsblatt, 2/1989, S. 11-16.

Just, R.E., Hueth, D.L. und Schmitz, A. (1982), Applied Welfare Economics and Public Policy, Englewood Cliffs, N.J.

Klarman, H.E. (1965), Syphilis Control Programs, in: Dorfman, R. (Ed.), Measuring Benefits of Government Investments, Washington, D.C., S. 367-410.

Kaufer, E. (1979), Die Ökonomie des Arzneimittels im Gesundheitswesen, in: Das Medikament. Wert-Erwartung-Ökonomie, hrsg. von Boehringer Mannheim GmbH, Mannheim, S. 35-47.

Kaufer, E. (1985), Volkswirtschaftliche Nutzen und Kosten einer prosperierenden pharmazeutischen Industrie, Vortrag auf dem Symposium "Der Pharma-Markt vor dem Umbruch", München.

Klauber, J. und Selke, G.W. (1993), Auswirkungen des Gesundheitsstrukturgesetzes, in: Schwabe, U. und Paffrath, D. (Hrsg.), Arzneiverordnungsreport '93, S. 467-489.

Kossow, K.D. und Trauboth, J. (1993), Das pharmazeutische Marketing nach dem Gesundheitsstrukturgesetz, in: Klinische Pharmakologie aktuell, 4. Jg., Heft 2, September 1993, S. 47-51. 
Lagergren, M. (1985), Public Health Care Services in the Advanced Welfare State. Observations from the Swedish Futures Study "Care in Society", in: Futures, Vol. 17, S. 348-359.

Leipert, Ch. (1978), Gesellschaftliche Berichterstattung. Eine Einführung in Theorie und Praxis sozialer Indikatoren, Berlin et al.

Leu, R.E. et al. (1986), Die quantitative Erfassung von Gesundheitszustand und Lebensqualität, illustriert am Beispiel von Psoriasiskranken, in: Horisberger, B. und Eimeren, W. van (Hrsg.), Die Kosten-Nutzen-Analyse, Berlin, S. 153-248.

Luce, B.R. and Elixhauser, A. (1990), Standards for Socioeconomic Evaluation of Health Care Products and Services, Berlin et al.

Marx, P. (1993), Auswirkungen des Gesundheitsstrukturgesetzes auf die pharmazeutische Industrie in der Bundesrepublik Deutschland - Ergebnisse einer Mitgliederbefragung des Bundesverbandes der Pharmazeutischen Industrie, in: Die Pharmazeutische Industrie, Bd. 55, 5, S. 445-450.

Mehrez, A. and Gafni, A. (1989), Quality-Adjusted Life Years, Utility Theory, and Healthy-Years Equivalents, in: Medical Decision Making, Vol. 9, No. 2, S. 142-149.

Mishan, E.J. (1988), Cost-Benefit Analysis, An Informal Introduction, 4th Ed., London et al.

Molinaro, R. (1986), Gesundheitswesen und Kostendämpfung in der Bundesrepublik. Beschreibung und Analyse aus schweizerischer Sicht, Berlin et al.

Mooney, G.H. (1977), The Valuation of Human Life, London and Basingstoke.

Moore, W.J. and Newman, R.J. (1989), An Economic Analysis of State Medicaid Formularies: Implications for the Recent Changes in the Louisiana Formulary, USA.

Müller, J. (1993), Finanzentwicklung der GKV im 1. Halbjahr 1993, in: Die Ersatzkasse, 10/93, S. 415-421. 
Müller, P. und Schöneich, D. (1992), Einfluß kombinierter Pharmako- und Psychotherapie in einer Schizophrenie-Ambulanz auf Rehospitalisierungszeiten und Behandlungskosten, in: Psychiatrische Praxis, 19, S. 91-95.

Müller W. (1992), Ausgaben für Gesundheit 1990, in: Wirtschaft und Statistik, 8/1992, S. $538-544$ u. $494^{*}-496^{*}$.

Mushkin, S.J. (1962), Health as an Investment, in: The Journal of Political Economy, Vol. 70, Supplement (Investment in Human Beings), S. 129-157.

Musgrave, R.A., Musgrave, P.B. und Kullmer, L. (1990), Die öffentlichen Finanzen in Theorie und Praxis, 1. Bd., 5. Aufl., Tübingen.

Neipp, J. (1987), Der optimale Gesundheitszustand der Bevölkerung. Methodische und empirische Fragen einer Erfolgskontrolle gesundheitspolitischer Maßnahmen, Berlin.

NERA (National Economic Research Associates, 1993a), Financing Health Care With Particular Reference to Medicines, Vol. 5: The Health Care System in Germany, London, New York.

NERA (National Economic Research Associates, 1993b), Financing Health Care With Particular Reference to Medicines, Vol. 15: The Role of the European Community, London, New York.

Oberender, P. (1986), Öffentliche Regulierung und innovative Aktivität in der pharmazeutischen Industrie, in: Gäfgen G. (Hrsg.), Ökonomie des Gesundheitswesens, Schriften des Vereins für Socialpolitik, Bd. 159, Berlin, S. 357-378.

OECD (1976), Measuring Social Well-Being. A Progress Report on the Development of Social Indicators, Paris.

OECD (1985), Measuring Health Care 1960-83. Expenditure, Costs and Performance, Paris.

OECD (1987), Financing and Delivering Health Care. A Comparative Analysis of OECD Countries, Paris. 
OECD(1990), Health Care Systems in Transition. The Search for Efficiency, Paris.

OECD (1992), The Reform of Health Care. A Comparative Analysis of Seven OECD Countries, Paris.

OECD (1993), OECD Health Data 1960-1991, Paris.

Pearce, D.W. (1983), Cost-Benefit Analysis, 2nd Ed., London, Basingstoke.

Pichler, H.E.T. (1991), Fortschritte der oralen Antibiotikatherapie in der Praxis, in: Infektion, 19, Supplement 1, S. 57-60.

Prest, A.R. und Turvey, R. (1965), Cost-Benefit Analysis: A Survey, in: The Economic Journal, Vol. 75, S. 683-735.

Reichelt, H. (1989), Arzneimittelfestbeträge, Eine Analyse der Preiskompensation der Pharmaindustrie, in: Ortskrankenkasse, Nr. 22/1989, S. 701-707.

Reis-Arndt, E. (1993), 30 Jahre Arzneimittelentwicklung - Neue pharmazeutische Wirkstoffe 1961-1990, in: Die Pharmazeutische Industrie, Bd. 55, 1, S. 14-21.

Rostalski, B. (1993), Das Arzneimittelbudget für 1993, in: Die Ersatzkasse, 5/93, S. 202-206.

Rubas, W. und Schreier, H. (1991), Liposomen: Fortschritte in HerstellungsTechnologie und Therapie, in: Pharmazie in unserer Zeit, 20, 6, S. 255-270.

Rüschmann, H.-H. (1986), Diagnosebezogene Verweildauerstandards und Krankenhaus-Bedarfsplanung, in: Gäfgen, G. (Hrsg.), Ökonomie des Gesundheitswesens, Schriften des Vereins für Socialpolitik, Bd. 159, Berlin, S. 189-204.

Sachverständigenrat für die Konzertierte Aktion im Gesundheitswesen (1990), Herausforderung und Perspektiven der Gesundheitsversorgung. Vorschläge für die Konzertierte Aktion im Gesundheitswesen, Jahresgutachten 1990, BadenBaden. 
Sachverständigenrat für die Konzertierte Aktion im Gesundheitswesen (1991), Das Gesundheitswesen im vereinigten Deutschland. Jahresgutachten 1991, Baden-Baden.

Sachverständigenrat für die Konzertierte Aktion im Gesundheitswesen (1992), Ausbau in Deutschland und Aufbruch nach Europa. Jahresgutachten 1992, Baden-Baden.

Sawhill, I.V. (1969), The Role of Social Indicators and Social Reporting in Public Expenditure Decisions, in: Subcommittee on Economy in Government, The Analysis and Evaluation of Public Expenditures: The PPB System. A Compendium of Papers, Joint Economic Committee, Vol. 1, 91st Congress, 1st Session, Washington, D.C., S. 473-485.

Scherer, F.M. (1993), Pricing, Profits, and Technological Progress in the Pharmaceutical Industry, in: Journal of Economic Perspectives, Vol. 7, 3, S. 97-115.

Scholz, H. (1992), Medikamentöse Therapie kardiovaskulärer Erkrankungen. Herzinsuffizienz - Einführung zum Thema. Fortschritte seit 1982, in: Zeitschrift für Kardiologie, 81, Supplement 4, S. 15-16.

Schwabe, U. und Paffrath, D., Hrsg. (1987-1993), Arzneiverordnungsreport '87 bis Arzneiverordnungsreport '93, Stuttgart und Jena.

Schwartz, F.W. (1987), Optionen für medizinische Orientierungsdaten und Gesundheitsziele, in: Gesellschaft für Versicherungswissenschaft und -gestaltung e.V. (Hrsg.): Weiterentwicklung des Gesundheitswesens - Medizinische, ökonomische und politische Orientierung, Bergisch Gladbach, S. 18-31.

Sheen, M.R. (1992), Barriers to Scientific and Technical Knowledge Acquisition in Industrial R \& D, in: Research and Development Management, Vol. 22, 2, S. 135-143.

Spitzenverbände der Krankenkassen (1993), Spitzenverbände der Krankenkassen in der Konzertierten Aktion zur Umsetzung des Gesundheits-Strukturgesetzes, Bonn den 23.04.1993. 
Statistisches Bundesamt (1980), Ausgaben für Gesundheit 1970 bis 1978, Fachserie 12, Reihe S. 2, Stuttgart und Mainz.

Statistisches Bundesamt (1991), Ausgaben für Gesundheit 1970 bis 1989, Fachserie 12, Reihe S. 2, Stuttgart.

Statistisches Bundesamt (1979-1993) Preise und Preisindizes für die Lebenshaltung 1978 bis 1992, Fachserie 17, Reihe 7, verschiedene Jahrgänge, Stuttgart, Mainz.

Sugden, R. and Williams, A. (1978), The Principles of Practical Cost-Benefit Analysis, Oxford.

Torrance, G.W. and Feeny, D. (1989), Utilities and Quality-Adjusted Life Years, in: International Journal of Technology Assessment in Health Care, Vol. 5, S. 559-575.

Ulrich, V. (1988), Preis- und Mengeneffekte im Gesundheitswesen. Eine Ausgabenanalyse von GKV-Behandlungsarten, Frankfurt et al.

Ulrich, V. und Wille, E. (1989), Zur Ausgabenentwicklung der gesetzlichen Krankenversicherung: Preis- und Mengeneffekte von Behandlungsarten, in: Finanzarchiv, Bd. 47, 3, S. 361-403.

Wachtel, H.-W. (1984), Determinanten der Ausgabenentwicklung im Krankenhauswesen, Berlin.

Wagstaff, A. (1991), QUALYs and the Equity-Efficiency Trade-off, in: Journal of Health Economics, Vol. 10, No. 1, S. 21-41.

Weisbrod, B.A. (1961), The Valuation of Human Capital, in: The Journal of Political Economy, Vol. 69, S. 425-436.

Weisbrod, B.A. (1984), Ökonomische Ansätze zur Evaluation einer neuen medizinischen Technologie: das Medikament Cimetidin, in: Culyer, A.J. und Horisberger, B. (Hrsg.), Technologie im Gesundheitswesen. Medizinische und wirtschaftliche Aspekte, Berlin et al., S. 220-241. 
Weisbrod, B.A. (1992), Productivity and Incentives in the Medical Care Sector, in: The Scandinavian Journal of Economics (Supplement), Vol. 94, S. 131-145.

Weltgesundheits-Organisation (1946), Die Satzung der Weltgesundheits-Organisation (Constitution of the World Health Organization), in: Dokumente, hrsg. von der Forschungsstelle für Völkerrecht und ausländisches öffentliches Recht der Universität Hamburg, Heft VI, Frankfurt, Berlin 1952, S. 14-28.

Wille, E. (1985), Rationalität, Effizienz und Effektivität aus der Sicht des Ökonomen, in: Vogel, H.R. (Hrsg.), Effizienz und Effektivität medizinischer Diagnostik, Stuttgart, S. 15-37.

Wille, E. (1986), Effizienz und Effektivität als Handlungskriterien im Gesundheitswesen, insbesondere im Krankenhaus, in: Wille, E. (Hrsg.), Informationsund Planungsprobleme in öffentlichen Aufgabenbereichen. Aspekte der Zielbildung und Outputmessung unter besonderer Berücksichtigung des Gesundheitswesens, Frankfurt et al., S. 91-126.

Wille, E. (1987), Gesamtwirtschaftliche Nutzen und Kosten der Trockenchemie: Chancen und Grenzen im ambulanten Bereich, in: Medizin Mensch Gesellschaft, Bd. 12, Heft 4, S. 319-327.

Wille, E. (1988), Ausgaben für Arzneimittel im System gesundheitlicher Leistungserstellung - Gefahren staatlicher Regulierung, in: Die Pharmazeutische Industrie, Bd. 50, 1, S. 17-35.

Wille, E. (1989), Kosten-Nutzen Analysen in der medizinischen Diagnostik Dargestellt am Beispiel automatisierter Diagnosesysteme -, in: Labor-Medizin, 12. Jg. Heft 11/89, S. 541-549 und Heft 12/89, S. 657-665.

Wille, E. und Ulrich, V. (1991), Bestimmungsfaktoren der Ausgabenentwicklung in der gesetzlichen Krankenversicherung (GKV), in: Hansmeyer, K.-H. (Hrsg.), Finanzierungsprobleme der sozialen Sicherung II, Schriften des Vereins für Socialpolitik, N.F. Bd. 194/II, Berlin, S. 9-115.

Wille, E. und Erbsland, M. (1993), Die Arzneimittelausgaben unter besonderer Berücksichtigung der demographischen Entwicklung. Empirischer Befund der 
beiden letzten Jahrzehnte, in: Ortwein, I. (Hrsg.), Mensch und Medikament. Die Pharmaindustrie im Spannungsfeld der Gesellschaft, München, Zürich, S. 176203.

Wissenschaftliches Institut der Ortskrankenkassen (1993), Auswirkungen des GSG im Arzneimittelmarkt - Trendanalyse für das 1. Halbjahr 1993 -, WIDOPreisinformation, Bonn den 18.08.1993.

Zerche, J. (1992), Die Festbetragsregelung für Arzneimittel nach dem Gesundheits-Reformgesetz - theoretische Grundlagen und empirische Befunde, in: Gäfgen, G. (Hrsg.), Systeme der Gesundheitssicherung im Wandel, BadenBaden, S.53-81.

Zweifel, P. und Zysset-Pedroni, G. (1992), Was ist Gesundheit und wie läßt sie sich messen?, in: Anderson, H.H., Henke, K.-D. und Graf von der Schulenburg, J.-M. (Hrsg.), Basiswissen Gesundheitsökonomie, Bd. 1: Einführende Texte, Berlin, S. 39-62. 
Eberhard Wille, Angelika Mehnert and Jan Philipp Rohweder - 978-3-631-75615-7 Heruntergeladen von PubFactory am05/04/2021 12:53:36PM via Victoria University of Wellington 


\section{STAATLICHE ALLOKATIONSPOLITIK IM MARKTWIRTSCHAFTLICHEN SYSTEM}

Band 1 Horst Siebert (Hrsg.): Umweltallokation im Raum. 1982.

Band 2 Horst Siebert (Hrsg.): Global Environmental Resources. The Ozone Problem. 1982.

Band 3 Hans-Joachim Schulz: Steuerwirkungen in einem dynamischen Unternehmensmodell. Ein Beitrag zur Dynamisierung der Steuerüberwälzungsanalyse. 1981.

Band 4 Eberhard Wille (Hrsg.): Beiträge zur gesamtwirtschaftlichen Allokation. Allokationsprobleme im intermediären Bereich zwischen öffentlichem und privatem Wirtschaftssektor. 1983.

Band 5 Heinz König (Hrsg.): Ausbildung und Arbeitsmarkt. 1983.

Band 6 Horst Siebert (Hrsg.): Reaktionen auf Energiepreissteigerungen. 1982.

Band 7 Eberhard Wille (Hrsg.): Konzeptionelle Probleme öffentlicher Planung. 1983.

Band 8 Ingeborg Kiesewetter-Wrana: Exporterlösinstabilität. Kritische Analyse eines entwicklungspolitischen Problems. 1982.

Band 9 Ferdinand Dudenhöfer: Mehrheitswahl-Entscheidungen über Umweltnutzungen. Eine Untersuchung von Gleichgewichtszuständen in einem mikroökonomischen Markt- und Abstimmungsmodell. 1983.

Band 10 Horst Siebert (Hrsg.): Intertemporale Allokation. 1984.

Band 11 Helmut Meder: Die intertemporale Allokation erschöpfbarer Naturressourcen bei fehlenden Zukunftsmärkten und institutionalisierten Marktsubstituten. 1984.

Band 12 Ulrich Ring: Öffentliche Planungsziele und staatliche Budgets. Zur Erfüllung öffentlicher Aufgaben durch nicht-staatliche Entscheidungseinheiten. 1985.

Band 13 Ehrentraud Graw: Informationseffizienz von Terminkontraktmärkten für Währungen. Eine empirische Untersuchung. 1984.

Band 14 Rüdiger Pethig (Ed.): Public Goods and Public Allocation Policy. 1985.

Band 15 Eberhard Wille (Hrsg.): Öffentliche Planung auf Landesebene. Eine Analyse von Planungskonzepten in Deutschland, Österreich und der Schweiz. 1986.

Band 16 Helga Gebauer: Regionale Umweltnutzungen in der Zeit. Eine intertemporale Zwei-Regionen-Analyse. 1985.

Band 17 Christine Pfitzer: Integrierte Entwicklungsplanung als Allokationsinstrument auf Landesebene. Eine Analyse der öffentlichen Planung der Länder Hessen, Bayern und Niedersachsen. 1985.

Band 18 Heinz König (Hrsg.): Kontrolltheoretische Ansätze in makroökonometrischen Modellen. 1985.

Band 19 Theo Kempf: Theorie und Empirie betrieblicher Ausbildungsplatzangebote. 1985.

Band 20 Eberhard Wille (Hrsg.): Konkrete Probleme öffentlicher Planung. Grundlegende Aspekte der Zielbildung, Effizienz und Kontrolle. 1986.

Band 21 Eberhard Wille (Hrsg.): Informations- und Planungsprobleme in öffentlichen Aufgabenbereichen. Aspekte der Zielbildung und Outputmessung unter besonderer Berücksichtigung des Gesundheitswesens. 1986.

Band 22 Bernd Gutting: Der Einfluß der Besteuerung auf die Entwicklung der Wohnungs- und Baulandmärkte. Eine intertemporale Analyse der bundesdeutschen Steuergesetze. 1986.

Band 23 Heiner Kuhl: Umweltressourcen als Gegenstand internationaler Verhandlungen. Eine theoretische Transaktionskostenanalyse. 1987. 
Band 24 Hubert Hornbach: Besteuerung, Inflation und Kapitalallokation. Intersektorale und internationale Aspekte. 1987.

Band 25 Peter Müller: Intertemporale Wirkungen der Staatsverschuldung. 1987.

Band 26 Stefan Kronenberger: Die Investitionen im Rahmen der Staatsausgaben. 1988.

Band 27 Armin-Detlef Rieß: Optimale Auslandsverschuldung bei potentiellen Schuldendienstproblemen. 1988.

Band 28 Volker Ulrich: Preis- und Mengeneffekte im Gesundheitswesen. Eine Ausgabenanalyse von GKV-Behandlungsarten. 1988.

Band 29 Hans-Michael Geiger: Informational Efficiency in Speculative Markets. A Theoretical Investigation. Edited by Ehrentraud Graw. 1989.

Band 30 Karl Sputek: Zielgerichtete Ressourcenallokation. Ein Modellentwurf zur Effektivitätsanalyse praktischer Budgetplanung am Beispiel von Berlin (West). 1989.

\section{ALLOKATION IM MARKTWIRTSCHAFTLICHEN SYSTEM}

Band 31 Wolfgang Krader: Neuere Entwicklungen linearer latenter Kovarianzstrukturmodelle mit quantitativen und qualitativen Indikatorvariablen. Theorie und Anwendung auf ein mikroempirisches Modell des Preis-, Produktions- und Lageranpassungsverhaltens von deutschen und französischen Unternehmen des verarbeitenden Gewerbes. 1991.

Band 32 Manfred Erbsland: Die öffentlichen Personalausgaben. Eine empirische Analyse für die Bundesrepublik Deutschland. 1991.

Band 33 Walter Ried: Information und Nutzen der medizinischen Diagnostik. 1992.

Band 34 Anselm U. Römer: Was ist den Bürgern die Verminderung eines Risikos wert? Eine Anwendung des kontingenten Bewertungsansatzes auf das Giftmüllrisiko. 1993.

Band 35 Eberhard Wille, Angelika Mehnert, Jan Philipp Rohweder: Zum gesellschaftlichen Nutzen pharmazeutischer Innovationen. 1994. 


\title{
Die Anwendung multivariater Methoden zur Analyse des ärztlichen Verschreibungsverhaltens Theoretische Grundlagen und empirische Ergebnisse Dargestellt am Beispiel der Orthopäden bei Arthrose
}

\author{
Frankfurt/M., Berlin, Bern, New York, Paris, Wien, 1992. $300 \mathrm{~S}$. \\ Europäische Hochschulschriften: Reihe 5, Volks- und Betriebswirtschaft. Bd. 1337 \\ ISBN 3-631-45255-1 br. DM 89.--*
}

\begin{abstract}
Das ärztliche Verschreibungsverhalten (VV) kann aufgrund seiner Vielschichtigkeit nur mit multivariaten statistischen Verfahren näher beleuchtet und erklärt werden. Das vorliegende Buch stellt zunächst die theoretischen Grundlagen des Ws dar und diskutiert seine potentiellen Determinanten. Diese münden in ein umfangreiches Determinantenmodell, das zahlreiche Facetten des Ws, wie z.B. Innovativität oder Markentreue, explizit modelliert. Im empirischen Teil werden sukzessiv fünf ineinandergreifende multivariate Verfahren (Faktoren-, Regressions-, LISREL-, Cluster- und Diskriminanzanalyse) eingesetzt, um bislang unerforschte Verordnungsstrukturen zu entdecken und Hypothesen zu überprüfen. Als Ergebnis der Studie wird u.a. deutlich, daß es eine indikationsspezifische Verschreibungstypologie der Ärzte gibt und diese Segmente sich auf der Basis leicht erfaßbarer Merkmale a priori identifizieren lassen.
\end{abstract}

Aus dem Inhalt: Rahmenbedingungen, Determinanten und Modelle des ärztlichen Verordnungsverhaltens - Klassifizierungsmöglichkeiten von Ärzten - Multivariate explorative und konfirmatorische Methoden der Pharmamarktforschung

Peter Lang Europäischer Verlag der Wissenschaften

Frankfurt a.M. - Berlin - Bern - New York - Paris - Wien

Auslieferung: Verlag Peter Lang AG, Jupiterstr. 15, CH-3000 Bern 15

Telefon (004131) 9411122, Telefax (004131) 9411131

- Preisănderungen vorbehalten - "exklusive Umsatzsteuer 
Eberhard Wille, Angelika Mehnert and Jan Philipp Rohweder - 978-3-631-75615-7 Heruntergeladen von PubFactory am05/04/2021 12:53:36PM via Victoria University of Wellington 